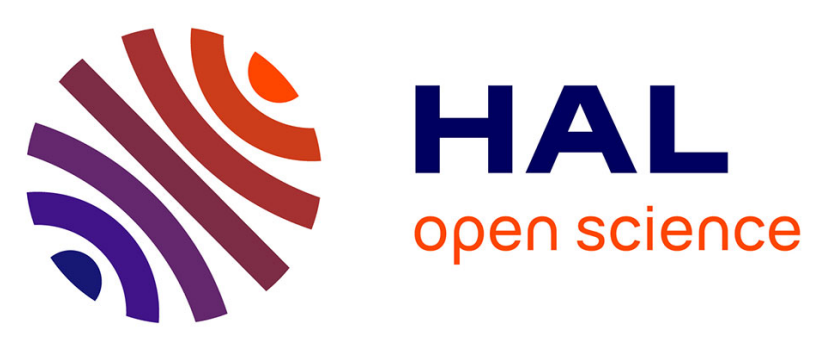

\title{
Synergistic Effect Between Ca 4 V 4 O 14 and Vanadium-Substituted Hydroxyapatite in the Oxidative Dehydrogenation of Propane
}

Sarah Petit, Cyril Thomas, Yannick Millot, Frederic Averseng, Dalil Brouri, Jean-marc Krafft, Stanislaw Dzwigaj, Gwenaelle Rousse, Christel Laberty-robert, Guylène Costentin

\section{To cite this version:}

Sarah Petit, Cyril Thomas, Yannick Millot, Frederic Averseng, Dalil Brouri, et al.. Synergistic Effect Between Ca 4 V 4 O 14 and Vanadium-Substituted Hydroxyapatite in the Oxidative Dehydrogenation of Propane. ChemCatChem, 2021, 13 (18), pp.3995-4009. 10.1002/cctc.202100807 . hal-03349135

\section{HAL Id: hal-03349135 \\ https://hal.sorbonne-universite.fr/hal-03349135}

Submitted on 20 Sep 2021

HAL is a multi-disciplinary open access archive for the deposit and dissemination of scientific research documents, whether they are published or not. The documents may come from teaching and research institutions in France or abroad, or from public or private research centers.
L'archive ouverte pluridisciplinaire HAL, est destinée au dépôt et à la diffusion de documents scientifiques de niveau recherche, publiés ou non, émanant des établissements d'enseignement et de recherche français ou étrangers, des laboratoires publics ou privés. 


\section{Synergistic Effect Between $\mathrm{Ca}_{4} \mathrm{~V}_{4} \mathrm{O}_{14}$ and Vanadium-Substituted Hydroxyapatite in the}

\section{Oxidative Dehydrogenation of Propane.}

Sarah Petit, ${ }^{\text {acc }}$ Cyril Thomas, ${ }^{a}$ Yannick Millot, ${ }^{a}$ Frederic Averseng, ${ }^{a}$ Dalil Brouri, ${ }^{a}$ Jean-Marc

Kraftt, ${ }^{\text {a }}$ Stanislaw Dzwigaj, ${ }^{a}$ Gwenaelle Rousse, ${ }^{\text {b }}$ Christel Laberty-Robert, ${ }^{c}$ Guylène Costentin $^{\mathrm{a}, *}$

a Sorbonne Université, CNRS, Laboratoire Réactivité de Surface, LRS, F-75005 Paris, France.

${ }^{\mathrm{b}}$ Sorbonne Université, Collège de France, Chimie du Solide et de l'énergie, Collège de France, 11 Place Marcelin Berthelot, 75231 Paris, France

${ }^{\mathrm{c}}$ Sorbonne Université, CNRS, Laboratoire Chimie de la Matière Condensée de Paris, LCMCP, F-75005 Paris, France.

Corresponding author: tel.: +331442736 32, fax: +33144276033

Email: guylene.costentin@upmc.fr 


\begin{abstract}
The present work reports on a new type of V-based catalysts, namely V-substituted hydroxyapatites, and the influence of the synthesis conditions on their catalytic performance in the oxidative dehydrogenation of propane (ODHP) reaction. $\mathrm{V}_{x}$-substituted hydroxyapatite materials prepared with the periodic addition of ammonia during the maturation step $\left(\mathrm{V}_{x}\right.$-HAppH-per) were shown to exhibit a $\mathrm{Ca}_{4} \mathrm{~V}_{4} \mathrm{O}_{14}$ phase in addition to the $\mathrm{V}$-substituted hydroxyapatite phase for $x$ greater than or equal to 3.5. TEM characterization of the biphasic samples allowed us to demonstrate that the $\mathrm{Ca}_{4} \mathrm{~V}_{4} \mathrm{O}_{14}$ phase was grown epitaxially on the $\mathrm{V}_{x}$-HAp nanorods. The close intimacy between the two phases was confirmed by NMR suggesting to involvement of $\mathrm{V}^{4+}$ species. Consistently EPR data of the fresh and spent samples showed that $\mathrm{V}^{4+}$ species may be stabilized at the boundaries of these two phases. The strong promotion of the oxidative dehydrogenation reaction to propene observed from $723 \mathrm{~K}$ for the $\mathrm{V}_{4}-\mathrm{HAp}$-pH-per composition is attributed to a synergistic effect between the $\mathrm{V}_{x}$-HAp nanorods that enable the activation of propane and the $\mathrm{Ca}_{4} \mathrm{~V}_{4} \mathrm{O}_{14}$ phase that helps the redox exchanges. This synergy may be attributed to an easier electron delocalization on the $\mathrm{V}_{4} \mathrm{O}_{14}$ units located at the phase's boundaries.
\end{abstract}




\section{Introduction}

In the context of the increasing gap between the production and the demand in propene on the world market, the catalytic oxidative dehydrogenation of propane (ODHP) reaction has been recently the subject of a renewed interest. ${ }^{[1]}$ This reaction appears as an interesting alternative for the production of propene from propane to the currently used endothermic processes such as steam cracking, fluid catalytic cracking and catalytic dehydrogenation. ${ }^{[2]}$ The main challenge for the ODHP reaction lies in the development of catalysts able to activate the $\mathrm{C}-\mathrm{H}$ bond of propane at a temperature low enough to avoid its total oxidation. It is usually well accepted that highly-polymerized oxide-like catalytic species are detrimental to the control of the propene selectivity, ${ }^{[3]}$ due to rapid electronic exchanges between adjacent metal species and /or fast surface oxygen ions mobility resulting in the overoxidation of adsorbed products to $\mathrm{CO}_{2} \cdot{ }^{[4]}$ Vanadium-based systems were found among the most performant catalysts for the ODHP reaction. ${ }^{[1 \mathrm{c}, 2 \mathrm{a}, 3]}$ For most supported vanadium systems, beside the support effect, ${ }^{[1 \mathrm{~b}, 5]}$ and the vanadium coordination environment, ${ }^{[6]}$ the propene formation rate per $\mathrm{V}$ atom (also defined as turnover frequency: TOF) has been found to depend on the vanadium surface density ${ }^{[3]}$ and to reach an optimum for intermediate surface densities, ${ }^{[5 c, 7]}$ suggesting that species of limited nuclearity would be beneficial to $\mathrm{C}_{3} \mathrm{H}_{6}$ selectivity. ${ }^{[2 \mathrm{a}]}$ This motivated the design of highly-dispersed species such as single sites for heterogeneous catalysis (SSHC) through metal anchoring of an organometallic complex, ${ }^{[1 \mathrm{c}, 8]}$ or controlled incorporation in hosting structures. ${ }^{[9]}$ Typically, in BEA zeolite, the TOF of monomeric pseudo-tetrahedral V species was found to be much higher than that of polynuclear oxide-like entities present as extra-framework species in the ODHP reaction. ${ }^{[9 b]}$ However, such a single-site catalytic species operates at relatively high temperature and it remains controversial whether these monomeric species, present mostly in a tetrahedral environment, ${ }^{[6]}$ correspond to the optimal organization for the active sites. ${ }^{[5 c]}$ Such a concept of SSHC is in line with the concept of isolation of active 
sites introduced by Grasselli for bulk catalysts as one of the seven pillars governing the catalytic mild oxidation reactions. ${ }^{[4]}$ The spatial isolation of active sites from each other was postulated to be a prerequisite for the control of the selectivity in mildly oxidized products by preventing them from overoxidation. ${ }^{[4,10]}$ For bulk catalysis, this could be successfully achieved through doping of the bulk system, as in the case of the $\mathrm{K}_{2} \mathrm{O}-\mathrm{V}_{2} \mathrm{O}_{5}$ catalyst commercialized for the selective oxidation and ammoxidation of propylene to acrolein and acrylonitrile, respectively. ${ }^{[4]}$ In other bulk systems, the uniqueness of the generated structures led to favorable designs of isolated entities. This is well illustrated by the $\mathrm{Mg}_{2} \mathrm{~V}_{2} \mathrm{O}_{7}$ phase that was claimed to be the active catalytic phase of the VMgO system for the ODHP reaction ${ }^{[11]}$ and for several metal transition phosphates matrices, in which $\mathrm{Mg}$ and $\mathrm{P}$ were mostly considered to be beneficial by limiting the size of the active sites made of transition metal entities. The question of the optimal size of the active sites for the control of the mild oxidation selectivity was long discussed in the case of bulk catalysts. ${ }^{[12]}$ The beneficial impact of clusters of limited size over isolated transition metal monomers in phosphate matrices was ascribed to a better control of the reducibility of the metal centers in size-limited polymeric clusters, as previously reported for propane oxidation $^{[13]}$, butane oxidation to maleic anhydride ${ }^{[14]}$ and isobutyric acid oxidative dehydrogenation to methacrylic acid. ${ }^{[15]}$

Such well-defined model bulk single phase catalysts that sometimes expose isolated and unique surface active sites, potentially made of several transition metals, can be considered as SSHC bulk catalysts. ${ }^{[16]}$ In few cases, especially for the $\mathrm{VMgO}$ system which is known to be active in the ODHP reaction, ${ }^{[1 b]}$ multiphasic compounds were however found to be more efficient than the model $\mathrm{Mg}_{2} \mathrm{~V}_{2} \mathrm{O}_{7}$ single phase catalyst. ${ }^{[11 \mathrm{a}, 17]}$ In addition to the site isolation principle, phase cooperation was also identified as one of the seven pillars of oxidation catalysis. ${ }^{[4]}$ Synergistic effects may result from the formation of a new active phase upon in situ heating of mechanical mixtures. ${ }^{[18]}$ The nanoscale intimacy between different phases, each of 
them exhibiting complementary catalytic functions that cannot be incorporated into a single host structure, may also lead to cooperative effects, ${ }^{[4]}$ eventually promoting the redox exchanges, ${ }^{[19]}$ which were sometimes associated with spillover of oxygen from one phase to the other. $^{[20]}$

In a recent work, we succeeded in preparing a full range of solid solutions of $\mathrm{Ca}_{10}\left(\mathrm{PO}_{4}\right)_{6-}$ ${ }_{x}\left(\mathrm{VO}_{4}\right)_{x}(\mathrm{OH})_{2}$ (with $x$ varying from 0 to 6 ) vanadium-substituted hydroxyapatites under synthesis conditions for which the $\mathrm{pH}$ of the medium was maintained to 9 by continuous addition of ammonia (samples referred to as $\mathrm{V}_{x}$-HAp-pH-9). ${ }^{[21]}$ These $\mathrm{V}_{x}$-HAp-pH-9 samples were found to dehydroxylate to $\mathrm{Ca}_{10}\left(\mathrm{PO}_{4}\right)_{6-x}\left(\mathrm{VO}_{4}\right)_{x}(\mathrm{OH})_{2-y} \mathrm{O}_{y}$ vanadium oxy-hydroxy-apatite solid solutions upon thermal treatment. ${ }^{[22]}$ In this series of samples, vanadium was shown to be present as highly-dispersed isolated monomeric tetrahedral species $\left(\mathrm{VO}_{4}{ }^{3-}\right.$ : vanadates, Figure 1 A, left). These compounds were investigated as a model system for the ODHP reaction as they likely provide increasing amounts of isolated vanadates upon increasing the V loading. ${ }^{[22]}$ Although the surface relaxation was found to result in the prevailing exposure of $\mathrm{Ca}^{2+}$ species on the surface at the expense of that of vanadates, the vanadium oxy-hydroxy-apatite solid solutions formed in situ upon heating were found to enable propane activation. This interesting peculiarity was attributed to the intrinsic and thermally-activated proton mobility that eventually generates, in situ, strongly basic $\mathrm{O}^{2-}$ species on the oxy-hydroxy-apatite surface. Yet the selectivity in propene was found to remain rather limited and below $30 \%$ over these series of catalysts. Various $\mathrm{pH}$ conditions were also applied during the synthesis of the $\mathrm{V}$-substituted HAp samples, with either a continuous or a periodic addition of ammonia. ${ }^{[21]}$ The series of samples prepared with a periodic addition of ammonia, referred to as $\mathrm{V}_{x}$-HAp-pH-per (with $x$ varying from 0 to 6$)$, was also found to form $\mathrm{Ca}_{10}\left(\mathrm{PO}_{4}\right)_{6-x}\left(\mathrm{VO}_{4}\right)_{x}(\mathrm{OH})_{2}$ solid solutions but only for low $\mathrm{V}$ contents $(x<4)$ compared to the $\mathrm{V}_{x}$-HAp-pH-9 series. For higher $\mathrm{V}$ contents $(4 \leq x$ $\leq 5.22)$, the $\mathrm{V}_{x}$-HAp-pH-per materials exhibited a mixture of $\mathrm{Ca}_{10}\left(\mathrm{PO}_{4}\right)_{6-z}\left(\mathrm{VO}_{4}\right)_{\mathrm{z}}(\mathrm{OH})_{2}($ with $z$ 
$<x$ ) solid solutions and $\mathrm{Ca}_{2} \mathrm{~V}_{2} \mathrm{O}_{7}$, whereas the $\mathrm{Ca}_{2} \mathrm{~V}_{2} \mathrm{O}_{7}$ sole phase was formed for $x=6$ only. ${ }^{[21]}$ $\mathrm{Ca}_{2} \mathrm{~V}_{2} \mathrm{O}_{7}$ is made of $\mathrm{V}_{4} \mathrm{O}_{14}$ tetramers in which the two edge-sharing $\mathrm{VO}_{5}$ square pyramids are connected by a corner to an external distorted $\mathrm{VO}_{4}$ tetrahedron. $\mathrm{Ca}_{2} \mathrm{~V}_{2} \mathrm{O}_{7}$ therefore exhibits a crystalline structure different from that of the $\mathrm{Mg}_{2} \mathrm{~V}_{2} \mathrm{O}_{7}$ magnesium pyrovanadate (2 cornersharing tetrahedra), which has been claimed as the active phase of the VMgO system. ${ }^{[11 \mathrm{a}, 23]}$ To avoid any misunderstanding in the present work between the two $\mathrm{Ca}_{2} \mathrm{~V}_{2} \mathrm{O}_{7}$ and $\mathrm{Mg}_{2} \mathrm{~V}_{2} \mathrm{O}_{7}$ crystalline structures, $\mathrm{Ca}_{2} \mathrm{~V}_{2} \mathrm{O}_{7}$ will be hereafter referred to as $\mathrm{Ca}_{4} \mathrm{~V}_{4} \mathrm{O}_{14}$ to account for the involvement of $\mathrm{V}_{4} \mathrm{O}_{14}$ units (Figure 1A, right) in comparison to the $\mathrm{V}_{2} \mathrm{O}_{7}$ pyrovanadate units present in $\mathrm{Mg}_{2} \mathrm{~V}_{2} \mathrm{O}_{7}$. The aim of the present study is to investigate and compare the catalytic behaviors of each of the $\mathrm{Ca}_{10}\left(\mathrm{PO}_{4}\right)_{6-x}\left(\mathrm{VO}_{4}\right)_{x}(\mathrm{OH})_{2}$ solid solutions and $\mathrm{Ca}_{4} \mathrm{~V}_{4} \mathrm{O}_{14}$ phases in the ODHP reaction. This will enable us to consider monomeric tetrahedral $\mathrm{VO}_{4}$ species to tetrameric $\mathrm{V}_{4} \mathrm{O}_{14}$ clusters associating both tetrahedral $\mathrm{VO}_{4}$ and $\mathrm{VO}_{5}$ square pyramid species. The samples which exhibit both of the above-mentioned phases will also be investigated. To evaluate whether there is a cooperation between these two phases in the ODHP reaction, the catalytic performance of the $\mathrm{V}_{5.22}-\mathrm{HAp}$-pH-per sample will be compared to that of the corresponding mechanical mixture of the two phases. This approach requires the precise quantification of the proportions of the two phases present in biphasic compounds, which was achieved by Rietveld refinements together with the determination of the bulk chemical composition of the corresponding samples. The influence of the $\mathrm{Ca}_{4} \mathrm{~V}_{4} \mathrm{O}_{14}$ phase on the surface composition was investigated by XPS. The origin of the observed synergistic effect in the ODHP reaction is discussed by considering the spatial proximity of the two phases and their phase boundary which were investigated by TEM, HRTEM, hetero and homo nuclear 2D solid state NMR and X-band EPR. The reducibility of the catalysts was also investigated by considering both the characterization of selected spent catalysts by EPR and in situ Raman 
characterization of selected samples submitted to subsequent reductive and oxidative treatments.

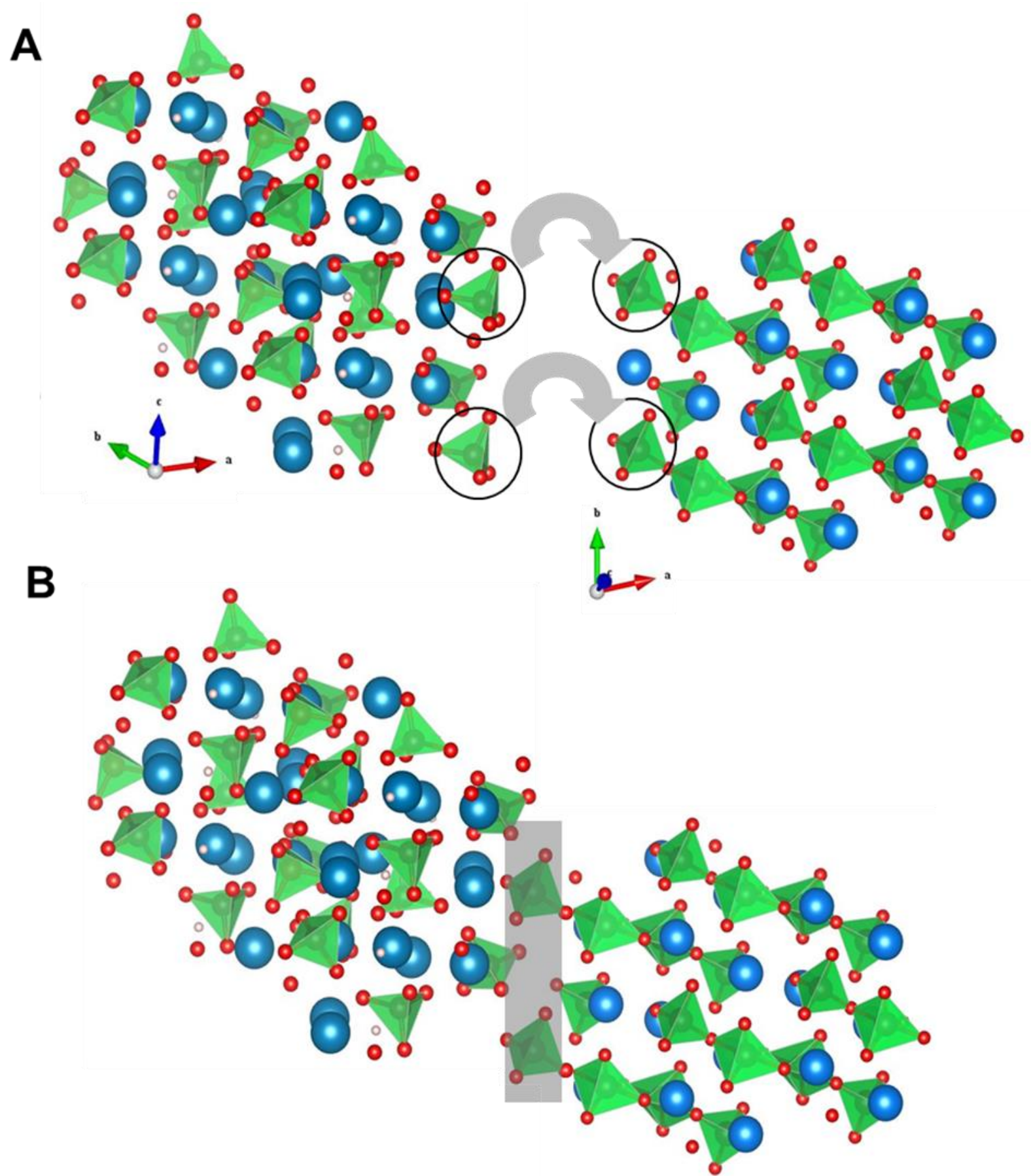

Figure 1: A) Representations of the structures of the vanadium-substituted hydroxyapatite exhibiting isolated $\mathrm{VO}_{4}$ or $\mathrm{PO}_{4}$ tetrahedra (left) and $\mathrm{Ca}_{4} \mathrm{~V}_{4} \mathrm{O}_{14}$ with $\mathrm{V}_{4} \mathrm{O}_{14}$ units made of two external $\mathrm{VO}_{4}$ tetrahedra and two central edgesharing $\mathrm{VO}_{5}$ square pyramids (right). The selected orientation of the two projected structures along $c$ and $b$ axis respectively, helps identifying the tetrahedra of each structures (circled) involved in the formation of a coherent interface. B) Representation of an epitaxially-grown $\mathrm{Ca}_{4} \mathrm{~V}_{4} \mathrm{O}_{14}$ layer on $\mathrm{V}$-substituted-HAp for the $\mathrm{V}_{4}-\mathrm{HAp}$ - $\mathrm{pH}$ per sample. The coherent interface, made of distorted tetrahedra identified in the grey area, benefits from the matching between the $c$ and $b$ cell parameters values of the V-hydroxyapatite and $\mathrm{Ca}_{4} \mathrm{~V}_{4} \mathrm{O}_{14}$ structures $(\sim 6.90$ and $6.89 \AA$, respectively). Ca, $\mathrm{O}$ atoms and $\mathrm{OH}$ groups are illustrated by blue, red and white spheres, respectively, and 
the phosphate tetrahedra (or vanadate ones in the case of vanadium-substituted hydroxyapatite) are colored in green.

\section{Experimental section}

\section{$\underline{2.1 \text { Sample synthesis }}$}

A series of vanadium-modified hydroxyapatite samples, with nominal compositions of the $\mathrm{Ca}_{10}\left(\mathrm{PO}_{4}\right)_{6-x}\left(\mathrm{VO}_{4}\right)_{x}(\mathrm{OH})_{2}$ solid solutions where $x$ varies from 0 to 6 , was prepared according to the co-precipitation procedure previously described using an automated reactor (Optimax 1001 synthesis workstation from Mettler Toledo). ${ }^{[21]} \mathrm{A} \mathrm{Ca}\left(\mathrm{NO}_{3}\right)_{2}$ (Sigma Aldrich $\left.\geq 99.0 \%\right)$ aqueous solution, which $\mathrm{pH}$ was adjusted to 10 , was heated up to $353 \mathrm{~K}$. A second aqueous solution containing $\mathrm{NH}_{4} \mathrm{VO}_{3}$ (Sigma Aldrich $\left.\geq 99.0 \%\right)$ and $\left(\mathrm{NH}_{4}\right) \mathrm{H}_{2} \mathrm{PO}_{4}$ (Acros, 99.9\%) of appropriate concentrations was adjusted to $\mathrm{pH} 10$ and added dropwise $\left(2.2 \mathrm{~mL} \mathrm{~min}{ }^{-1}\right)$ to the $\mathrm{Ca}\left(\mathrm{NO}_{3}\right)_{2}$ aqueous solution maintained under reflux, with a stirring rate of $400 \mathrm{rpm}$ and under $\mathrm{N}_{2}$ flow to limit the carbonation of the materials. The white suspension was then aged under stirring for 4 h with a periodic addition of $28 \% \mathrm{NH}_{4} \mathrm{OH} / \mathrm{H}_{2} \mathrm{O}$ solution to maintain the medium under basic conditions, as adapted from Ben Osman et al. ${ }^{[24]}$ The washed precipitate was dried overnight at $373 \mathrm{~K}$, thermally treated under $\operatorname{Ar}\left(150 \mathrm{~mL} \mathrm{~min}^{-1}\right)$ up to $773 \mathrm{~K}\left(5 \mathrm{~K} \mathrm{~min}^{-1}\right)$ and maintained at this temperature for $90 \mathrm{~min}$. Due to the $\mathrm{pH}$ control procedure, this series of samples will be hereafter referred to as $\mathrm{V}_{x}$-HAp-pH-per where $x$ is the molar content in vanadates.

For comparison with the $\mathrm{V}_{5.22}-\mathrm{HAp}-\mathrm{pH}$-per sample, a sample was prepared using a similar coprecipitation procedure, except that the $\mathrm{pH}$ was maintained at 9 during the precipitation and aging steps by continuous addition of $\mathrm{NH}_{4} \mathrm{OH}$. In that case, a $\mathrm{Ca}_{10}\left(\mathrm{VO}_{4}\right)_{5.22}\left(\mathrm{PO}_{4}\right)_{0.78}(\mathrm{OH})_{2}$ single phase was obtained and will be hereafter referred to as $\mathrm{V}_{5.22}-\mathrm{HAp}-\mathrm{pH}-9 .{ }^{[21-22]}$ 


\section{$\underline{2.2 \text { Characterizations }}$}

Laboratory X-ray diffraction (XRD) patterns were recorded with a Bruker D8 Advance diffractometer equipped with a copper source $\left(\lambda_{\mathrm{Cu}-\mathrm{K \alpha} \alpha}=1.54056 \AA, \lambda_{\mathrm{Cu}-\mathrm{K} \alpha 2}=1.54439 \AA\right)$ and a LynxEye detector. XRD patterns were recorded by $0.02^{\circ}$ steps in the $2 \theta$ range of $2 \theta$ range of 8 $80^{\circ}$. The recorded patterns were refined using the Rietveld method ${ }^{[25]}$ as implemented in the FullProf program. ${ }^{[26]}$

Chemical analyses were performed by inductively-coupled plasma atomic emission spectroscopy (ICP-AES, CREALINS).

XP (X-ray Photoelectron) spectra were collected on a SPECS PHOIBOS 100-5MCD photoelectron spectrometer. A monochromated $\mathrm{Al} \mathrm{K \alpha}(\mathrm{h} v=1486.6 \mathrm{eV})$ radiation source having a $300 \mathrm{~W}$ electron beam power was used for analysis. The emission of photoelectrons from the sample was analyzed at a takeoff angle of $90^{\circ}$ under ultra-high vacuum conditions $\left(1 \times 10^{-8} \mathrm{~Pa}\right)$. Photoelectrons were collected at a pass energy of $20 \mathrm{eV}$ with $0.1 \mathrm{eV}$ steps for $\mathrm{C}_{1 \mathrm{~s}}, \mathrm{O}_{1 \mathrm{~s}}, \mathrm{~V}_{2 \mathrm{p}}, \mathrm{Ca}_{2 \mathrm{p}}$ and $\mathrm{P}_{2 \mathrm{p}}$ XPS core levels. After data collection, the binding energies were calibrated with respect to the binding energy of the $\mathrm{C}_{1 \mathrm{~s}}$ peak at $284.7 \mathrm{eV}$. The peak areas were determined after subtraction of a Shirley background. The atomic ratio calculations were performed after normalization by Scofield factors. Spectrum processing was carried out using the Casa XPS software package.

After outgassing of the samples at $573 \mathrm{~K}$ overnight, specific surface areas were obtained by nitrogen sorption performed on a Belsorp-max apparatus and were deduced from the BET method in the $0.05<\mathrm{P} / \mathrm{P}_{0}<0.3$ range.

TEM characterization was carried out at the Plateforme de microscopie of Institut des Materiaux de Paris Centre. Morphologic analysis at low magnification was performed using a JEOL JEM 1100 microscope operating at $100 \mathrm{keV}$ electron beam. HRTEM and X-EDS for 
structural and chemical investigations were carried out on JEOL JEM 2100 and JEOL JEM 2011 microscopes operating at $200 \mathrm{kV}$, emitting with LaB6 tip equipped with an X-ray detector (Oxford SDD X-max 80). Micrographs were recorded on all microscopes on a $4 \mathrm{~K}$ camera (Gatan Orius). The samples were suspended in ethanol and dispersed with an ultrasonic bath before being rapidly deposited onto a carbone coated copper grid. In addition, two samples were also embedded in a resin, then thin ultramicrotomy sections $(50-70 \mathrm{~nm})$ were collected on the copper grids.

The one dimensional and two dimensional (2D) solid state Nuclear Magnetic Resonance (MAS NMR) spectra were recorded at RT using a Bruker Advance spectrometer operating in a static field of $11.7 \mathrm{~T}$. The resonance frequency of ${ }^{51} \mathrm{~V}$ and ${ }^{31} \mathrm{P}$ were 131.5 and $202.5 \mathrm{MHz}$, respectively. A Bruker $4 \mathrm{~mm}$ MAS probe was used to perform the experiments at a spinning speed of $12.5 \mathrm{kHz}$. The ${ }^{51} \mathrm{~V}$ and ${ }^{31} \mathrm{P}$ chemical shifts were referenced to $\mathrm{NH}_{4} \mathrm{VO}_{3}$ and $85 \% \mathrm{H}_{3} \mathrm{PO}_{4}$ aqueous solution external standards, respectively. The ${ }^{51}$ V-DP NMR spectra were recorded with a pulse duration of $1 \mu \mathrm{s}(\pi / 8)$, recycle delays of $0.5 \mathrm{~s}$ and a scan number of 128 . The ${ }^{31} \mathrm{P}-$ DP NMR spectra were recorded with a pulse duration of $3.2 \mu \mathrm{s}$, a recycle delay of 10 or $450 \mathrm{~s}$ and a scan number of 64 and 8 , respectively. The ${ }^{31} \mathrm{P}$ MAS saturation recovery measurements were achieved by using the pulse sequence « $(\mathrm{d} 20-\mathrm{P} 1)_{\mathrm{n}}-\tau_{\mathrm{r}}-\mathrm{P} 1-$ acquisition $»$ with a P1 impulsion time of $2.75 \mu \mathrm{s}$, a recycling delay of $15 \mathrm{~s}$, and a scan number of 8 , a delay d20 of 50 $\mathrm{ms}$, a $\mathrm{n}$ value of 20 and a duration of $\tau_{\mathrm{r}}$ from $50 \mathrm{~ms}$ to $2000 \mathrm{~s}$. The SIMFIT program from TOPSPIN (Bruker) was used to determine the T1 value.

The ${ }^{51} \mathrm{~V}-{ }^{31} \mathrm{P}$ D-HMQC (heteronuclear multiple quantum coherence) ${ }^{[27]}$ experiments were performed with rf nutation frequencies of 3 and $25 \mathrm{kHz}$ for ${ }^{51} \mathrm{~V}$ and ${ }^{31} \mathrm{P}$, respectively. $S R 4_{1}^{2}$ was used as the recoupling sequence to re-introduce ${ }^{51} \mathrm{~V}-{ }^{31} \mathrm{P}$ dipolar interaction with a rf field strength of $25 \mathrm{kHz}\left(=2 * v_{\text {rot }}\right)$ during $3360 \mu$ s. Spectra result from averaging 8192 transients and a recycle delay of $1 \mathrm{~s}$. 
The ${ }^{51} \mathrm{~V}_{-}{ }^{51} \mathrm{~V}$ double-quantum single-quantum ${ }^{[28]}$ spectrum used the supercycled symmetrybased $B R 2_{2}^{1}$ sequence for excitation and reconversion with $\tau_{\mathrm{exc}}=\tau_{\mathrm{rec}}=888.8 \mu \mathrm{s}$. The rotorsynchronized $t_{1}$ increment interval in the indirect dimension was set to $74.07 \mu \mathrm{s}\left(\nu_{\text {rot }}=13.5\right.$ $\mathrm{kHz}$ ). The relaxation delay was $1 \mathrm{~s}$ and the indirect dimension was acquired with 50 slices with 1024 transients. The rf nutation frequency was $6.25 \mathrm{kHz}$ for the central-transition $\pi$ and $\pi / 2$ pulses. The parameter $q$, for unequal incremented time period ( $\mathrm{qt}_{1}$ and $(1-\mathrm{q}) \mathrm{t}_{1}$ ), was set to 0.2 and the $2 \mathrm{D}$ spectra have been re-scaled along $\mathrm{F}_{1}$ to obtain the normal chemical shift values.

The EPR spectra were recorded at RT and $77 \mathrm{~K}$ on a JEOL FA300 computerized spectrometer working at $\sim 9.3 \mathrm{GHz}$ (X-band) and $100 \mathrm{kHz}$ field modulation by applying a microwave power of $2 \mathrm{~mW}$. Depending on the width and amplitude of the signal, a modulation width between 0.25 and $1 \mathrm{mT}$ was applied. Fresh powdered samples $(50-100 \mathrm{mg})$ were introduced into a suprasil tube (int. diameter of $4 \mathrm{~mm}$ ) and care was taken to always keep the same height of powder in the EPR tube $(\sim 2 \mathrm{~cm})$. The dedicated cell used to investigate the spent catalysts consists in a U-tube reactor, connected to an EPR tube (sealed perpendicularly to the U-tube reactor), equipped with valves that allow the transfer of the sample from the U-tube reactor to the EPR tube without exposure to ambient atmosphere. For comparison purpose, the spectra were normalized per gram of sample. The g-factors were calibrated by using solid 2,2-diphenyl1-picrylhydrazyl (DPPH). Computer simulations of the spectra were performed using the EPRsim32 program. ${ }^{[29]}$

In situ Raman spectra were collected using a Kaiser Optical system equipped with a charge couple detector (CCD) and a LASER with $\lambda=785 \mathrm{~nm}\left(\mathrm{P}=300 \mathrm{~mW}\right.$, resolution $4 \mathrm{~cm}^{-1}$, accumulation time: 10 s, 30 scans per spectrum) equipped with a fiber optic Raman probe (MR Probe) using the Spectra-Tech "Collector" diffuse reflection accessory to focus the laser and collect the raman scattering in a high-temperature cell. About $30 \mathrm{mg}$ of powdered sample was loaded inside the heated crucible located in this cell equipped with appropriate gas inlet and 
outlet connections as to pass the gas flow $\left(30 \mathrm{~mL} \mathrm{~min}^{-1}\right.$ of $\mathrm{H}_{2}(5 \%) / \mathrm{Ar}$ or $\left.\mathrm{O}_{2}(2.5 \%) / \mathrm{Ar}\right)$ through the sample.

\section{$\underline{2.3 \text { ODHP reaction }}$}

Prior to the catalytic runs, the samples $\left(0.10 \mathrm{~g}\right.$ unless stated otherwise) were heated in $\mathrm{O}_{2}$ (2.1\%)-He mixture $\left(11.75 \mathrm{mLNTP}_{\mathrm{Nin}}^{-1}\right)$ at $773 \mathrm{~K}\left(2 \mathrm{~K} \mathrm{~min}^{-1}\right)$ for $3 \mathrm{~h}$. The temperature was then decreased to $673 \mathrm{~K}$.

The $\mathrm{C}_{3} \mathrm{H}_{8} \mathrm{ODH}$ experiments were carried out in a U-type quartz reactor $(10 \mathrm{~mm}$ i.d.). The samples were held on a plug of quartz wool, and the temperature was controlled by a Eurotherm 2408 temperature controller using a K-type thermocouple. Reactant gases (Air Liquide, used as received) were fed from independent mass flow controllers (Brooks 5850 TR and Bronkhorst F-201CV-200-RAD-11-V). Unless stated otherwise, the catalyst was typically contacted with the reaction mixture at $673 \mathrm{~K}$ and the temperature was increased by steps of $25 \mathrm{~K}\left(5 \mathrm{~K} \mathrm{~min}^{-1}\right)$ up to $773 \mathrm{~K}$ for about $1 \mathrm{~h} 30$ at each reaction step at atmospheric pressure. Analysis of the composition of the reactor outflow was performed on-line using a $\mu$-GC (Agilent, CP4900) using three different columns running in parallel. The 5A molecular sieve column $(353 \mathrm{~K}, 150$ $\mathrm{kPa} \mathrm{He}, 200 \mathrm{~ms}$ injection time, $30 \mathrm{~s}$ backflush time) was used to separate $\mathrm{H}_{2}, \mathrm{O}_{2}, \mathrm{CH}_{4}$ and $\mathrm{CO}$. The poraplot Q column (373 K, $150 \mathrm{kPa} H e, 50 \mathrm{~ms}$ injection time, $6 \mathrm{~s}$ backflush time), was used to separate $\mathrm{CO}_{2}, \mathrm{C}_{2} \mathrm{H}_{4}, \mathrm{C}_{2} \mathrm{H}_{6}, \mathrm{H}_{2} \mathrm{O}, \mathrm{C}_{3} \mathrm{H}_{6}$ and $\mathrm{C}_{3} \mathrm{H}_{8}$. The CP-SIL5 column $(318 \mathrm{~K}, 150 \mathrm{kPa}$ $\mathrm{He}, 50 \mathrm{~ms}$ injection time) was used to separate $\mathrm{C}_{3} \mathrm{H}_{6} \mathrm{O}$ compounds (acetone + propenal) from $\mathrm{C}_{3} \mathrm{H}_{4} \mathrm{O}$ (acrolein).

The conversion of $\mathrm{C}_{3} \mathrm{H}_{8}\left(\mathrm{X} \mathrm{C}_{3} \mathrm{H}_{8}\right)$ and the product selectivities $\left(\mathrm{S}_{i}\right)$ were calculated as follows: $\mathrm{X} \mathrm{C}_{3} \mathrm{H}_{8}(\%)=\left(\sum \mathrm{n}_{\mathrm{i}}\left[\mathrm{A}_{\mathrm{i}}\right] /\left(3 \times\left[\mathrm{C}_{3} \mathrm{H}_{8}\right]_{\text {inlet }}\right)\right) \times 100$, $\mathrm{S} A_{i}(\%)=\left(\mathrm{n}_{\mathrm{i}}\left[\mathrm{A}_{\mathrm{i}}\right] / \Sigma \mathrm{n}_{\mathrm{i}}\left[\mathrm{A}_{\mathrm{i}}\right]\right) \times 100$, 
where $\mathrm{n}_{\mathrm{i}},\left[\mathrm{A}_{\mathrm{i}}\right]$ and $\left[\mathrm{C}_{3} \mathrm{H}_{8}\right]_{\text {inlet }}$ are the number of carbon atoms in the $\mathrm{A}_{\mathrm{i}}$ products, the concentrations of the $A_{i}$ products, and the inlet concentration of propane, respectively.

The composition of the $\mathrm{C}_{3} \mathrm{H}_{8}-\mathrm{O}_{2}-\mathrm{He}(3.5-1.0-43.1)$ reaction mixture was: $7.4 \% \mathrm{C}_{3} \mathrm{H}_{8}$ and 2.2 $\% \mathrm{O}_{2}$ in He with a total gas flow of $12.5 \mathrm{~mL}_{\mathrm{NTP}} \mathrm{min}^{-1}$

The spent catalysts were characterized by EPR after reaction at $723 \mathrm{~K}$. In these experiments, the samples loaded in the dedicated cell reactor (see above) were flushed under helium at 723 $\mathrm{K}$ before being kept under $\mathrm{He}$ (using the closing valves of the reactor) and rapidly cooled down to RT under static conditions.

Under the present experimental conditions, it was checked that the reactor did not contribute to the transformation of $\mathrm{C}_{3} \mathrm{H}_{8}$ to a significant extent at $773 \mathrm{~K}$ and that both $\mathrm{C}_{3} \mathrm{H}_{8}$ and $\mathrm{O}_{2}$ conversions measured at $723 \mathrm{~K}$ varied proportionally to the amount of catalyst loaded in the reactor, indicating the absence of external limitations. The carbon balance was found to be above $98 \%$.

\section{Results}

\subsection{Structural and surface characterizations}

Earlier characterization of the $\mathrm{V}_{x}$-HAp-pH-per series, ${ }^{[21]}$ by $\mathrm{XRD}$, and ${ }^{31} \mathrm{P}$ and ${ }^{51} \mathrm{~V} \mathrm{NMR}$ spectroscopy showed the presence of a single $\left.\mathrm{Ca}_{10}\left(\mathrm{PO}_{4}\right)_{6-x}\left(\mathrm{VO}_{4}\right)_{x}(\mathrm{OH})_{2}\right)$ vanadium hydroxyapatite solid solution for the materials with $x<4$, in which the vanadate groups substitute the phosphate ones in the apatite framework (Figure 1a). For higher vanadium contents $(x \geq 4)$, new diffraction peaks around $28-30.5^{\circ}$ assigned to the $\mathrm{Ca}_{4} \mathrm{~V}_{4} \mathrm{O}_{14}$ phase $\mathrm{e}^{[23 \mathrm{~b}]}$ (Figure 2) were found to grow at the expense of those related to HAp. This results eventually in the formation of the pure $\mathrm{Ca}_{4} \mathrm{~V}_{4} \mathrm{O}_{14}$ phase for the $\mathrm{V}_{6}-\mathrm{HAp}$-pH-per sample, whereas a mixture 
of $\mathrm{Ca}_{4} \mathrm{~V}_{4} \mathrm{O}_{14}$ and of the vanadium hydroxyapatite solid solution $\left(\left(\mathrm{Ca}_{10}\left(\mathrm{PO}_{4}\right)_{6-y}\left(\mathrm{VO}_{4}\right)_{y} \mathrm{OH}\right)_{2}\right.$ with $\mathrm{y}<x$ ) phases are obtained for $\mathrm{V}_{4-}$ and $\mathrm{V}_{5.22}-\mathrm{HAp}-\mathrm{pH}$-per samples (Figure 2). As reported previously, $\mathrm{Ca}_{4} \mathrm{~V}_{4} \mathrm{O}_{14}$ formation is favored at high vanadium content due to the predominant speciation of polymeric vanadium species in solution under such high $\mathrm{pH}$ conditions. ${ }^{[5 \mathrm{~b}, 21]}$ The crystalline compositions could be extracted from the Rietveld refinements ${ }^{[25-26]}$ (Figure 2) and the weight loading in $\mathrm{Ca}_{4} \mathrm{~V}_{4} \mathrm{O}_{14}$ was found to increase (5, 34 and $\left.100 \mathrm{wt} \%\right)$ as $x$ increased (4, 5.22 and 6), respectively (Table 1). The molar ratios deduced from Rietveld refinements regarding these samples (Table 1) allowed us to estimate the associated $y$ values, assuming that stoichiometric vanadium-substituted hydroxyapatites were formed (Table 1). This table also shows that the $\mathrm{Ca} /(\mathrm{P}+\mathrm{V})$ ratios determined by $\mathrm{ICP}$ are lower than that expected for stoichiometric $\mathrm{V}_{x}$-HAP solid solutions (nominal $\mathrm{Ca} /(\mathrm{P}+\mathrm{V})=1.67$ ). For samples with $\mathrm{x} \geq 4$, these differences can be mainly attributed to the presence of the $\mathrm{Ca}_{4} \mathrm{~V}_{4} \mathrm{O}_{14}$ crystalline phase, as shown by XRD (Figure 2) and Rietveld analysis (Table 1). These differences in $\mathrm{Ca} /(\mathrm{P}+\mathrm{V})$ ratios may also be attributed to the formation of non-stoichiometric $\mathrm{V}_{x}-\mathrm{HAp}-\mathrm{pH}$-per materials under the particular conditions used for their synthesis for which the addition of ammonia was done periodically during the aging step $^{[21,30]}$ and/or the existence of a minor fraction of amorphous material.

The surface composition determined by X-Ray photoelectron spectrometry shows that the $\mathrm{Ca} /(\mathrm{P}+\mathrm{V})$ molar ratios of the $\mathrm{V}_{x}-\mathrm{HAp}-\mathrm{pH}$-per series of samples are always significantly higher than those of the bulk composition determined by ICP analyses (Table 1). Such a finding has already been observed for the pure vanadium-substituted hydroxyapatite solid solution and was accounted for the involvement of Ca-rich terminations of the hydroxyapatite phase. ${ }^{[22]}$ This effect is the more pronounced as the $\mathrm{Ca}_{4} \mathrm{~V}_{4} \mathrm{O}_{14}$ fraction becomes predominant $(x=5.22$ and 6$)$, which suggests that $\mathrm{Ca}$ terminations should be favored also in the lamellar structure of $\mathrm{Ca}_{4} \mathrm{~V}_{4} \mathrm{O}_{14} \cdot{ }^{[21,23 \mathrm{~b}]}$ Similarly, the higher surface P/V molar ratios (XPS) compared to those found 
for the bulk (ICP) in Table 1 indicates that the prepared materials exhibit V-deficient surfaces. $^{[22]}$

The slightly higher $\mathrm{V}_{2 \mathrm{p}}$ binding energy obtained for $\mathrm{V}_{6}-\mathrm{HAp}-\mathrm{pH}$-per compared to the other samples (517.2 vs $516.9 \mathrm{eV}$ ) (Table 1) is attributed to a $\mathrm{V}$ surface environment in $\mathrm{Ca}_{4} \mathrm{~V}_{4} \mathrm{O}_{14}$ different from that found in the biphasic systems. Such binding energies indicate that vanadium is mostly present as $\mathrm{V}^{5+}$, even though the presence of a very small shoulder at $516.2 \mathrm{eV}$ observable for the $\mathrm{V}_{x}$-HAp-pH-per materials with $3<x \leq 6$ (not shown) may be indicative of the presence of a low amount of surface $\mathrm{V}^{4+}$ species. Note that the formation of $\mathrm{Ca}_{4} \mathrm{~V}_{4} \mathrm{O}_{14}$ upon heating a $\mathrm{CaO}-\mathrm{V}_{2} \mathrm{O}_{5}$ mixture at $1723 \mathrm{~K}$ was reported to exhibit up to $36 \%$ of surface $\mathrm{V}$ as $\mathrm{V}^{4+}$ species. $^{[31]}$ 

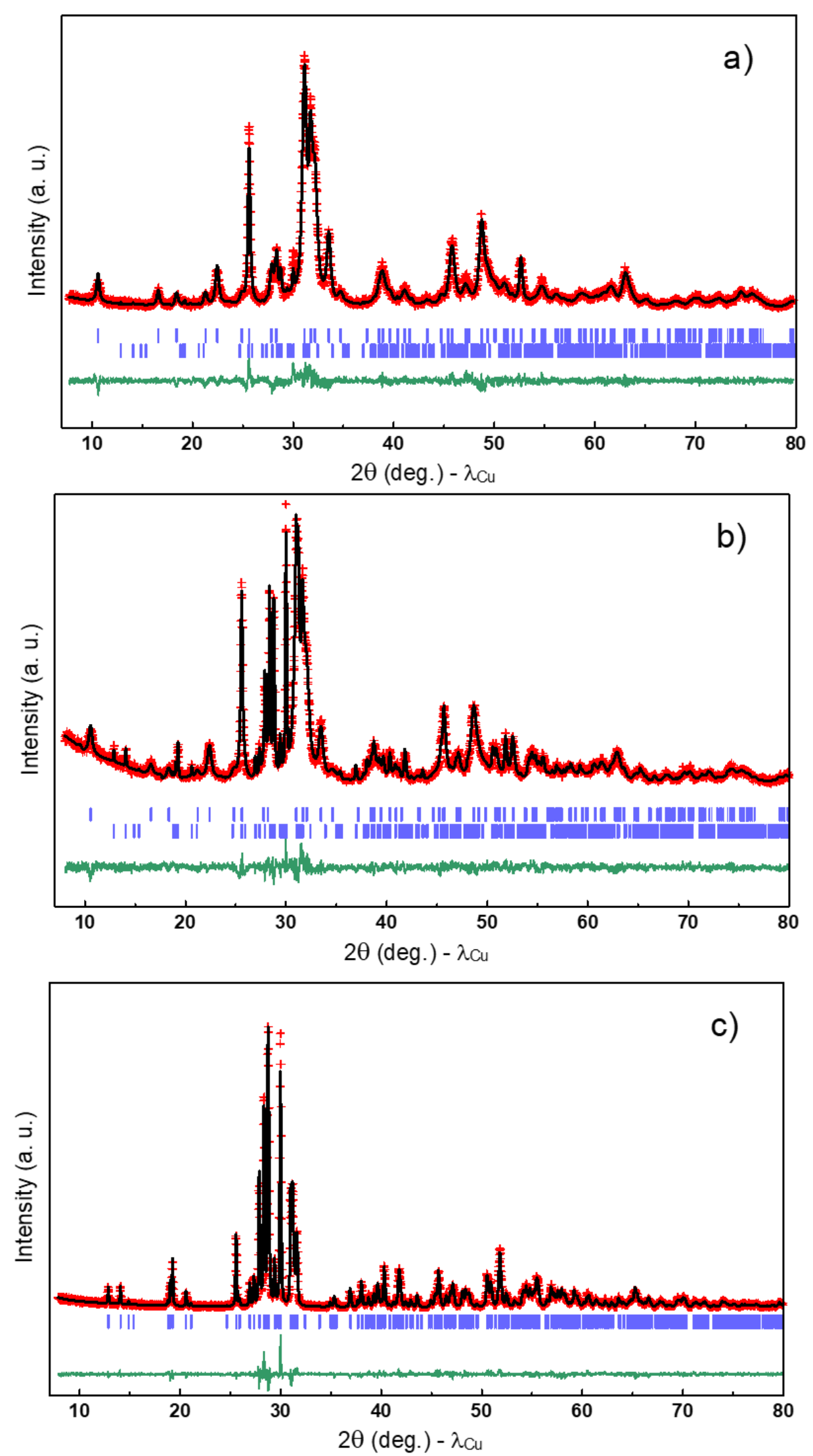

Figure 2: Rietveld refinements of the X-ray diffraction patterns of a) $\mathrm{V}_{4}-\mathrm{HAp}$ - $\mathrm{pH}$-per (Bragg R-factor $=3.43 \%$, $\left.\chi^{2}=1.51\right)$, b) $\mathrm{V}_{5.22}-\mathrm{HAp}$-pH-per (Bragg R-factor $\left.=3.37 \%, \chi^{2}=1.69\right)$ and c) $\mathrm{V}_{6}$-HAp-pH-per (Bragg R-factor $=$ $\left.4.42 \%, \chi^{2}=1.71\right)$. The red crosses, black and green continuous lines represent the observed, calculated and difference patterns, respectively. Vertical blue tick marks represent the Bragg reflections of Hap ( $1^{\text {st }}$ row) and of $\mathrm{Ca}_{4} \mathrm{~V}_{4} \mathrm{O}_{14}$ ( $2^{\text {nd }}$ row), the latter being observed as a pure phase in c). 
Table 1: Phase compositions deduced from Rietveld refinements, comparison of the bulk nominal $\mathrm{Ca} /(\mathrm{P}+\mathrm{V})$ and $\mathrm{P} / \mathrm{V}$ molar ratios with those estimated from the Rietveld refinements and determined experimentally by ICP (bulk) and XPS (surface), and $\mathrm{V}_{2 \mathrm{p}}$ binding energy within the $\mathrm{V}_{x}$-HAp-pH-per series

\begin{tabular}{|c|c|c|c|c|c|c|c|c|c|c|c|c|}
\hline \multirow[t]{2}{*}{$x$} & \multicolumn{3}{|c|}{$\begin{array}{c}\text { Rietveld Composition } \\
\mathrm{Ca}_{10}\left(\mathrm{PO}_{4}\right)_{6-y}\left(\mathrm{VO}_{4}\right)_{y}(\mathrm{OH})_{2}{ }^{\mathfrak{f}} / \mathrm{Ca}_{4} \mathrm{~V}_{4} \mathrm{O}_{14}\end{array}$} & \multicolumn{4}{|c|}{$\mathrm{Ca} /(\mathbf{P}+\mathrm{V})$ molar ratio } & \multicolumn{4}{|c|}{$\mathrm{P} / \mathrm{V}$ molar ratio } & $\begin{array}{l}V_{2 p} \text { binding } \\
\text { energy }(e V)\end{array}$ \\
\hline & wt ratio & molar ratio & $y$ & nominal: & Rietveld $^{\$}$ & ICP & XPS & nominal $^{*}$ & Rietveld $^{\$}$ & ICP & XPS & \\
\hline 3 & $100 / 0$ & $100 / 0$ & 3.00 & 1.67 & 1.67 & 1.59 & 1.63 & 1.00 & 1.00 & 1.09 & 2.00 & 516.9 \\
\hline 4 & $95 / 5$ & $91 / 9$ & 3.85 & 1.67 & 1.63 & 1.48 & 1.73 & 0.50 & 0.51 & 0.52 & 1.14 & 516.9 \\
\hline 5.22 & $66 / 34$ & $51 / 49$ & 4.71 & 1.67 & 1.40 & 1.44 & 1.91 & 0.15 & 0.15 & 0.18 & 0.64 & 516.9 \\
\hline 6 & $0 / 100$ & $0 / 100$ & - & 1.67 & 1.00 & 1.02 & 1.66 & 0 & 0 & 0 & 0 & 517.2 \\
\hline
\end{tabular}

$£$ with $\mathrm{y} \leq x$

* based on a $\mathrm{Ca}_{10}\left(\mathrm{PO}_{4}\right)_{6-x}\left(\mathrm{VO}_{4}\right)_{x}(\mathrm{OH})_{2}$ nominal composition

$\$$ calculated values assuming a stoichiometric $\mathrm{Ca}_{10}\left(\mathrm{PO}_{4}\right)_{6-y}\left(\mathrm{VO}_{4}\right)_{y}(\mathrm{OH})_{2}$ hydroxyapatite in biphasic mixtures. 


\subsection{Interface structure}

\subsubsection{Electronic microscopy}

The formation of the pure $\mathrm{Ca}_{4} \mathrm{~V}_{4} \mathrm{O}_{14}$ phase for $\mathrm{V}_{6}-\mathrm{HAp}$-pH-per results in the presence of large particles ( $\geq 200 \mathrm{~nm}$, Figure 3a), which is consistent with the very low specific surface area measured for this sample (Table S1). The EDX Ca/V molar ratio found to be close to 1 for this sample is also consistent with the presence of the $\mathrm{Ca}_{4} \mathrm{~V}_{4} \mathrm{O}_{14}$ phase (Table S1). It must be recalled that the reliability of the EDX analysis for the estimation of the bulk composition of the samples was ascertained for $\mathrm{V}_{5.22}-\mathrm{HAp}-\mathrm{pH}-9$, which exhibited a $\mathrm{Ca} /(\mathrm{P}+\mathrm{V})$ EDX ratio (1.68) in good agreement with that obtained by ICP (1.67). ${ }^{[21]}$ Even though very few large particles exhibiting a Ca/V EDX ratio of about 0.92 are still visible for the biphasic $\mathrm{V}_{5.22}-\mathrm{HAp}-\mathrm{pH}$-per sample (Figure 3b), this sample mainly shows the presence of rod-shaped particles. Such elongated rods are typical of hydroxyapatites and vanadium-substituted hydroxyapatites (S1, Figure S1). In contrast to what can be observed for HAp (Figure S1a) and $\mathrm{V}_{6}-\mathrm{HAp}-\mathrm{pH}-9$ (Figure S1b), higher magnification micrographs show that the rods of the $\mathrm{V}_{5.22^{-}}, \mathrm{V}_{4.5^{-}}, \mathrm{V}_{4-}$ and $\mathrm{V}_{3.5}$-HAp-pH-per samples appear to be encapsulated, at least partly, by an external layer (Figures 3c-f). The $\mathrm{Ca} / \mathrm{V}$ ratios estimated by EDX were found to be consistent with those estimated from the Rietveld analyses for $\mathrm{V}_{4-}, \mathrm{V}_{5.22^{-}}$and $\mathrm{V}_{6-}$ HAp-pH-per samples (S1 Table S1). The comparison of Figures 3c-f suggests that the thickness of the external layer is heterogeneous (see Figure 3e for $\mathrm{V}_{4}-\mathrm{HAp}-\mathrm{pH}-\mathrm{per}$ ). This is supported by the partial encapsulation of the rods deduced from complementary TEM examination of ultramicrotome sections showing areas with unencapsulated terminations for rod particles of $\mathrm{V}_{4^{-}}$and $\mathrm{V}_{5.22^{-}}$ HAp-pH-per (Figure S2). 


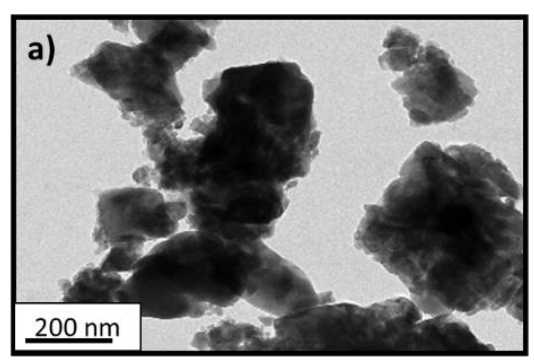

d)

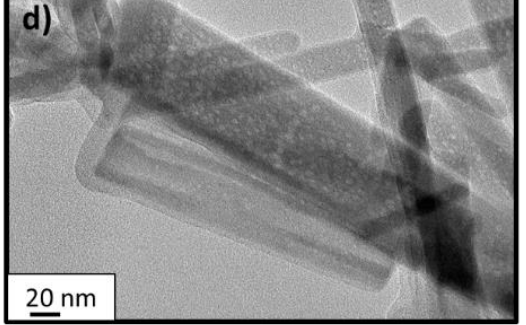

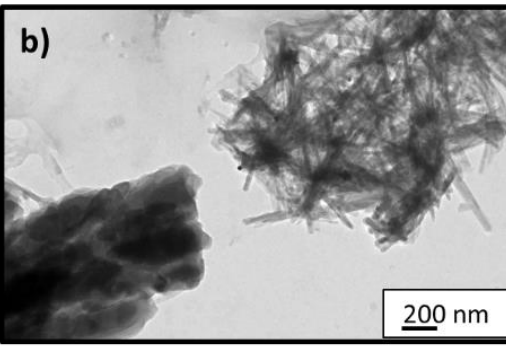

e)

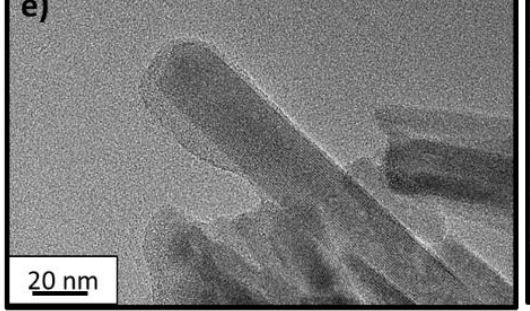

c)

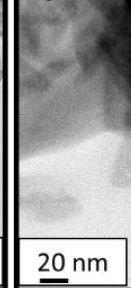

f)

$\underline{20 \mathrm{~nm}}$

Figure 3: TEM micrographs of a) $\mathrm{V}_{6}-\mathrm{HAp}-\mathrm{pH}-\mathrm{per}$, b) and c) $\mathrm{V}_{5.22}-\mathrm{HAp}-\mathrm{pH}-\mathrm{per}$ d) $\mathrm{V}_{4.5}-\mathrm{HAp}-\mathrm{pH}-\mathrm{per}$, e) $\mathrm{V}_{4-}$ HAp-pH-per, and f) $\mathrm{V}_{3.5}$-HAp-pH-per samples.

The coated rods were further studied by HRTEM. The presence of an inter-reticular distance of $2.63 \AA$ is characteristic of the apatite structure ([202] plane), as illustrated in the case of the $\mathrm{V}_{4}$ HAp-pH-per sample and the related Fourier transform reported in the top inset of Figure 4. The external layer was found to be difficult to characterize due to its degradation under the electron beam, except in the case of the $\mathrm{V}_{4}-\mathrm{HAp}-\mathrm{pH}$-per sample. Despite its very low thickness the crystalline structure of the external could be revealed by the observation of the characteristic inter-reticular distance $2.73 \AA$ (Fourier transform in the bottom inset of Figure 4) that can be attributed to the [012], [201] or [2-21] planes of $\mathrm{Ca}_{4} \mathrm{~V}_{4} \mathrm{O}_{14 \cdot}{ }^{[23 \mathrm{~b}]}$ In addition, angles of 8.1 and $5.6^{\circ}$ are measured between the horizontal axis of the Fourier transforms and the series of planes typical of the HAp and $\mathrm{Ca}_{4} \mathrm{~V}_{4} \mathrm{O}_{14}$ structures, respectively. This corresponds to a disorientation angle between the two series of planes of $2.5^{\circ}$. Such a low value is indicative of the formation of a coherent interface leading to an epitaxial growth of the $\mathrm{Ca}_{4} \mathrm{~V}_{4} \mathrm{O}_{14}$ phase onto the $\mathrm{V}_{4}-\mathrm{HAp}$ rods (Figure 1B).

The agreement found between the $\mathrm{Ca} / \mathrm{P}$ ratios estimated by EDX and Rietveld analysis on $\mathrm{V}_{5.22-}$ HAp-pH-per (Table S1) provides support for a coating of the V-HAp rods by the $\mathrm{Ca}_{4} \mathrm{~V}_{4} \mathrm{O}_{14}$ 
phase. Despite the absence of XRD diffraction peaks related to $\mathrm{Ca}_{4} \mathrm{~V}_{4} \mathrm{O}_{14}$ for $\mathrm{V}_{3.5}-\mathrm{HAp}-\mathrm{pH}$-per (not shown), the coating of the V-HAp rods by an amorphous $\mathrm{Ca}_{4} \mathrm{~V}_{4} \mathrm{O}_{14}$ phase (Figure $3 \mathbf{f}$ ) is further supported by the lower $\mathrm{Ca} / \mathrm{V}$ EDX ratio (2.50, Table S1) compared to that expected for the $\mathrm{Ca}_{10}\left(\mathrm{PO}_{4}\right)_{2.5}\left(\mathrm{VO}_{4}\right)_{3.5}(\mathrm{OH})_{2}$ solid solution (2.86, Table S1).

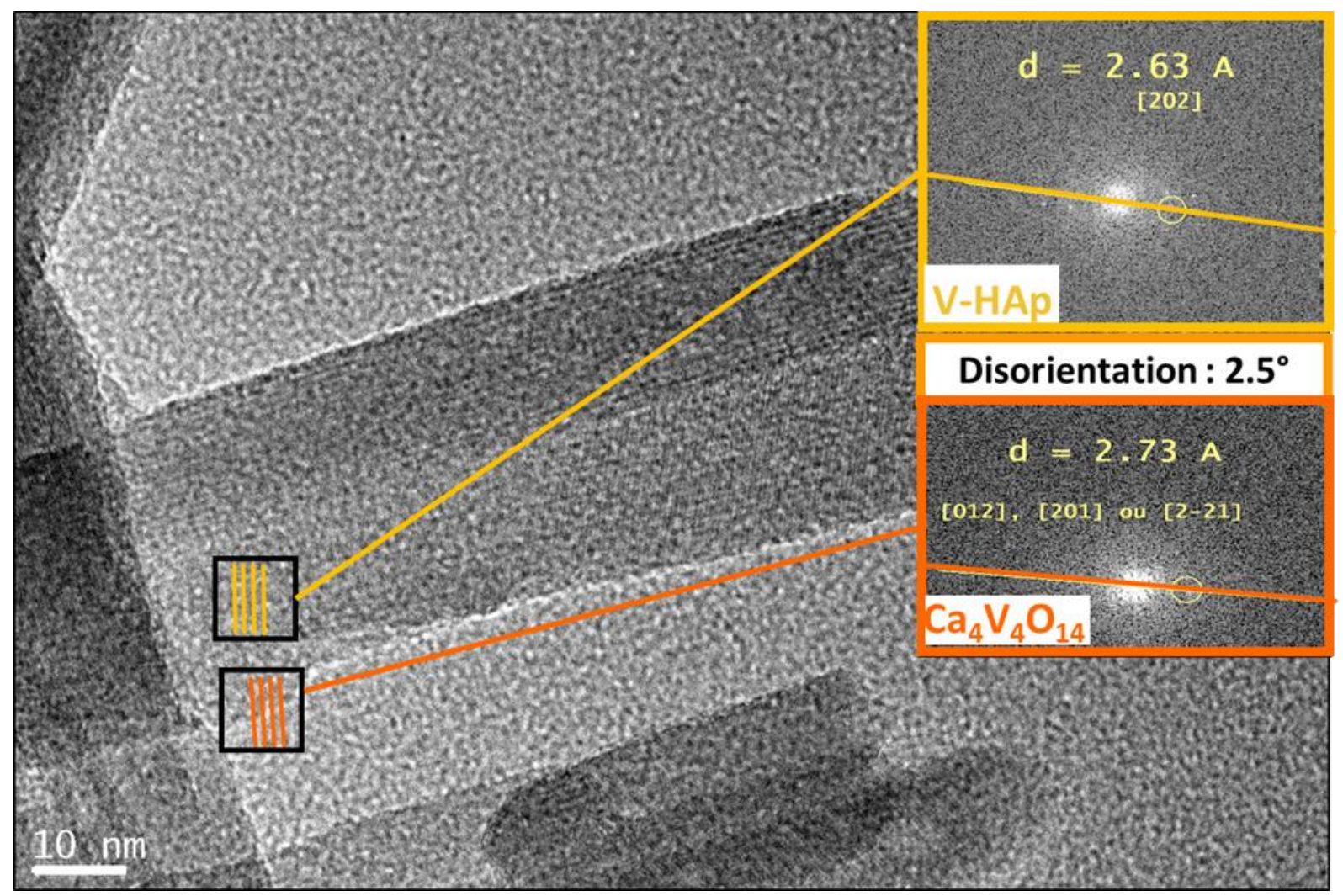

Figure 4: HRTEM micrograph of $\mathrm{V}_{4}-\mathrm{HAp}-\mathrm{pH}$-per sample showing partially-coated rods. The top and bottom insets correspond to the Fourier Transforms recorded for the rod and its surface coating, respectively. The interreticular distances measured for each areas and the disorientation angle of $2.5^{\circ}$ between the two series of characteristic diffraction planes of the two phases is indicative of an epitaxial growth of the $\mathrm{Ca}_{4} \mathrm{~V}_{4} \mathrm{O}_{14}$ phase onto the V-HAp rods.

\subsubsection{Solid state NMR spectroscopy}

The spatial intimacy between the two crystalline phases revealed by TEM (Figures 3 and 4 ) was investigated by solid state NMR by probing the local spatial proximity between the various $\mathrm{V}$ and $\mathrm{P}$ species. For the sake of a qualitative comparison, the intensity normalized ${ }^{31} \mathrm{P}-\mathrm{DP}$ NMR spectra are reported in Figure 5 a. The typical narrow phosphate resonance peak observed at $2.8 \mathrm{ppm}$ for $\mathrm{V}_{0}-\mathrm{HAp}-\mathrm{pH}-\mathrm{per},{ }^{[32]}$ is found to shift progressively to higher $\delta_{31 \mathrm{P}}$ chemical shifts and to broaden as the phosphorus content decreases. These observations are 
consistent with the formation of a $\mathrm{Ca}_{10}\left(\mathrm{PO}_{4}\right)_{6-y}\left(\mathrm{VO}_{4}\right)_{y}(\mathrm{OH})_{2}$ solid solution and the progressive modification of the environment of phosphates. ${ }^{[21]}$ However, close examination of the spectra recorded with a repetition time of $10 \mathrm{~s}$ (repetition time usually used for qualitative comparison of ${ }^{31} \mathrm{P}$ species) without intensity normalization (Figure $5 \mathbf{b}$ ) reveals that the area of the related ${ }^{31} \mathrm{P}$ signals increases from $\mathrm{V}_{0}-\mathrm{HAp}$-pH-per to $\mathrm{V}_{5.22}-\mathrm{HAp}$-pH-per (100 vs 185 a.u., respectively), whereas a reverse tendency is expected with the lowering of phosphorus content. This led us to conclude that such short repetition time conditions should not be applied for quantitative comparisons due to the involvement of significantly different relaxation times (T1) along the samples under study. From the saturation recovery sequence, irrespectively of their preparation routes ( $\mathrm{pH}$ control procedures), ${ }^{[21]}$ all of the samples associated with single phase vanadium hydroxyapatite solid solutions, i.e. $\mathrm{V}_{x}$-HAp-pH-per $(x=0,1.38)$ and $\mathrm{V}_{5.22}-\mathrm{HAp}-\mathrm{pH}-9$, exhibit similar curves (Figure 6). Their associated relaxation times deduced from the curve fitting processing agree with those usually reported for biological hydroxyapatites ${ }^{[33]}(\sim 300 \mathrm{~s})$ (Table 2). In contrast, for the biphasic samples made of particles exhibiting rod-like particles encapsulated by an irregular $\mathrm{Ca}_{4} \mathrm{~V}_{4} \mathrm{O}_{14}$ layer ( $\mathrm{V}_{x}$-HAp-pH-per, $x=3.5,4$ and 5.22), a very different behavior is observed (Figure 6). The curve fitting of these data (with two components for $\mathrm{V}_{5.22}-\mathrm{HAp}-\mathrm{pH}$-per) shows that the relaxation times are about twice as low for $\mathrm{V}_{3.5^{-}}$and $\mathrm{V}_{4^{-}}$ HAp-pH-per, and even much lower for $\mathrm{V}_{5.22}$-HAp-pH-per, compared to the non- and lowlyloaded $\mathrm{V}_{x}$-HAp-pH-per $(x=0,1.38)$ samples and $\mathrm{V}_{5.22}$-HAp-pH-9 (Table 2). In the case of the mechanical mixture, which mimics the composition of the $\mathrm{V}_{5.22}-\mathrm{HAp}-\mathrm{pH}-\mathrm{per}$ biphasic compound, the corresponding relaxation time ( $287 \mathrm{~s}$ ) was found to be quite close to those estimated for the single-phase solid solutions (Table 2). Hence, the decrease in relaxation time can only be observed for biphasic compounds exhibiting peculiar intimacy between the two phases, as corroborated by HRTEM micrographs (Figures 3 and 4). This clearly shows that this 
peculiar interface between the two phases must influence the NMR signal of phosphorus of the apatite phase.

a)

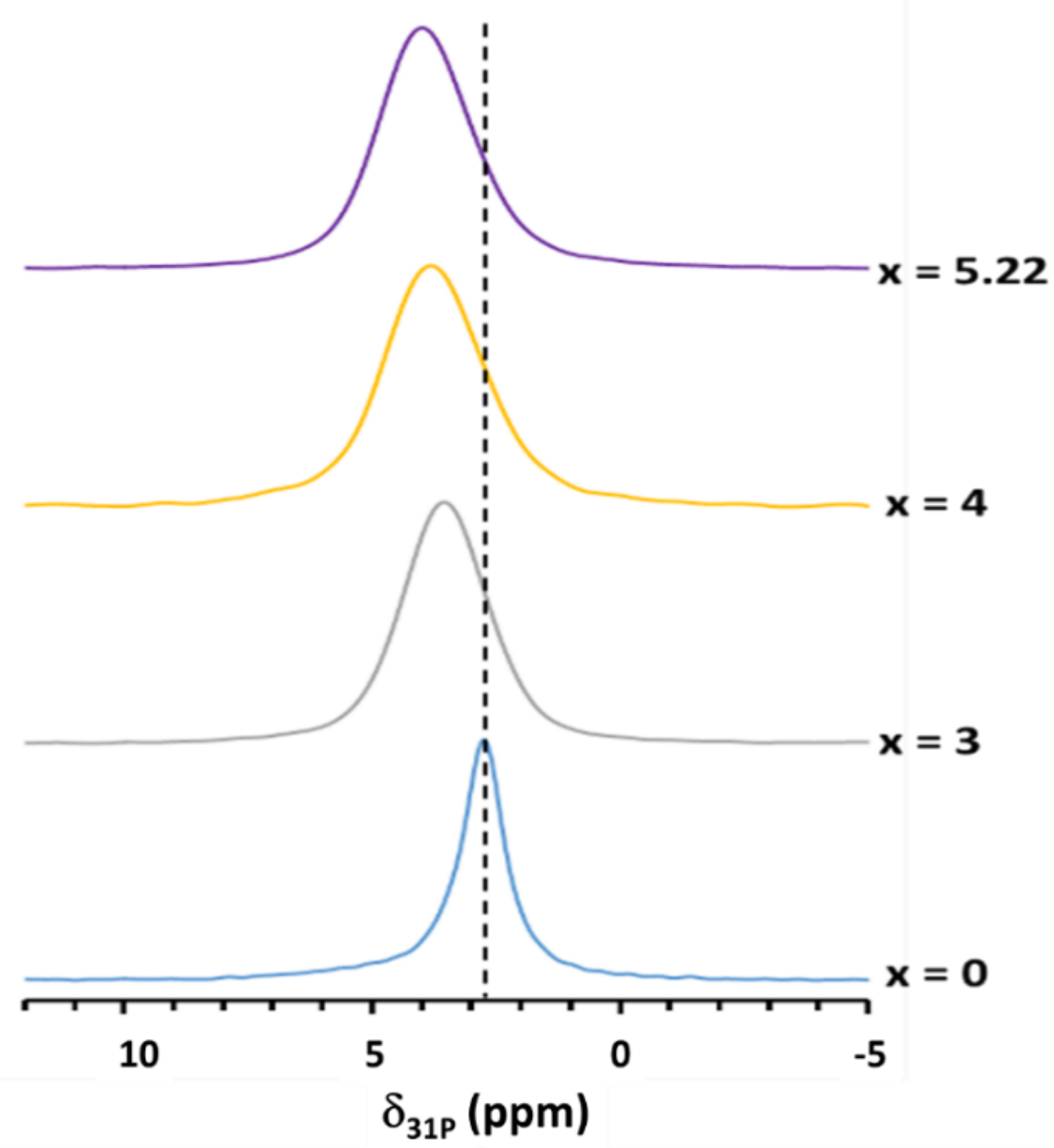

b)

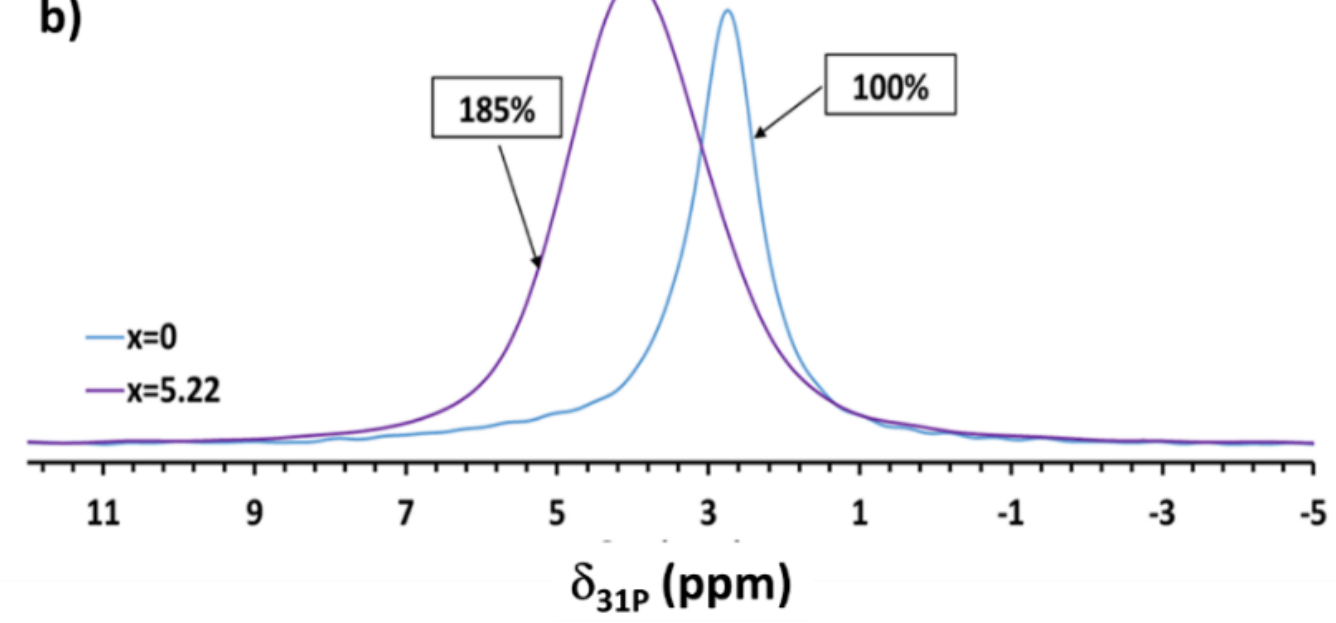

Figure 5: ${ }^{31} \mathrm{P}-\mathrm{DP}$ NMR spectra of the $\mathrm{V}_{x}$-HAp-pH-per series a) with intensity normalization achieved using the $\mathrm{V}_{0}-\mathrm{HAp}$-pH-per sample as a reference, $\mathrm{b}$ ) without normalization with a repetition time of $10 \mathrm{~s}$. 


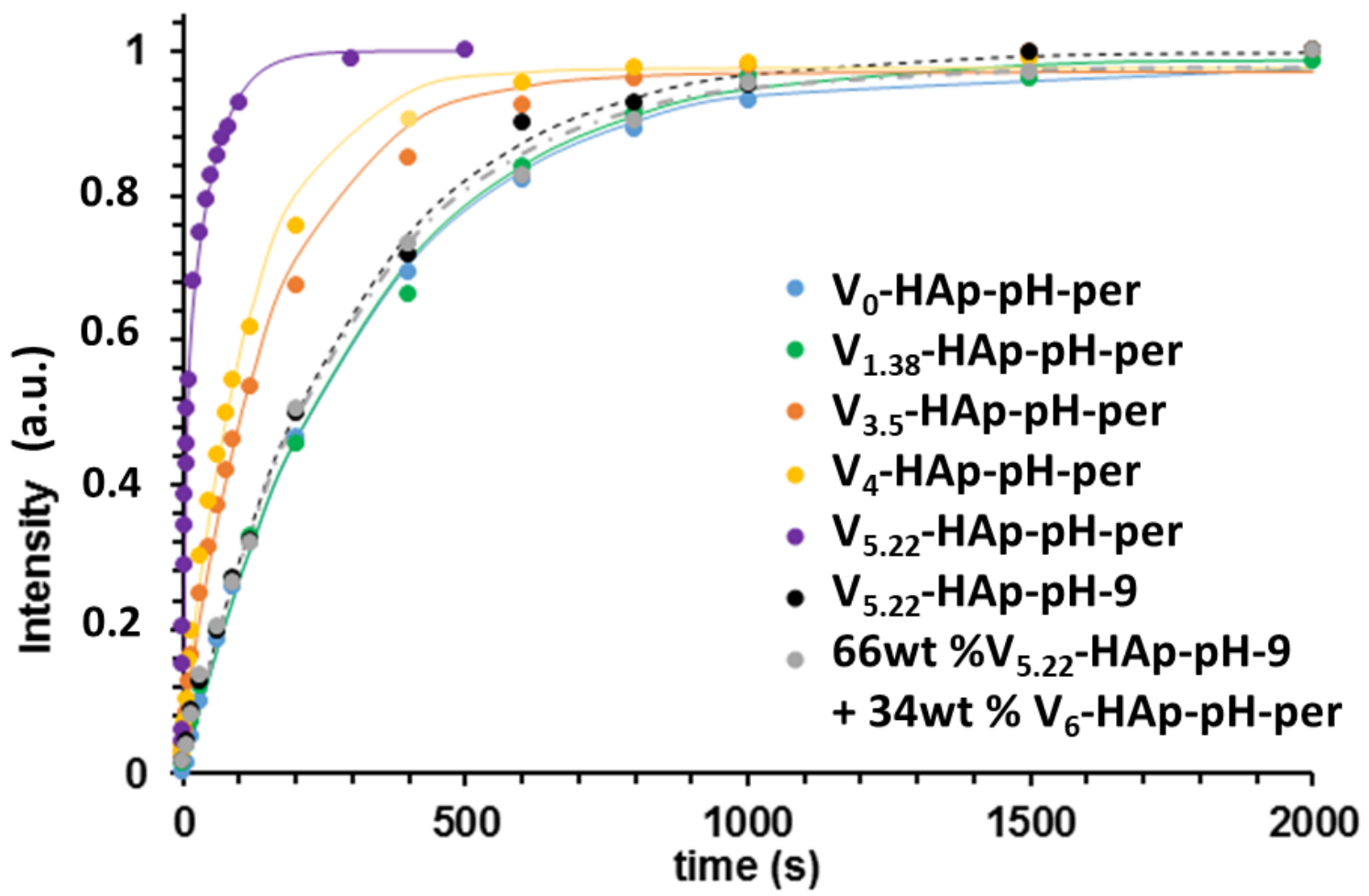

Figure 6: Experimental data (circles) taken from the saturation recovery sequence for pure vanadium-substituted hydroxyapatite solid solutions ( $\mathrm{V}_{0}-\mathrm{HAp}-\mathrm{pH}$-per, $\mathrm{V}_{1.38}-\mathrm{HAp}-\mathrm{pH}-$ per and $\mathrm{V}_{5.22}-\mathrm{HAp}-\mathrm{pH}-9$ ), biphasic $\mathrm{V}_{x}-\mathrm{HAp}-\mathrm{pH}-$ per samples with rod particles encapsulated by an irregular layer $\left(\mathrm{V}_{3.5}-\mathrm{HAp}-\mathrm{pH}-\mathrm{per}, \mathrm{V}_{4}-\mathrm{HAp}-\mathrm{pH}-\mathrm{per}\right.$ and $\mathrm{V}_{5.22^{-}}$ HAp-pH-per) and a mechanical mixture $\left(\mathrm{V}_{5.22}-\mathrm{HAp}-\mathrm{pH}-9\right.$ (66 wt $\left.\%\right)+\mathrm{V}_{6}-\mathrm{HAp}-\mathrm{pH}-\mathrm{per}(34 \mathrm{wt} \%)$ ), and their corresponding fitted traces (solid and dashed lines).

Table 2: Comparison of the relaxation time of phosphorus estimated from saturation recovery experiments for different nominal $\mathrm{Ca}_{10}\left(\mathrm{PO}_{4}\right)_{6-x}\left(\mathrm{VO}_{4}\right)_{x}(\mathrm{OH})_{2}$ compositions.

\begin{tabular}{ccc}
\hline sample & $x$ & Relaxation time (s) \\
\hline V $_{5.22}$-HAp-pH-9 & $5.22^{1}$ & 291 \\
& $0^{2}$ & 313 \\
$\mathrm{~V}_{x}$-HAp-pH-per & $1.38^{2}$ & 316 \\
& $3.5^{3}$ & 158 \\
& $4^{3}$ & 120 \\
& $5.22^{3}$ & $4 / 48^{4}$ \\
Mechanical mixture & $34 \mathrm{wt} \% \mathrm{~V}_{6}$-HAp-pH-per + & 287 \\
& $66 \mathrm{wt} \%$ V & \\
\hline
\end{tabular}

\footnotetext{
${ }^{1} \mathrm{Ca}_{10}\left(\mathrm{PO}_{4}\right)_{0.78}\left(\mathrm{VO}_{4}\right)_{5.22}(\mathrm{OH})_{2}$ single phase materials obtained by maintaining the $\mathrm{pH}$ to 9 during the whole synthesis process ${ }^{[21]}$

${ }^{2}$ low vanadium loading $\mathrm{Ca}_{10}\left(\mathrm{PO}_{4}\right)_{6-x}\left(\mathrm{VO}_{4}\right)_{x}(\mathrm{OH})_{2}$ single phase compound prepared in the present work associated to typical rod particles.

${ }^{3}$ biphasic samples associated to rod-like particles encapsulated by an irregular $\mathrm{Ca}_{4} \mathrm{~V}_{4} \mathrm{O}_{14}$ layer.

${ }^{4}$ the data were fitted with two components.

${ }^{5}$ mechanical mixture representative of the chemical composition of the $\mathrm{V}_{5.22}-\mathrm{HAp}-\mathrm{pH}$-per biphasic compound.
} 
One dimensional (1D) Heteronuclear correlations were performed in order to investigate the spatial proximity between the ${ }^{51} \mathrm{~V}$ and ${ }^{31} \mathrm{P}$ nuclei. ${ }^{51} \mathrm{~V}-{ }^{31} \mathrm{P}$ DHMQC heteronuclear multiple quantum coherence sequence is required to probe a quadripolar nucleus such as ${ }^{51} \mathrm{~V}$ ( $\mathrm{spin}=$ $7 / 2$ ), close $\mathrm{a}^{31} \mathrm{P}$ nucleus $($ spin $=1 / 2)$. Figure 7 shows a comparison of the spectra recorded with the ${ }^{51} \mathrm{~V}$-DP and ${ }^{51} \mathrm{~V}_{-}{ }^{31} \mathrm{P}$ DHMQC sequences for $\mathrm{V}_{1.38}-\mathrm{HAp}$-pH-per and $\mathrm{V}_{5.22}-\mathrm{HAp}-\mathrm{pH}-$ per. For the $\mathrm{V}_{1.38}-\mathrm{HAp}-\mathrm{pH}$-per single phase compound (Figure 7 a), a resonance peak is observed at $-625 \mathrm{ppm}$ for ${ }^{51} \mathrm{~V}-{ }^{31} \mathrm{P}$ DHMQC, ascribed to isolated $\mathrm{VO}_{4}{ }^{3-}$ tetrahedra substituting the $\mathrm{PO}_{4}{ }^{3-}$ groups in the vanadium-substituted hydroxyapatite solid solution, for both sequences. ${ }^{[21]}$ The very limited shift of the ${ }^{51} \mathrm{~V}$ contributions observed between the two experiments ( $\left.4 \mathrm{ppm}\right)$ is explained by the probe of slightly different environments: the vanadium species close to the phosphorus ones (observed in the ${ }^{51} \mathrm{~V}-{ }^{31} \mathrm{P}$ DHMQC spectrum) are detected at a slightly lower chemical shift than those surrounded by other vanadium species (also detected in the ${ }^{51} \mathrm{~V}$-DP spectrum). Due to a higher vanadium content compared to $\mathrm{V}_{1.38}-\mathrm{HAp}-\mathrm{pH}-\mathrm{per}, \mathrm{V}_{5.22}-\mathrm{HAp}-\mathrm{pH}-$ per shows a ${ }^{51} \mathrm{~V}$ signal associated with isolated vanadates in the solid solution at a higher chemical shift (- 605 ppm, ${ }^{51} \mathrm{~V}$-DP sequence Figure 7 b). ${ }^{[21]}$ The slightly higher difference in ${ }^{51} \mathrm{~V}$ chemical shift observed between the two sequences for $\mathrm{V}_{5.22}-\mathrm{HAp}-\mathrm{pH}$-per compared to $\mathrm{V}_{1.38}$-HAp-pH-per (6 ppm against 4ppm), with -605 and -611 ppm for ${ }^{51} \mathrm{~V}-\mathrm{DP}$ and ${ }^{51} \mathrm{~V}-{ }^{31} \mathrm{P}$ DHMQC spectra respectively, is consistent with the increased probability for the $\mathrm{VO}_{4}{ }^{3-}$ tetrahedra to be close to another $\mathrm{VO}_{4}{ }^{3-}$ tetrahedron in the apatite framework in $\mathrm{V}_{5.22}-\mathrm{HAp}-\mathrm{pH}$ per compared to $\mathrm{V}_{1.38}-\mathrm{HAp}-\mathrm{pH}-$ per. More interesting is the presence of a signal at lower chemical shift (- 574 ppm, Figure 7 b) observed in the ${ }^{51} \mathrm{~V}$ DP spectrum of $\mathrm{V}_{5.22}$-HAp-pH-per, which can be ascribed to the $\mathrm{VO}_{4}{ }^{3-}$ distorted tetrahedra of the $\mathrm{Ca}_{4} \mathrm{~V}_{4} \mathrm{O}_{14}$ phase. The additional contribution at $-540 \mathrm{ppm}$, ascribed to the $\mathrm{VO}_{5}{ }^{5-}$ square pyramids of $\mathrm{Ca}_{4} \mathrm{~V}_{4} \mathrm{O}_{14}$, could not be observed in these conditions as such a contribution is expected to be much broader and less intense than that at - 574 ppm, as seen in earlier studies. ${ }^{[23 a, 34]}$ The absence of the signal at -574 
ppm in the ${ }^{51} \mathrm{~V}_{-}{ }^{31} \mathrm{P}$ DHMQC spectrum of the biphasic compound (Figure 7 b) shows that the phosphate groups constitutive of the apatite solid solution must not be close enough to the vanadate tetrahedra of the $\mathrm{Ca}_{4} \mathrm{~V}_{4} \mathrm{O}_{14}$ phase and/or this approach was not sensitive enough to probe the interface between the two phases.

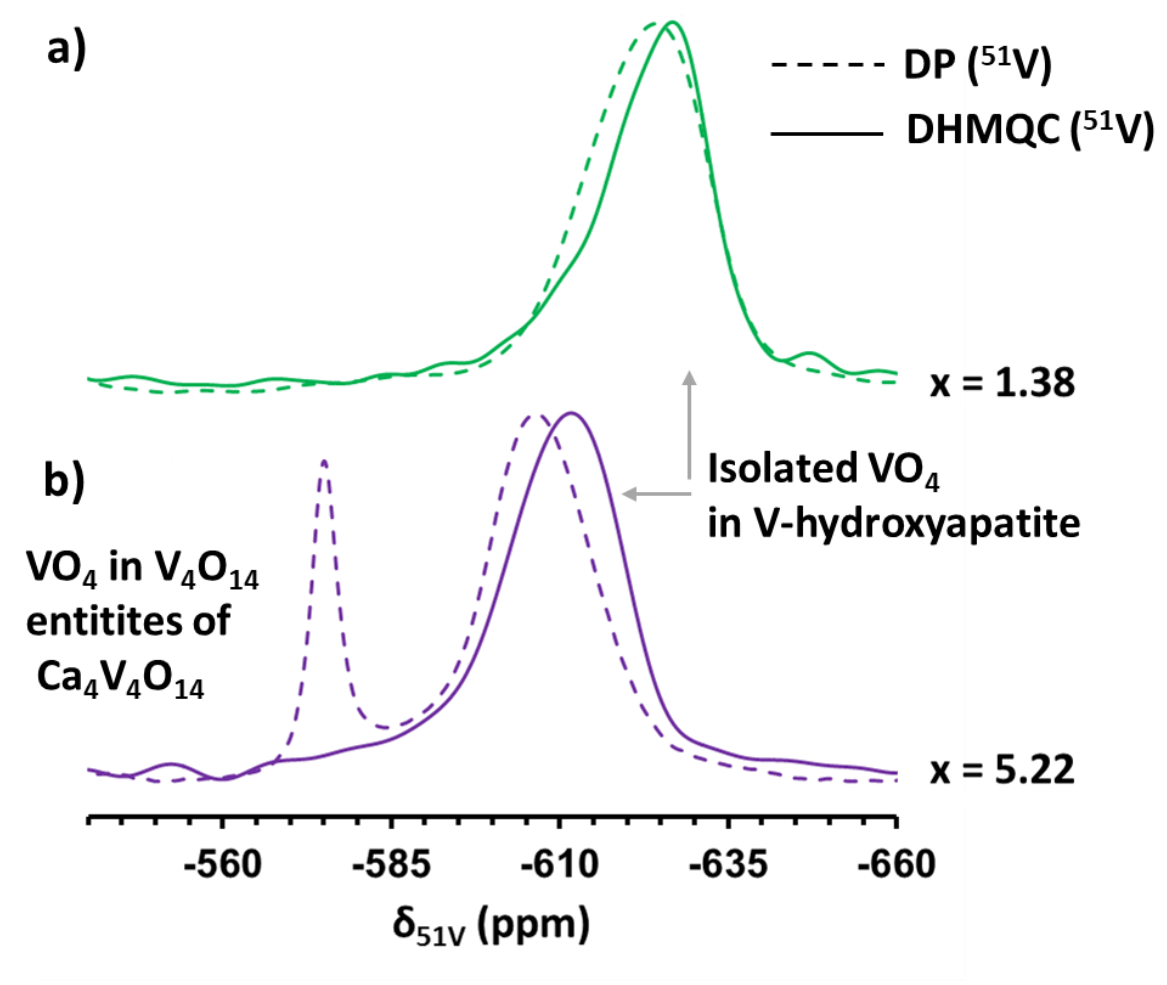

Figure 7: Comparison of ${ }^{51} \mathrm{~V}-\mathrm{DP}$ and ${ }^{51} \mathrm{~V}_{-}{ }^{31} \mathrm{P}$ DHMQC spectra for a) $\mathrm{V}_{1.38}-\mathrm{HAp}-\mathrm{pH}$-per and $\mathrm{b}$ ) $\mathrm{V}_{5.22}$-HAp-pH-per.

Two dimensional homonuclear ${ }^{51} \mathrm{~V}_{-}{ }^{51} \mathrm{~V}$ correlations were also probed via $^{51} \mathrm{~V}$ DQ/SQ (double quanta/simple quanta) experiments. ${ }^{[28,35]}$ The parameters used for such complex experiments were preliminary validated on the $\alpha-\mathrm{Mg}_{2} \mathrm{~V}_{2} \mathrm{O}_{7}$ pyrovanadate compound (supplementary information S3). In the case of the $\mathrm{V}_{5.22}-\mathrm{HAp}-\mathrm{pH}$-per sample, the 2D mapping within the -560 to $-625 \mathrm{ppm}$ range was investigated in order to probe the signals associated with $\mathrm{VO}_{4}{ }^{3-}$ tetrahedra $(\sim-605 \mathrm{ppm})$ in the apatite solid solution and the more intense signal of $\mathrm{Ca}_{4} \mathrm{~V}_{4} \mathrm{O}_{14}$ (-575 ppm) ascribed to the external distorted tetrahedra of the $\mathrm{V}_{4} \mathrm{O}_{14}$ entities. Only the two related autocorrelation signals located on the diagonal are observed in Figure 8. The absence of cross correlation signal (between the -605 and -575 ppm components) means that the $\mathrm{V}^{5+}$ 
species from the solid solution are not close enough to the $\mathrm{V}^{5+}$ species of the distorted tetrahedra of $\mathrm{Ca}_{4} \mathrm{~V}_{4} \mathrm{O}_{14}$. One cannot totally exclude that, despite the favorable narrowness of the related signals, the detection limit would be too low to probe the hetero and homonuclear correlations. However, it is noteworthy that the proximity between the two phases is close enough so that the presence of $\mathrm{Ca}_{4} \mathrm{~V}_{4} \mathrm{O}_{14}$ induces a modification of the relaxation time of phosphorus. This effect may also result from the involvement of paramagnetic species. ${ }^{[36]}$ Hence, the involvement of $\mathrm{V}^{4+}$ species instead of $\mathrm{V}^{5+}$ species at the interface between the two phases may account for the apparently conflicting NMR results, as such paramagnetic $\mathrm{V}^{4+}$ species are NMR silent yet likely to induce perturbations in the spectra. An EPR study was thus undertaken to investigate this particular matter.

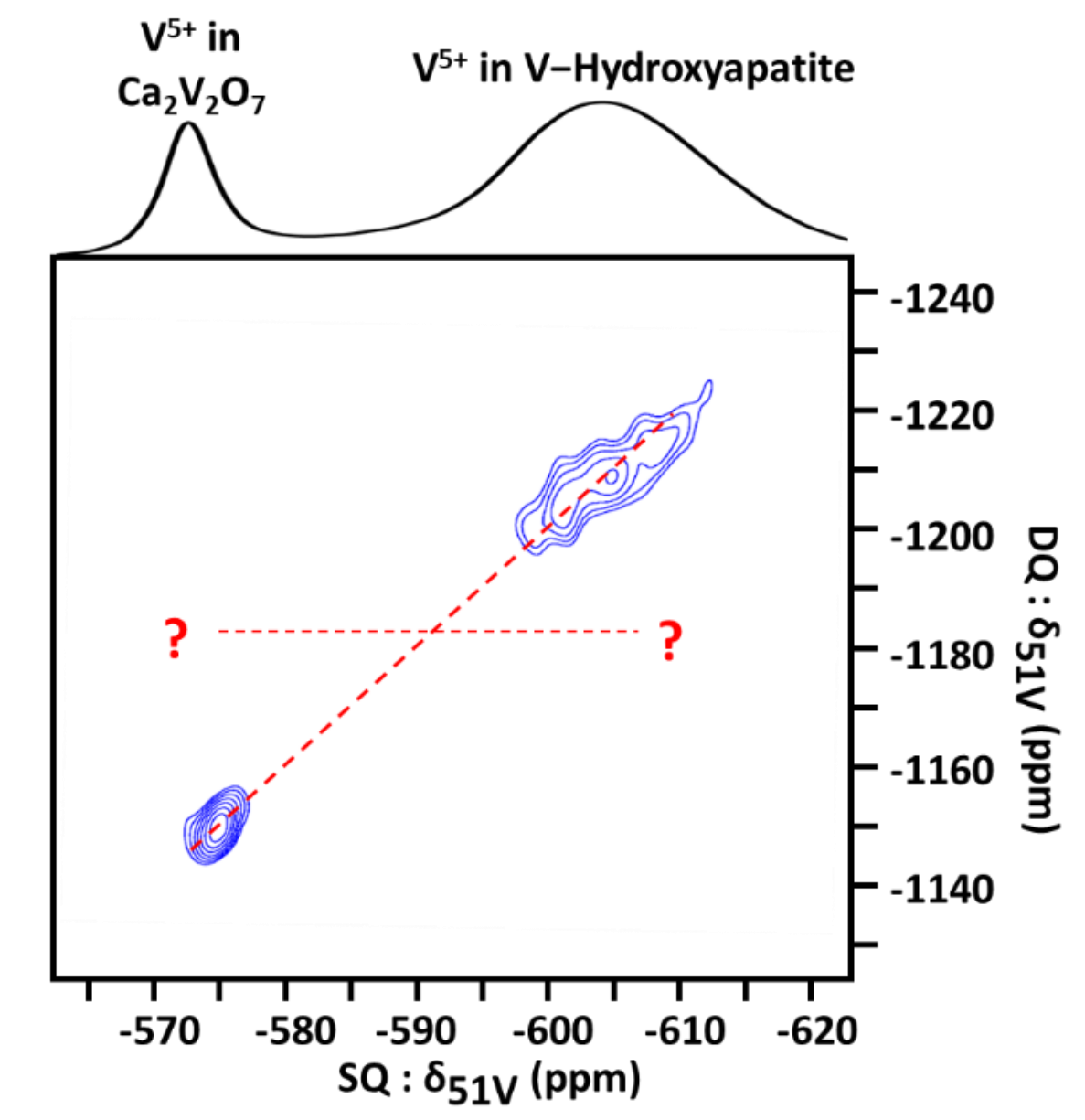

Figure 8: ${ }^{51} \mathrm{~V}$ DQ/SQ 2D spectrum of the $\mathrm{V}_{5.22}-\mathrm{HAp}-\mathrm{pH}$-per sample. The DP ${ }^{51} \mathrm{~V} 1 \mathrm{D}$ spectrum is reported on the top to help identification of the $\mathrm{V}$ species in the $2 \mathrm{D}$ spectrum. 


\subsubsection{EPR spectroscopy}

Figure 9 shows representative EPR spectra recorded at $77 \mathrm{~K}$ on highly-loaded $\mathrm{V}_{x}$-HAp samples. In the case of the $\mathrm{V}_{5.22}-\mathrm{HAp}-\mathrm{pH}-9$ sample, which has been shown to be a single solidsolution $\mathrm{Ca}_{10}\left(\mathrm{PO}_{4}\right)_{0.78}\left(\mathrm{VO}_{4}\right)_{5.22}(\mathrm{OH})_{2}$ phase, ${ }^{[21]}$ spectrum a of Figure 9 shows a multiplet signal of weak intensity, which can be attributed to the presence of isolated $\mathrm{V}^{4+}$ species. Similar EPR signals, albeit of higher intensity, were reported by Boechat et al. upon $\mathrm{H}_{2}$ thermal treatment of $\mathrm{Ca}_{10}\left(\mathrm{PO}_{4}\right)_{6-x}\left(\mathrm{VO}_{4}\right)_{x}(\mathrm{OH})_{2}$ materials. ${ }^{[37]}$. The spectrum recorded on $\mathrm{V}_{6}$-HAp-pH-per (pure $\mathrm{Ca}_{4} \mathrm{~V}_{4} \mathrm{O}_{14}$ compound, spectrum $\mathbf{b}$ of Figure 9) appears to be much more intense and complex. This very atypical spectrum exhibits both hyperfine and remarkably defined superhyperfine structures. The hyperfine splitting is characteristic of the interaction between the $3 \mathrm{~d}^{1}$ electron and the ${ }^{51} \mathrm{~V}(\mathrm{I}=7 / 2)$ nucleus of a $\mathrm{V}^{4+}$ species (Table 3). The superhyperfine sub-structure,

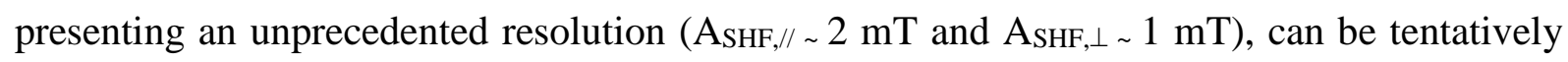
decomposed into two long-distance interactions: a first one between the $3 \mathrm{~d}^{1}$ electron and a neighboring $\mathrm{V}^{5+}$ nucleus $(\mathrm{I}=7 / 2)$ and a second one, of comparable magnitude, with a neighboring nucleus with $I=1 / 2$, such as $\mathrm{H}$. Comparison of the $\mathrm{V}_{6}-\mathrm{HAp}-\mathrm{pH}$-per spectra recorded at $77 \mathrm{~K}$ and at RT (S4, Figure S4) shows that both spectra are similar in shape, whereas the spectrum recorded at RT was found to be about 4 times less intense than that recorded at $77 \mathrm{~K}$. This difference in intensity that is in line with the Curie law dependence of the EPR signals discards the involvement of more than one $\mathrm{V}^{4+}$ center and indicates that this $\mathrm{V}^{4+}$ species does not exhibit a tetrahedral environment. ${ }^{[38]}$ Yet, this rather suggests its localization in the square pyramid of the $\mathrm{V}_{4} \mathrm{O}_{14}$ unit. The higher intensity of spectrum $\mathbf{b}$ compared to spectrum a in Figure 9 is in line with the computational calculations of Cheng et al. concluding to a better stabilization of $\mathrm{V}^{4+}$ species in dimeric square pyramids compared to isolated tetrahedra supported on anatase. ${ }^{[6]}$ 


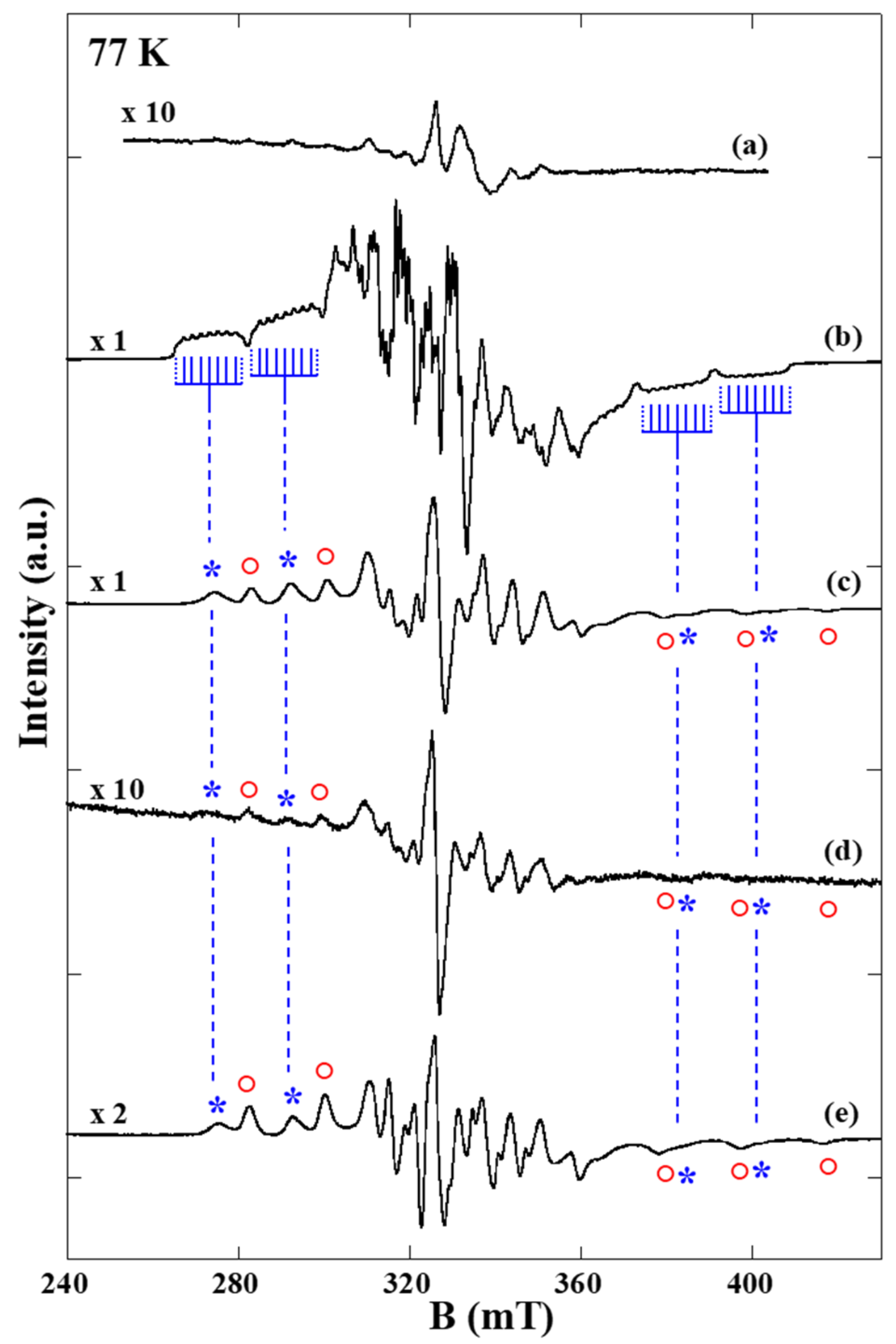

Figure 9: EPR spectra recorded at $77 \mathrm{~K}$ for a) $\mathrm{V}_{5.22}-\mathrm{HAp}-\mathrm{pH}-9$, b) $\mathrm{V}_{6}-\mathrm{HAp}-\mathrm{pH}-\mathrm{per}$, c) $\mathrm{V}_{5.22}-\mathrm{HAp}-\mathrm{pH}-\mathrm{per}$ d) $\mathrm{V}_{4-}$ HAp-pH-per and e) spent $\mathrm{V}_{4}-\mathrm{HAp}$-pH-per catalysts. The signals labeled with $*$ and $\bigcirc$ symbols correspond to the two distinct signals of $\mathrm{V}^{4+}$ species exhibiting superfine splitting. The former signals exhibit similar characteristics to those observed in spectrum a (except the loss of the superhyperfine structures). 
The comparison of materials with similar V loadings exhibiting either a single V-HAp solid solution (V.22-HAp-pH-9, spectrum (a) of Figure 9) or a biphasic composition (V-HAp solid solution and $\mathrm{C}_{4} \mathrm{~V}_{4} \mathrm{O}_{14}, \mathrm{~V}_{5.22}-\mathrm{HAp}-\mathrm{pH}-$ per, spectrum (c) of Figure 9) shows that the intensity of the EPR signal not only is more than one order of magnitude higher for the latter sample compared to the former one but the shape of the signal also becomes much more complex. The spectrum recorded on the biphasic $\mathrm{V}_{4}-\mathrm{HAp}-\mathrm{pH}$-per sample (spectrum (d) of Figure 9) was found to be qualitatively similar to that recorded on $\mathrm{V}_{5.22}-\mathrm{HAp}-\mathrm{pH}-\mathrm{per}$ (spectrum (c) of Figure 9). The complexity of the central signal region of the latter spectra may be assigned to the superimposition of two signals due to isolated $\mathrm{V}^{4+}$ species. Interestingly, as illustrated in Figure 9, among the two $\mathrm{V}^{4+}$ species exhibiting superfine splitting in the biphasic compounds (spectra (c) and (d)), the one associated with $\mathrm{g}_{\|}=1.920$ (Table 3) with characteristic signals labelled with a * agrees with that observed for the $\mathrm{Ca}_{4} \mathrm{~V}_{4} \mathrm{O}_{14}$ compound (spectrum (b)). The corresponding signal (* label) is thus ascribed to $\mathrm{V}^{4+}$ species located in the square pyramid of the $\mathrm{V}_{4} \mathrm{O}_{14}$ units of $\mathrm{Ca}_{4} \mathrm{~V}_{4} \mathrm{O}_{14}$. The loss of the superhyperfine structures observed for $\mathrm{Ca}_{4} \mathrm{~V}_{4} \mathrm{O}_{14}$ in the biphasic compounds (spectra (c) and (d) of Figure 9) clearly indicates the occurrence of some geometrical distortion of $\mathrm{V}_{4} \mathrm{O}_{14}$ unit in the latter samples. The second $\mathrm{V}^{4+}$ species observed in the biphasic samples $\left(\mathrm{g}_{\|}=1.860\right.$, characteristic signals labelled with $\mathrm{a} \odot$ in spectra (c) and (d) of Figure 9), which was not observable in the spectrum (b) of Figure 9, must be located in a different environment. According to Figure 10, both * and $\circ$ signals are observed at $\mathrm{RT}$ for $\mathrm{V}_{5.22}-\mathrm{HAp}$-pH-per. Although the intensity of both signals was found to increase as the temperature decreases, the increase in the intensity of the $\odot$ signal was the more pronounced. This indicates that the corresponding $\mathrm{V}^{4+}$ species exhibits a shorter relaxation time compared to that of the $\mathrm{V}^{4+}$ species located in the-square pyramidal environment of the $\mathrm{V}_{4} \mathrm{O}_{14}$ unit (* signals). Simulation of the $\mathrm{g}$ and A coupling constant values associated with these two paramagnetic species are listed in Table 3 for the $\mathrm{V}_{5.22}-\mathrm{HAp}-\mathrm{pH}$-per sample (similar results 
were obtained for $\mathrm{V}_{4}-\mathrm{HAp}-\mathrm{pH}$-per, not shown). The parallel components $\mathrm{g}_{\|}$and $\mathrm{A}_{\|}$could be more accurately modelled than the perpendicular ones and were reported in Figure 10. Table 3 shows that the EPR features obtained for the first species are quite close to those estimated for $\mathrm{Ca}_{4} \mathrm{~V}_{4} \mathrm{O}_{14}$ (without superhyperfine structure), confirming its assignment to $\mathrm{V}^{4+}$ ions located in square pyramids. According to earlier literature EPR studies (Table S5) dealing with $\mathrm{V}^{4+}$ located either in tetrahedral or in distorted octahedra, ${ }^{[38 c, 39]}$ the combination of the EPR parameters estimated for the second $\mathrm{V}^{4+}$ species (Table 3) appears to be quite unusual with i) a strong axial deformation, (ii) a low $\mathrm{g}_{\|}$value (1.86) and (iii) a high value for $\mathrm{A}_{\|}$component. The $\mathrm{g}_{\|}$value found in the present study is close to those reported for $\mathrm{V}^{4+}$ species in a tetrahedral environment, though that of $g_{\perp}$ is lower than the values classically reported for a tetrahedral geometry and that of $\mathrm{A}_{\perp}$ is intermediate between the two sets of values reported earlier for $\mathrm{V}^{4+}$ species in tetrahedral or distorted octahedral environments (Table S5). Moreover, the relaxation time is also estimated to be intermediate between those usually found for those environments, being responsible for the large increase in the signal intensity at low temperature and the fact that the signal remains observable at RT (Figure 10). Hence, all of these EPR features associated with the second hyperfine structure ( $\circ$ signals) indicate that these $\mathrm{V}^{4+}$ species must be present as strongly distorted tetrahedra. Given that such a species could only be observed in the biphasic compounds, it is inferred that such a strongly distorted tetrahedron results from the formation of a coherent interface between the V-substituted hydroxyapatite solid solution (rods in Figure 3d-f) and the $\mathrm{Ca}_{4} \mathrm{~V}_{4} \mathrm{O}_{14}$ phase (external layer in Figure 3d-f). This coherent interface could thus result from the epitaxial growth of $\mathrm{V}_{4} \mathrm{O}_{14}$ units onto isolated $\mathrm{VO}_{4}{ }^{3-}$ tetrahedra also belonging to the V-substituted hydroxyapatite solid solution (Figure 1A, 1B). As depicted in Figure 1B, such an epitaxial growth is made possible due to the very good matching between the $c$ and $b$ cell parameters of the vanadium-substituted hydroxyapatite and $\mathrm{Ca}_{4} \mathrm{~V}_{4} \mathrm{O}_{14}$ structures, $\sim 6.90$ and $6.89 \AA$ A, respectively. ${ }^{[21,23 b]}$ As indicated by EPR, such an epitaxial growth 
favors the formation of an additional defective $\mathrm{V}^{4+}$ in interfacial highly-distorted tetrahedron and must also be responsible for some distortion of the square pyramid resulting in the loss of the superhyperfine structure that could be observed in the pure $\mathrm{Ca}_{4} \mathrm{~V}_{4} \mathrm{O}_{14}$ compound.

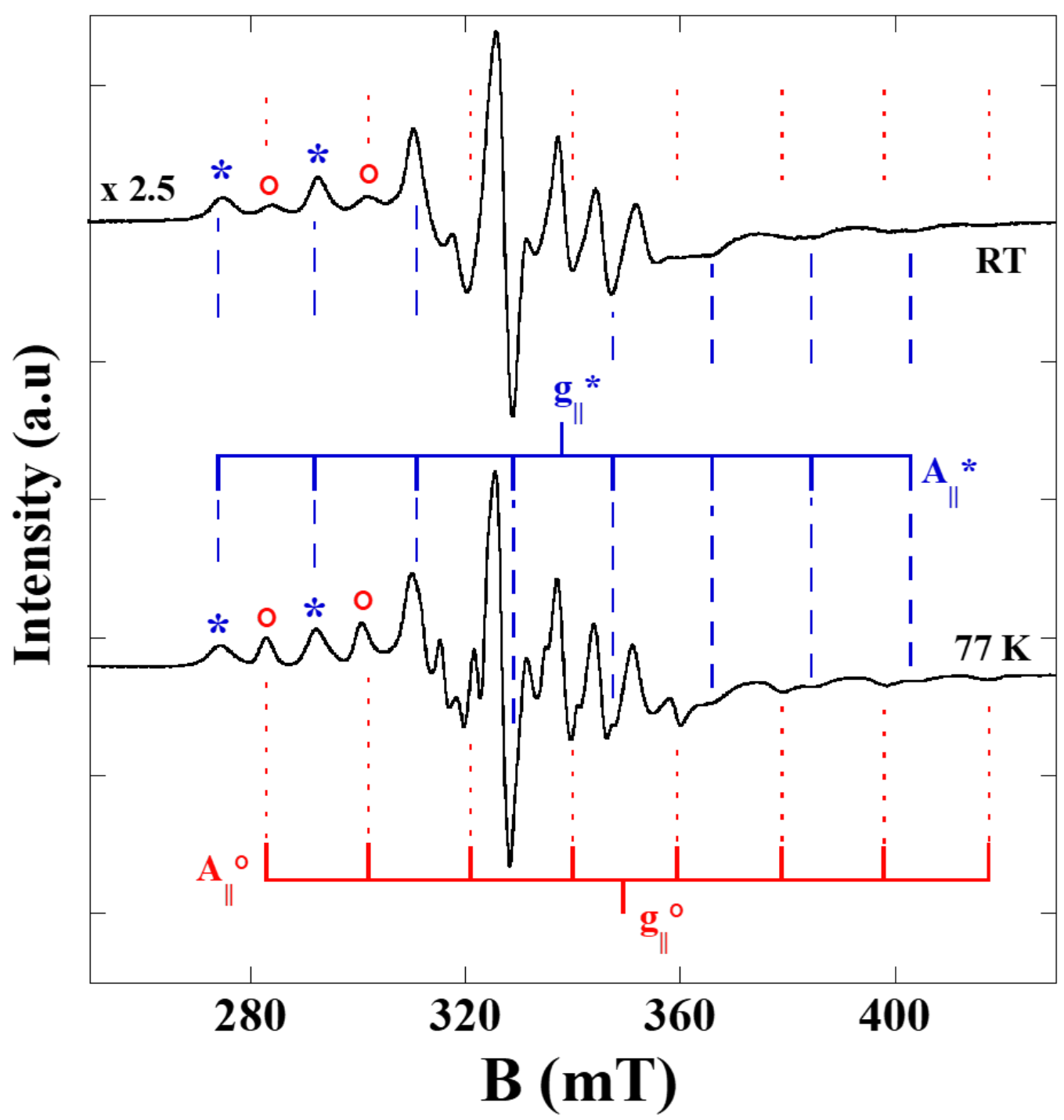

Figure 10: EPR spectra of $\mathrm{V}_{5.22}-\mathrm{HAp}-\mathrm{pH}-$ per recorded at $\mathrm{RT}$ and $77 \mathrm{~K} .{ }^{*}$ and $\circ$ symbols show the positions of the hyperfine structures $\left(A_{\|}\right.$only) of the two $V^{4+}$ species. 
Table 3: $g$ values and A hyperfine coupling constants of the $\mathrm{V}^{4+}$ species determined by simulation of the $\mathrm{V}_{6}$ - $\mathrm{HAp}^{-}$ pH-per and $\mathrm{V}_{5.22}$-HAp-pH-per spectra.

\begin{tabular}{|c|c|c|c|c|c|c|}
\hline EPR signal & $\mathrm{g}_{\|}$ & $\mathrm{A}_{\|}(\mathrm{mT})$ & $g_{\perp}$ & $\mathrm{A}_{\perp}(\mathrm{mT})$ & $\begin{array}{c}\text { Relaxation } \\
\text { time } \mathrm{t}\end{array}$ & Localisation \\
\hline $\begin{array}{l}\text { V } 6 \text {-HAp-pH-per } \\
\left(\mathrm{Ca}_{4} \mathrm{~V}_{4} \mathrm{O}_{14}\right)\end{array}$ & $\begin{array}{c}1.935 \\
( \pm 0.005)\end{array}$ & $\begin{array}{c}18.2 \\
( \pm 0.2)\end{array}$ & $\begin{array}{c}1.960 \\
( \pm 0.015)\end{array}$ & $\begin{array}{c}5.5 \\
( \pm 1.0)\end{array}$ & & $\begin{array}{c}\text { Square } \\
\text { pyramid }\end{array}$ \\
\hline $\begin{array}{l}\text { V } 5.22-\mathrm{HAp}-\mathrm{pH}- \\
\text { per } \\
\text { *signals }\end{array}$ & $\begin{array}{c}1.920 \\
( \pm 0.005)\end{array}$ & $\begin{array}{r}18.6 \\
( \pm 0.2)\end{array}$ & $\begin{array}{c}1.96 \\
( \pm 0.01)\end{array}$ & $\begin{array}{c}5.5 \\
( \pm 0.5)\end{array}$ & $\mathrm{t}^{*}$ & $\begin{array}{c}\text { Square } \\
\text { pyramid }\end{array}$ \\
\hline osignals & $\begin{array}{c}1.860 \\
( \pm 0.005)\end{array}$ & $\begin{array}{c}19.3 \\
( \pm 0.2)\end{array}$ & $\begin{array}{c}1.930 \\
( \pm 0.015)\end{array}$ & $\begin{array}{c}5.2 \\
( \pm 0.5)\end{array}$ & $t^{\circ}<t^{*}$ & $\begin{array}{l}\text { Interfacial } \\
\text { distorted } \\
\text { tetrahedra }\end{array}$ \\
\hline
\end{tabular}

\subsection{ODHP reaction}

\subsection{1 $V_{x}$-HAp-pH-per samples}

The catalytic behavior of the $\mathrm{V}_{x}$-HAp-pH-per samples, whose specific surface areas are listed in Table 4, has been evaluated for the ODHP reaction. The evolution of the concentrations of the $\mathrm{C}_{3} \mathrm{H}_{8}, \mathrm{O}_{2}, \mathrm{CO}_{x}\left(\mathrm{CO}+\mathrm{CO}_{2}\right)$ and $\mathrm{C}_{3} \mathrm{H}_{6}$ as a function of the reaction temperature and time on stream recorded on the $\mathrm{V}_{x}$-HAp-pH-per series of catalysts were found to be similar (not shown) to that reported in our earlier study on $\mathrm{V}_{5.22}-\mathrm{HAp}-\mathrm{pH}-9$ in the same operating conditions $(7.4 \%$

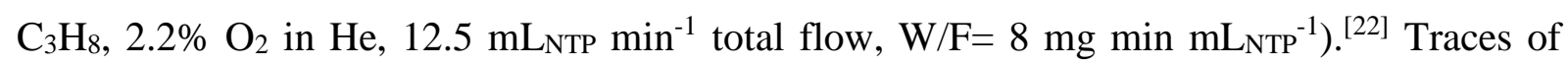
ethylene, acetone/propanal and acrolein were also recorded. As was the case for the $\mathrm{V}_{x}$-HAppH-9 series, traces of hydrogen were also observed. ${ }^{[22]}$ Overall, the conversions of $\mathrm{C}_{3} \mathrm{H}_{8}$ and $\mathrm{O}_{2}$ were found to remain essentially constant with time on stream.

Table 4: Specific surface areas of the $\mathrm{V}_{x}$-HAp-pH-per samples

\begin{tabular}{cccccccc}
\hline$x$ & 0 & 3 & 3.5 & 4 & 4.5 & 5.22 & 6 \\
\hline Specific surface area $\left(\mathrm{m}^{2} \mathrm{~g}^{-1}\right)$ & 50 & 35 & 43 & 34 & 41 & 28 & 3 \\
\hline
\end{tabular}


The influence of the vanadium loading in the $\mathrm{V}_{x}-\mathrm{HAp}-\mathrm{pH}$-per materials on $\mathrm{C}_{3} \mathrm{H}_{8}$ conversion and $\mathrm{C}_{3} \mathrm{H}_{6}$ selectivity are shown in Figure 11. The V-free sample was found to be poorly active and selective in the ODHP reaction at $723 \mathrm{~K}$. The low conversion measured for the fullysubstituted sample ( $\mathrm{V}_{6}$-HAp-pH-per) is ascribed to its very low specific surface area (Table 4) and/or to poor intrinsic ability to activate $\mathrm{C}_{3} \mathrm{H}_{8}$. At $723 \mathrm{~K}, \mathrm{C}_{3} \mathrm{H}_{8}$ conversions do not differ to a significant extent from those reported earlier for the $\mathrm{V}_{x}$-HAp-pH-9 series in similar operating conditions $^{[22]}$ and are only slightly modified by the introduction of $\mathrm{V}$, except for the $\mathrm{V}_{4}-\mathrm{HAp}$ pH-per sample. The $\mathrm{C}_{3} \mathrm{H}_{8}$ conversion of the latter catalyst appears to be promoted drastically by a factor of about 4 compared to that of the other samples of the series (Figure 11). This maximum of activity, which was found to be measured reproducibly on several catalytic measurements and several batches of catalyst, could definitively not be ascribed to differences in specific surface areas (Table 4) and was observed for the whole range of reaction temperatures investigated. Note that at $748 \mathrm{~K}$, a more progressive decrease of the $\mathrm{C}_{3} \mathrm{H}_{8}$ conversion is observed for $x$ higher than 4 compared to what was observed at $723 \mathrm{~K}$ (Figure 11). $\mathrm{C}_{3} \mathrm{H}_{6}$ selectivity increases to a much greater extent on the $\mathrm{V}_{x}-\mathrm{HAp}-\mathrm{pH}-$ per series $(\sim 45 \%$, Figure 11) compared to the $\mathrm{V}_{x}-\mathrm{HAp}-\mathrm{pH}-9$ series $\left(\sim 25 \%{ }^{[22]}\right)$ and is found to remain essentially constant for $x$ higher than or equal to 3 . 


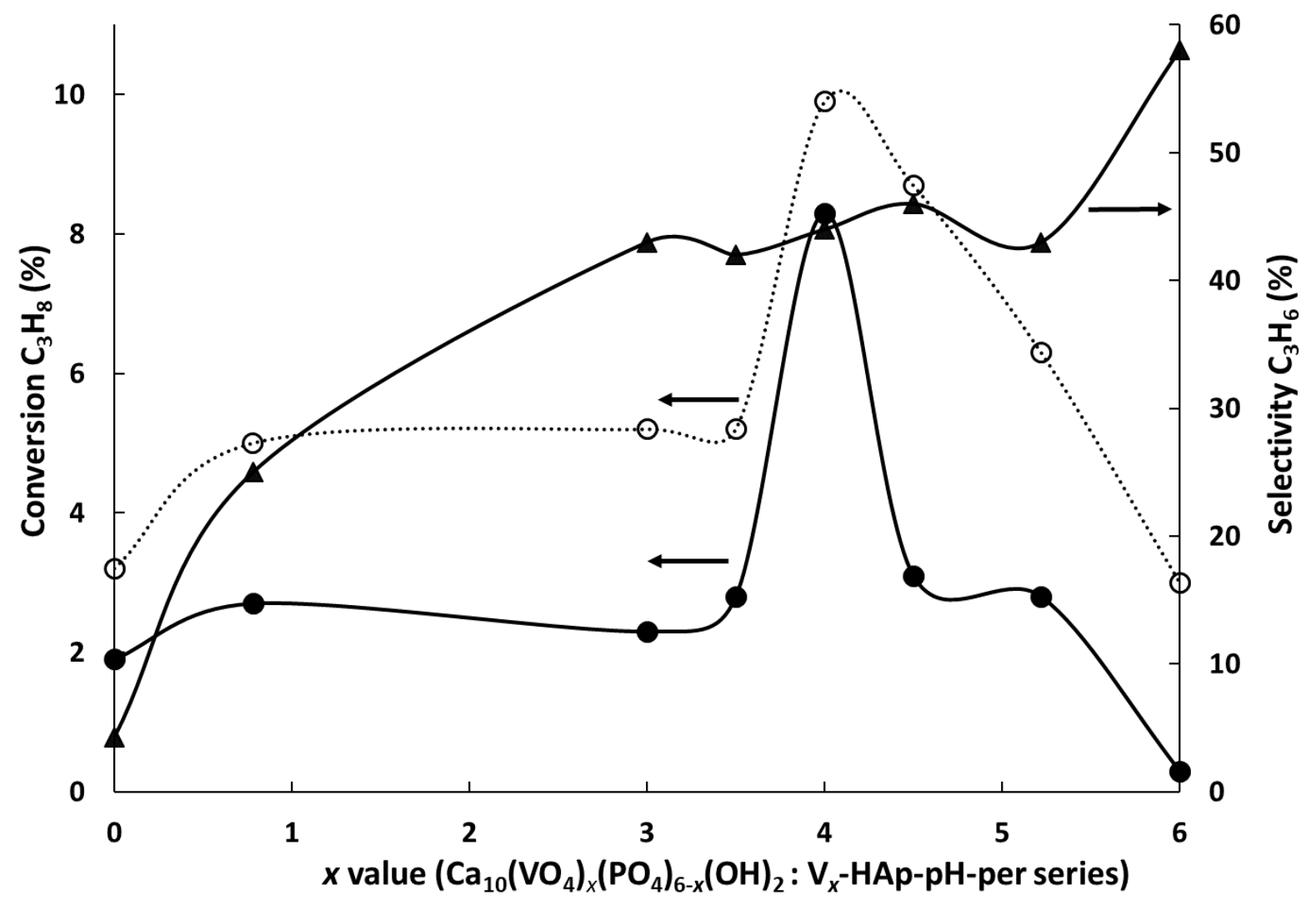

Figure 11: Influence of the vanadium loading in the $\mathrm{V}_{x}$-HAp-pH-per series on $\mathrm{C}_{3} \mathrm{H}_{8}$ conversion at 723 ( $O$, solid line $)$ and $748 \mathrm{~K}(\mathrm{O}$, dotted line $)(-)$ and $\mathrm{C}_{3} \mathrm{H}_{6}$ selectivity $(\boldsymbol{\Delta})$ at $723 \mathrm{~K}\left(7.4 \% \mathrm{C}_{3} \mathrm{H}_{8}, 2.2 \% \mathrm{O}_{2}\right.$ in $\mathrm{He}, 12.5 \mathrm{~mL}$ NTP $\min ^{-1}$ total flow, $\left.\mathrm{W} / \mathrm{F}=8 \mathrm{mg} \min \mathrm{mL}_{\mathrm{NTP}}{ }^{-1}\right)$.

The selectivity in propene was also found to remain stable with increasing temperature for the whole $\mathrm{V}_{x}$-HAp-pH-per series (Figure S6). This peculiarity is attributed to the similar activation energies measured for the productions of $\mathrm{C}_{3} \mathrm{H}_{6}$ and $\mathrm{CO}_{x}$ (Table S6), which suggests that $\mathrm{CO}_{x}$ are formed from a direct route rather than from over-oxidation of propene.

Given that the $\mathrm{VMgO}$ system is considered as a reference for the ODHP reaction, ${ }^{[11 \mathrm{a}-\mathrm{c}]}$ additional set of experiments were performed in oxygen rich conditions to compare the behavior of our most active $\mathrm{V}_{4}-\mathrm{HAp}-\mathrm{pH}$-per sample with that of $69-\mathrm{VMgO}$ catalyst exhibiting a similar V weight loading ${ }^{[11 \mathrm{a}]}$ (S7, Figure $\left.\mathbf{S 7}\right)$. It was found that the catalytic performance recorded on $\mathrm{V}_{4}-\mathrm{HAp}-\mathrm{pH}-$ per compares reasonably well with that reported on $69-\mathrm{VMgO}$ by Siew Hew Sam et al., albeit substantially lower $\mathrm{C}_{3} \mathrm{H}_{6}$ selectivity is achieved on $\mathrm{V}_{4}-\mathrm{HAp}$-pH-per compared to that reported earlier on a 69-VMgO sample $\mathrm{e}^{[11 \mathrm{a}]}$ (Table S7). 


\subsubsection{Synergistic effect in the ODHP reaction due to phase cooperation}

When both of the vanadium-substituted hydroxyapatite and $\mathrm{Ca}_{4} \mathrm{~V}_{4} \mathrm{O}_{14}$ phases were formed simultaneously, an intimate contact was observed between them (Figures 3 and 4 ) in the $V_{x^{-}}$ HAp-pH-per series, resulting in a synergistic effect that promoted both $\mathrm{C}_{3} \mathrm{H}_{6}$ selectivity (for $x$ $\geq 3$ ) and $\mathrm{C}_{3} \mathrm{H}_{8}$ conversion (for $x=4$ at $723 \mathrm{~K}$ and from $x=4$ to 5.22 at $748 \mathrm{~K}$ ) (Figure S7). In contrast, a mechanical mixture mimicking the composition of the $\mathrm{V}_{5.22}-\mathrm{HAp}-\mathrm{pH}-\mathrm{per}$ sample (Table 1) prepared by grinding the two $\mathrm{V}_{5.22}-\mathrm{HAp}-\mathrm{pH}-9$ and $\mathrm{Ca}_{4} \mathrm{~V}_{4} \mathrm{O}_{14}\left(\mathrm{~V}_{6}-\mathrm{HAp}-\mathrm{pH}\right.$-per) pure phases with a 66/34 weight ratio and subsequent thermal treatment did not show any benefit on the $\mathrm{C}_{3} \mathrm{H}_{6}$ selectivity (Figure S8) compared to what was obtained for the $\mathrm{V}_{x}-\mathrm{HAp}-\mathrm{pH}-9$ samples series. $^{[22]}$

Identified as one of the seven pillars of oxidation catalysis by Grasselli, ${ }^{[4]}$ a cooperative effect between two phases in intimate contact usually benefits from complementary catalytic functions that cannot be incorporated into a single host structure. Such a synergistic effect is typically observed in the present study as biphasic materials of the $\mathrm{V}_{x}$-HAp-pH-per series were found to be more active and more selective in the ODHP reaction than the two phases taken separately (vanadium-substituted hydroxyapatite in the $\mathrm{V}_{x}$-HAp-pH-9 series with isolated $\mathrm{VO}_{4}$ tetrahedra ${ }^{[22]}$ or $\mathrm{Ca}_{4} \mathrm{~V}_{4} \mathrm{O}_{14}$ in $\mathrm{V}_{6}$-HAp-pH-per involving $\mathrm{V}_{4} \mathrm{O}_{14}$ clusters, Figures $1 \mathrm{~A}$ and 11) or associated in a mechanical mixture (Figure S8)). Figure 11 shows that $\mathrm{C}_{3} \mathrm{H}_{6}$ selectivity is drastically improved with the formation of $\mathrm{Ca}_{4} \mathrm{~V}_{4} \mathrm{O}_{14}$ in the $\mathrm{V}_{x}$-HAp-pH-per series (Figure 3). Yet the low activity of $\mathrm{V}_{6}-\mathrm{HAp}$-pH-per suggests that $\mathrm{Ca}_{4} \mathrm{~V}_{4} \mathrm{O}_{14}$ does not contribute in itself to $\mathrm{C}_{3} \mathrm{H}_{8}$ activation and that $\mathrm{C}_{3} \mathrm{H}_{8}$ activation should more likely occur on the V-HAp phase. ${ }^{[2]}$ The HAp host lattice exhibits a unique structural property, which has been found to be promoted with the incorporation of vanadates, resulting in the formation of an oxy-HAp active phase, whose $\mathrm{O}^{2-}$ surface anions are basic enough to activate the $\mathrm{C}-\mathrm{H}$ bond of propane. ${ }^{[22]}$ The observed maximum in $\mathrm{C}_{3} \mathrm{H}_{8}$ conversion (Figure 11) for $\mathrm{V}_{4}-\mathrm{HAp}$-pH-per may be attributed to the 
formation of a coherent interface between the V-HAp nanorods and the $\mathrm{Ca}_{4} \mathrm{~V}_{4} \mathrm{O}_{14}$ coating layer (Figure 4) and to an optimal balance between these two phases (V-HAp/Ca4 $\mathrm{V}_{4} \mathrm{O}_{14}=95 / 5$ weight ratio, Table 1). The amount of vanadates present in the HAp lattice is thought to be too low to efficiently promote $\mathrm{C}_{3} \mathrm{H}_{8}$ activation because of the two low $\mathrm{V}$ content for $x<4$ and the competitive formation of the $\mathrm{Ca}_{4} \mathrm{~V}_{4} \mathrm{O}_{14}$ phase for $x>4$ (Table 1). It must be highlighted here that the activation energy of the ODHP reaction for the production of $\mathrm{C}_{3} \mathrm{H}_{6}$ is the greatest for $\mathrm{V}_{4}$-HAp-pH-per $(155 \mathrm{~kJ} / \mathrm{mol})$ compared to those of the other samples of the $\mathrm{V}_{x}$-HAp-pH-per series $(115-118 \mathrm{~kJ} / \mathrm{mol})$ (Table S6). Based on the well-known compensation effect phenomenon in catalysis between the activation energy and the pre-exponential factor, ${ }^{[40]}$ the fact that the catalyst exhibiting the greatest activation energy also appears as the most active sample among the series may be attributed to a much greater pre-exponential factor. It must be stressed that the pre-exponential factor of the kinetic constant also includes the number of active sites. ${ }^{[40]}$ This optimum composition between the two phases on the $\mathrm{V}_{4}-\mathrm{HAp}-\mathrm{pH}$-per material may therefore be attributed to an optimum composition in terms of number of active sites and/or facilitated access of the reactants to these active sites.

$\mathrm{C}_{3} \mathrm{H}_{6}$ selectivity was found to be strongly promoted (Figure 11) when the isolated tetrahedral vanadates present in the vanadium-substituted hydroxyapatite nanorods are associated with minute amounts of $\mathrm{V}_{4} \mathrm{O}_{14}$ clusters present in the $\mathrm{Ca}_{4} \mathrm{~V}_{4} \mathrm{O}_{14}$ coating layer (Figure 1B. Dasireddy et al. also concluded to a beneficial influence of the formation of $\mathrm{Ca}_{2} \mathrm{~V}_{2} \mathrm{O}_{7}$ pyrovanadate on the olefin selectivity in the ODH of $n$-octane. ${ }^{[41]}$ Whereas too rapid redox exchanges were claimed to be responsible for over-oxidation reactions in transition metal oxide-like compounds, and isolated transition metal species were found to be too hardly reducible, ${ }^{[1 c, 3-4]}$ metal clusters of limited size (potentially isolated from each other in phosphate matrices also referring to as the concept of isolation of active sites ${ }^{[4,10,12]}$ ) were reported to be beneficial for a better control of the electronic exchanges in oxidation reactions. ${ }^{[13-15,42]}$ In order to monitor the redox properties 
of the $\mathrm{Ca}_{4} \mathrm{~V}_{4} \mathrm{O}_{14}$-containing samples, an in situ Raman investigation was carried out under successive reductive $\left(\mathrm{H}_{2}(5 \%) / \mathrm{Ar}\right)$ and oxidative $\left(\mathrm{O}_{2}(2.5 \%) / \mathrm{Ar}\right)$ atmospheres (Figure 13). The intensity of the Raman V-O bands ${ }^{[21,43]}$ of $\mathrm{V}_{4}-\mathrm{HAp}-\mathrm{pH}-\mathrm{per}$ at $423 \mathrm{~K}$ were found to decrease upon thermal reductive atmosphere at 623 and $723 \mathrm{~K}$ (without any alteration of the bandwidth). This loss of the V-O vibrators was found to be reversible as subsequent treatment at $723 \mathrm{~K}$ under an oxidative $\left(\mathrm{O}_{2}(2.5 \%) / \mathrm{Ar}\right)$ atmosphere results in the recovery of the initial intensities of the various contributions (Figure 12). Such a removal of the lattice oxygen anions from the host structure and their recovery in an oxidizing atmosphere are important prerequisites for oxidation catalysts ${ }^{[4,44]}$ active in the ODHP reaction. ${ }^{[1 \mathrm{a}, 1 \mathrm{~b}, 45]}$ Similar behaviors were observed for all of the $\mathrm{Ca}_{4} \mathrm{~V}_{4} \mathrm{O}_{14}$-containing samples (not shown). The ability of the epitaxially-grown $\mathrm{C}_{4} \mathrm{~V}_{4} \mathrm{O}_{14}$ phase to favor redox exchanges was also confirmed by EPR as a significant increase in the intensity of the two EPR signals assigned to paramagnetic $\mathrm{V}^{4+}$ species could be observed in the spent biphasic catalyst (Figure 9, spectrum e). Interestingly, the relative concentration of the $\mathrm{V}^{4+}$ species present in external tetrahedral vanadates of interfacial $\mathrm{V}_{4} \mathrm{O}_{14}$ units seems to be more impacted than the $\mathrm{V}^{4+}$ species in the square pyramids in the spent sample (Figure 9, spectrum e $v s$ spectrum d). Yet, given the global decrease in intensity of all Raman bands (Figure 12), and the lack of operando EPR data, it remains difficult in the present study, as it is in earlier literature reports, ${ }^{[42 a, 46]}$ to formally assess whether the $\mathrm{V}_{\mathrm{t}^{-}} \mathrm{O}-\mathrm{V}_{\text {spyr }}$ oxygen species (interfacial $\mathrm{O}$ species located between a tetrahedron and a square pyramid, Figure 1B)) is preferentially involved in the reduction process compared to those of the bridges associated with edge-sharing square pyramids or not. Nevertheless, this EPR study puts particular emphasis on the redox exchanges occurring at the coherent interface between the VHAp rods and the $\mathrm{Ca}_{4} \mathrm{~V}_{4} \mathrm{O}_{14}$ overlayer (Figure 1B). Such an easy electron transfer occurring between adjacent vanadium species may favor the spreading of the electrons over several 
vanadium species of interfacial $\mathrm{V}_{4} \mathrm{O}_{14}$ entities, finally making these electrons accessible for the adsorbed molecules, as discussed earlier for iron $\mathrm{Fe}_{3} \mathrm{O}_{12}$ trimeric clusters ${ }^{[46]}$ present in $\alpha-\mathrm{Fe}_{3}\left(\mathrm{P}_{2} \mathrm{O}_{7}\right)_{2}$ active in the oxidative dehydrogenation of isobutyric acid to methacrylic acid. ${ }^{[15]}$

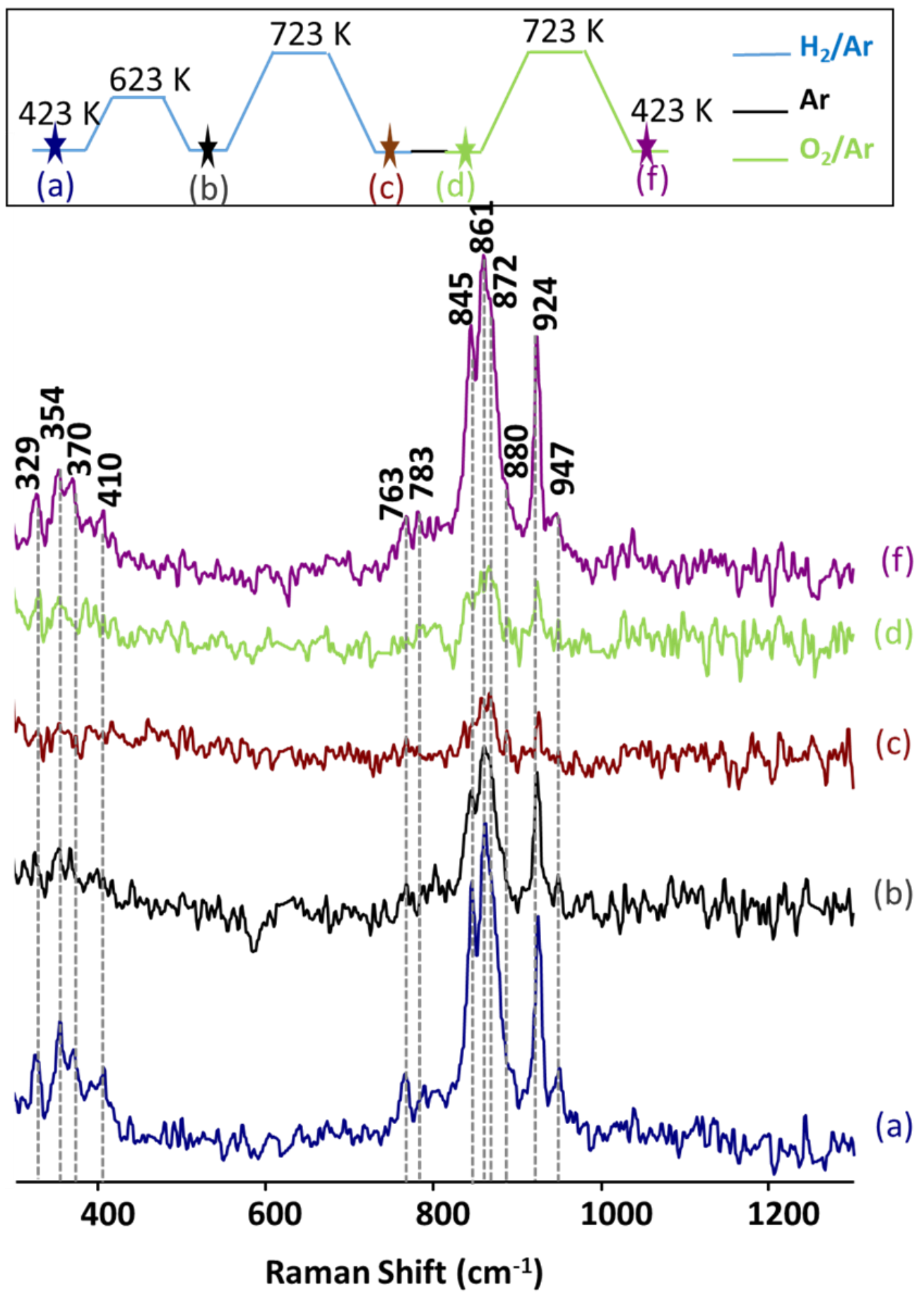

Figure 12: Changes in the Raman spectra recorded at $423 \mathrm{~K}$ for $\mathrm{V}_{4}-\mathrm{HAp}-\mathrm{pH}$-per upon the temperature profile detailed in the top inset under reductive $\left(\mathrm{H}_{2}(5 \%) / \mathrm{Ar}\right)$ and then oxidative $\left(\mathrm{O}_{2}(2.5 \%) / \mathrm{Ar}\right)$ flows $\left(30 \mathrm{~mL} \mathrm{~min}^{-1}\right)$. 


\section{Conclusion}

$\mathrm{V}_{x}$-substituted hydroxyapatite materials prepared with a periodic addition of ammonia during the maturation step ( $\mathrm{V}_{x}-\mathrm{HAp}-\mathrm{pH}$-per) were shown to exhibit a $\mathrm{Ca}_{4} \mathrm{~V}_{4} \mathrm{O}_{14}$ phase in addition to the V-substituted hydroxyapatite phase for $x$ value greater than or equal to 3.5 . Its crystalline fraction deduced from Rietveld analysis was found to rapidly increase from 5 to $100 \mathrm{wt} \%$ as $x$ increases from 4 to 6 . TEM characterization of the biphasic samples allowed us to demonstrate that the $\mathrm{Ca}_{4} \mathrm{~V}_{4} \mathrm{O}_{14}$ phase was grown epitaxially on the $\mathrm{V}_{x}$-HAp nanorods, which ensures a close intimacy between the two phases, even if encapsulation of nanorods remained partial. According to Solid State NMR, the modification of the relaxation time of phosphorus present in the $\mathrm{V}$-substituted hydroxyapatite phase coated by $\mathrm{Ca}_{4} \mathrm{~V}_{4} \mathrm{O}_{14}$ strongly suggested the involvement of paramagnetic $\mathrm{V}^{4+}$ in the structuration of the interface. This was confirmed by EPR showing, in addition to the $\mathrm{V}^{4+}$ species located in the central square pyramids of the $\mathrm{V}_{4} \mathrm{O}_{14}$ units of the $\mathrm{Ca}_{4} \mathrm{~V}_{4} \mathrm{O}_{14}$ phase, a second $\mathrm{V}^{4+}$ signal for biphasic compounds ascribed to $\mathrm{V}^{4+}$ species stabilized at the boundaries of these two phases. Compared to the other samples of the series and the fully-substituted V-HAp counterparts $\left(\mathrm{V}_{x}-\mathrm{HAp}-\mathrm{pH}-9^{[22]}\right)$, the oxidative dehydrogenation of propane to propene reaction was found to be strongly promoted as soon as $723 \mathrm{~K}$ over the $\mathrm{V}_{4}-\mathrm{HAp}$-pH-per sample. This promotion is attributed to a synergistic effect between the $\mathrm{V}_{x}$-HAp nanorods and the $\mathrm{Ca}_{4} \mathrm{~V}_{4} \mathrm{O}_{14}$ phase providing that they are in close intimacy, which could not be achieved in a mechanical mixture. This synergy may be attributed to the combination of complementary functions of the two phases: (i) the ability to activate $\mathrm{C}_{3} \mathrm{H}_{8}$ over $\mathrm{V}$-substituted oxy-hydroxy-apatite phase ${ }^{[22]}$ and (ii) the promotion of $\mathrm{C}_{3} \mathrm{H}_{6}$ selectivity, provided by optimized redox properties of $\mathrm{V}_{4} \mathrm{O}_{14}$ units that favor easier electron delocalization on the $\mathrm{V}_{4} \mathrm{O}_{14}$ units located at the phases' boundaries. This was illustrated by the modification of the fresh and spent EPR spectra of $\mathrm{V}_{4}-\mathrm{HAp}-\mathrm{pH}$-per catalyst and its peculiar ability to lose and recover its network oxygen species under reductive and oxidative 
atmospheres, respectively, as shown by in situ Raman spectroscopy. The optimal catalytic ODHP performance achieved for the $\mathrm{V}_{4}-\mathrm{HAp}$ - $\mathrm{pH}$-per probably results from its optimal composition, which combines a higher fraction of $\mathrm{C}_{3} \mathrm{H}_{8}$ activation sites (V-substituted phase) and the formation of a coherent interface with the $\mathrm{Ca}_{4} \mathrm{~V}_{4} \mathrm{O}_{14}$ phase that would prevent $\mathrm{C}_{3} \mathrm{H}_{6}$ overoxidation. Finally, the catalytic performance of the $\mathrm{V}_{4}-\mathrm{HAp}-\mathrm{pH}-\mathrm{per}$ catalyst was found to compare reasonably well with that of a $\mathrm{VMgO}$ reference catalyst.

\section{Acknowledgments:}

The authors thank the DIM OXYMORE program of the Région Ile-de-France for supporting the $\mathrm{PhD}$ work of Dr. S. Petit. The authors are grateful to C. Calers and V. Losinho from the Laboratoire de Réactivité de Surface, Sorbonne Université, for their help in the XPS measurements and the in situ Raman set-up, respectively.

Keywords: Epitaxial growth, EPR, NMR, Oxidation, Phase Cooperation.

\section{REFERENCES}

[1] a) R. Grabowski, Catal. Rev. 2006, 48, 199-268; b) C. A. Carrero, R. Schloegl, I. E. Wachs, R. Schomaecker, ACS Catal. 2014, 4, 3357-3380; c) S. Dong, N. R. Altvater, L. O. Mark, I. Hermans, Appl. Catal. A 2021, 617, 118121.

[2] a) F. Cavani, N. Ballarini, A. Cericola, Catal. Today 2007, 127, 113-131; b) F. Cavani, Catal. Today 2010, 157, 8-15; c) P. Kube, B. Frank, S. Wrabetz, J. Krohnert, M. Havecker, J. VelascoVelez, J. Noack, R. Schlögl, A. Trunschke, ChemCatChem 2017, 9, 573-585.

[3] J. T. Grant, J. M. Venegas, W. P. McDermott, I. Hermans, Chem. Rev. 2018, 118, 2769-2815.

[4] R. K. Grasselli, Catal. Today 2014, 238, 10-27.

[5] a) A. Dinse, B. Frank, C. Hess, D. Habel, R. Schomäcker, J. Mol. Catal. 2008, 289, 28-37; b) I. E. Wachs, Dalton Trans. 2013, 42, 11762-11769; c) G. Liu, Z. J. Zhao, T. Wu, L. Zeng, J. Gong, ACS Catal. 2016, 6, 5207-5214.

[6] L. Cheng, G. A. Ferguson, S. A. Zygmunt, L. A. Curtiss, J. Catal. 2013, 302, 31-36.

[7] A. Khodakov, B. Olthof, A. T. Bell, E. Iglesia, J. Catal. 1999, 181, 205-216.

[8] S. Barman, N. Maity, K. Bhatte, S. Ould-Chikh, O. Dachwald, C. Haeßner, Y. Saih, E. AbouHamad, I. Llorens, J. L. Hazemann, K. Kohler, V. D'Elia, J. M. Basset, ACS Catal. 2016, 6, 59085921.

[9] a) Y. M. Liu, Y. Cao, S. R. Yan, W. L. Dai, K. N. Fan, Catal. Lett. 2003, 88; b) K. Chalupka, C. Thomas, Y. Millot, F. Averseng, S. Dzwigaj, J. Catal. 2013, 305, 46-55.

[10] J. L. Callahan, R. K. Grasselli, AlChE J. 1963, 9, 755-760. 
[11] a) D. Siew Hew Sam, V. Soenen, J. C. Volta, J. Catal. 1990, 123, 417-435; b) A. Guerrero-Ruiz, I. Rodriguez-Ramos, J. L. G. Fierro, V. Soeben, J. M. Herrmann, J. C. Volta, Stud. Surf. Sci.

1992, 72, 203-212; c) V. Soenen, J. M. Herrmann, J. C. Volta, J. Catal. 1996, 159, 410-417; d) J. C. Vedrine, J. M. M. Millet, J. C. Volta, Catal. Today 1996, 32, 115-123; e) X. Gao, P. Ruiz, Q. Xin, X. Guo, B. Delmon, Catal. Lett. 1994, 23, 321-337; f) S. Sugiyama, T. Hashimoto, N. Shigemoto, H. Hayashi, Catal. Lett. 2003, 89, 229-233.

[12] J. C. Védrine, Appl. Catal. A 2014, 474, 40-50.

[13] a) G. Costentin, L. Savary, J. C. Lavalley, M. M. Borel, A. Grandin, Chem. Mater. 1998, 10, 5964; b) L. Savary, G. Costentin, F. Maugé, J. C. Lavalley, J. E. Fallah, F. Studer, A. Guesdon, H. Ponceblanc, J. Catal. 1997, 169, 287-300.

[14] P. A. Agashar, L. De Caul, R. K. Grasselli, Catal. Lett. 1994, 23, 339-351.

[15] a) J.M. M. Millet, J. C. Vedrine, G. Hecquet, Stud. Surf. Sci. Catal. 1990, 55, 833-841; b) J. M. M. Millet, Catal. Rev. Sci. Eng. 1998, 40, 1-38.

[16] H. W. Zanthoff, S. A. Buchholz, A. Pantazidis, C. Mirodatos, Chem. Eng. Sci. 1999, 54, 43974405.

[17] a) M. A. Chaar, D. Patel, H. H. Kung, J. Catal. 1988, 109, 463-467; b) A. Corma, J. M. LopezNieto, N. Paredes, J. Catal. 1993, 144, 425-423.

[18] a) B. P. Barbero, L. E. Cadus, Appl. Catal. A 2002, 237, 263-273; b) J. E. Miller, N. B. Jackson, L. Evans, A. G. Sault, M. M. Gonzales, Catal. Lett. 1999, 58, 147-152.

[19] a) S. R. G. Carrazan, C. Peres, J. P. Bernard, M. Ruwet, P. Ruiz, B. Delmon, J. Catal. 1996, 158, 452-476 ; b) L. E. Cadus, M. F. Gomez, M. C. Abello, Catal. Lett. 1997, 43, 229-233.

[20] M. T. Le, V. H. Do, D. D. Truong, E. Bruneel, I. Van Driessche, A. Riisager, R. Fehrmann, Q. T. Trinh, Ind. Eng. Chem. Res. 2016, 55, 4846-4855.

[21] S. Petit, T. Gode, C. Thomas, S. Dzwigaj, Y. Millot, D. Brouri, J. M. Krafft, G. Rousse, C. LabertyRobert, G. Costentin, Phys. Chem. Chem. Phys. 2017, 19, 9630-9640.

[22] S. Petit, C. Thomas, Y. Millot, J. M. Krafft, C. Laberty-Robert, G. Costentin, ChemCatChem 2020, 12, 2506-2521.

[23] a) U. G. Nielsen, H. J. Jakobsen, J. Skibsted, J. Phys. Chem. C 2001, 105, 425-429; b) A. Ould Saleck, A. Assani, M. Saadi, L. El Ammari, Acta Cryst. E 2013, 69, i79.

[24] M. Ben Osman, J. M. Krafft, Y. Millot, F. Averseng, T. Yoshioka, J. Kubo, G. Costentin, Eur. J. Inorg. Chem. 2016, 17, 2709-2720.

[25] H. M. Rietveld, J. Appl. Cryst. 1969, 2, 65-71.

[26] J. Rodríguez-Carvajal, Physica B 1993, 192, 55-69.

[27] X. Lu, O. Lafon, J. Trébosc, G. Tricot, L. Delevoye, F. Méar, L. Montagne, J. P. Amoureux, J. Chem. Phys. 2012, 137, 144201.

[28] Q. Wang, B. Hu, O. Lafon, J. Trébosc, F. Deng, J. Amoureux, J. Magn. Reson. 2009, 200, 251260.

[29] T. Spalek, P. Pietrzyk, Z. Sojka, J. Chem. Inf. Model. 2005, 45, 18-29.

[30] T. Tsuchida, J. Kubo, T. Yoshioka, S. Sakuma, T. Takeguchi, W. Ueda, J. Jpn. Petrol. Inst. 2009, 52, 51-59.

[31] W. Song, H. Li, F. Zhu, K. Li, Q. Zheng, Trans. Nonferrous Met. Soc. China 2014, 24, 2687-2694.

[32] a) T. Isobe, S. Nakamura, R. Nemoto, M. Senna, H. Sfihi, J. Phys. Chem. B 2002, 106, 51695176; b) C. Jäger, T. Welzel, W. Meyer-Zaika, M. Epple, Magn. Reson. Chem. 2006, 44, $573-$ 580 ; c) M. Jarlbring, D. E. Sandström, O. N. Antzutkin, W. Forsling, Langmuir 2006, 22, 47874792.

[33] a) A. Kaflak, W. Kolodziejski, Solid State Nucl. Magn. Reson. 2007, 31, 174-183; b) A. C. Seifert, A. C. Wright, S. L. Wehrli, H. H. Ong, C. Li, F. W. Wehrli, NMR Biomed. 2013, 26, 11581166; c) W. Kolodziejski, Top. Curr. Chem. 2005, 246, 235-270.

[34] a) O. B. Lapina, V. M. Mastikhin, A. A. Shubin, V. N. Krasilnikov, K. I. Zamaraev, Progr. NMR Spectrosc. 1992, 24, 457-525; b) M. L. Occelli, R. S. Maxwell, H. Eckert, Microporous Mesoporous Mater. 1994, 3, 305-318.

[35] G. Mali, G. Fink, F. Taulelle, J. Chem. Phys. 2004, 120, 2835-2845. 
[36] M. Bertmer, Solid State Nucl. Magn. Reson. 2017, 81, 1-7.

[37] C. Bauer Boechat, J. Terra, J. G. Eon, D. E. Ellis, A. Malta Rossi, Phys. Chem. Chem. Phys. 2003, 5, 4290-4298.

[38] a) R. Baran, Y. Millot, T. Onfroy, F. Averseng, J. M. Krafft, S. Dzwigaj, Microporous Mesoporous Mater. 2012, 161, 179-186; b) N. Steinfeldt, D. Müller, H. Berndt, Appl. Catal. A 2004, 272, 201-213; c) S. Di Gregorio, M. Greenblatt, J. H. Pifer, M. D. Sturge, J. Chem. Phys. 1982, 76, 2931-2937.

[39] a) V. Halicek, P. Novak, M. Vichr, Phys. Status Solidi B 1971, 44, K21-K24; b) L. D. Bogomolova, A. N. Khabarova, E. V. Klimashina, N. A. Krasil'Nikova, V. A. Jachkin, J. Non-Cryst. Solids 1988, 103, 319-324; c) I. L. Moudrakovski, A. Sayari, C. I. Ratcliffe, J. A. Ripmeester, K. F. Preston, J. Phys. Chem. 1994, 98, 10895-10900; d) M. Yamaga, B. Henderson, T. Yosida, N. Kodama, Y. Inoue, Phys. Rev. B 1995, 51, 3438-3448; e) G. Sperlich, Phys. Lett. 1969, 29A, 141-142.

[40] G. C. Bond, M. A. Keane, H. Kral, J. A. Lercher, Catal. Rev. 2000, 42, 323-383.

[41] V. D. B. C. Dasireddy, S. Singh, H. B. Friedrich, Appl. Catal. A 2012, 421-422, 58-69.

[42] a) L. Savary, G. Costentin, M. M. Bettahar, J. C. Lavalley, S. Boudin, A. Grandin, M. Gubelmann-Bonneau, J. Chem. Soc., Faraday Trans. 1996, 92, 1423-1428; b) G. Costentin, J. C. Lavalley, F. Studer, J. Catal. 2001, 200, 360-369.

[43] S. Hayakawa, T. Yoko, S. Sakka, J. Ceram. Soc. Jpn. 1994, 102, 522-529.

[44] P. Mars, D. W. van Krevelen, Chem. Eng. Sci. 1954, 3, 41-59.

[45] J. C. Védrine, Appl. Catal. A 2019, 575, 170-179.

[46] a) V. Robert, S. A. Borshch, B. Bigot, Chem. Phys. Lett. 1995, 236, 491-496; b) V. Robert, S. A. Borshch, B. Bigot, J. Phys. Chem. 1996, 100, 580-584. 


\section{Graphical abstract}

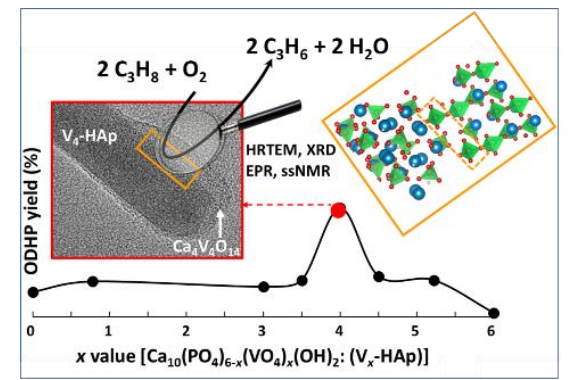

The epitaxial growth of a $\mathrm{Ca}_{4} \mathrm{~V}_{4} \mathrm{O}_{14}$ phase onto vanadium-substituted hydroxyapatite (V-HAp) resulted in a synergistic effect for the oxidative dehydrogenation of propane (ODHP). Such a phase cooperation highlighted on the $\mathrm{V}_{4}-\mathrm{HAp}$ sample is ascribed to complementary catalytic functions: i) peculiar ability of V-HAp to activate propane and ii) easier electron delocalization on the vanadium tetramers in $\mathrm{Ca}_{4} \mathrm{~V}_{4} \mathrm{O}_{14}$ compared to monomeric vanadates in V-HAp that is beneficial to propene selectivity. 


\section{Synergistic Effect Between $\mathrm{Ca}_{4} \mathrm{~V}_{4} \mathrm{O}_{14}$ and Vanadium-Substituted Hydroxyapatite in the Oxidative Dehydrogenation of Propane.}

Sarah Petit, ${ }^{\mathrm{a}, \mathrm{c}}$ Cyril Thomas, ${ }^{\mathrm{a}}$ Yannick Millot, ${ }^{\mathrm{a}}$ Frederic Averseng, ${ }^{\mathrm{a}}$ Dalil Brouri, ${ }^{\mathrm{a}}$ Jean-Marc Kraftt, ${ }^{\text {a }}$ Stanislaw Dzwigaj, ${ }^{a}$ Gwenaelle Rousse, ${ }^{\text {b }}$ Christel Laberty-Robert, ${ }^{c}$ Guylène Costentin $^{\mathrm{a}, *}$

${ }^{a}$ Sorbonne Université, CNRS, Laboratoire Réactivité de Surface, LRS, F-75005 Paris, France.

${ }^{\mathrm{b}}$ Sorbonne Université, Collège de France, Chimie du Solide et de l'énergie, Collège de France, 11 Place Marcelin Berthelot, 75231 Paris, France

${ }^{\mathrm{c}}$ Sorbonne Université, CNRS, Laboratoire Chimie de la Matière Condensée de Paris, LCMCP, F-75005 Paris, France.

Corresponding author: tel.: +331442736 32, fax: +33144276033

Email: guylene.costentin@upmc.fr

\section{S1 TEM and HRTEM study of $\mathrm{Ca}_{10}\left(\mathrm{VO}_{4}\right)_{6}(\mathrm{OH})_{2}$ and $\mathrm{Ca}_{10}\left(\mathrm{VO}_{4}\right)_{6}(\mathrm{OH})_{2}$ single phases.}

As already described in the case of non-substituted hydroxyapatite samples prepared under similar conditions, the hydroxyapatite particles consist of elongated rods well crystallized till their surface terminations (Figure S1a). ${ }^{[1]}$ Successful substitution of phosphate species by vanadate species in the HAp framework allows the preservation of a single phase, leading to a morphology similar to that found for HAp, as illustrated in Figure S1b for the fully-substituted vanadium sample $\left(\mathrm{Ca}_{10}\left(\mathrm{VO}_{4}\right)_{6}(\mathrm{OH})_{2}\right.$ single phase $)$ prepared with continuous addition of $\mathrm{NH}_{4} \mathrm{OH}$ during the synthesis to maintain the precipitation medium at $\mathrm{pH} 9$ (measured at 80 $\left.{ }^{\circ} \mathrm{C}\right) .{ }^{[2]}$ 


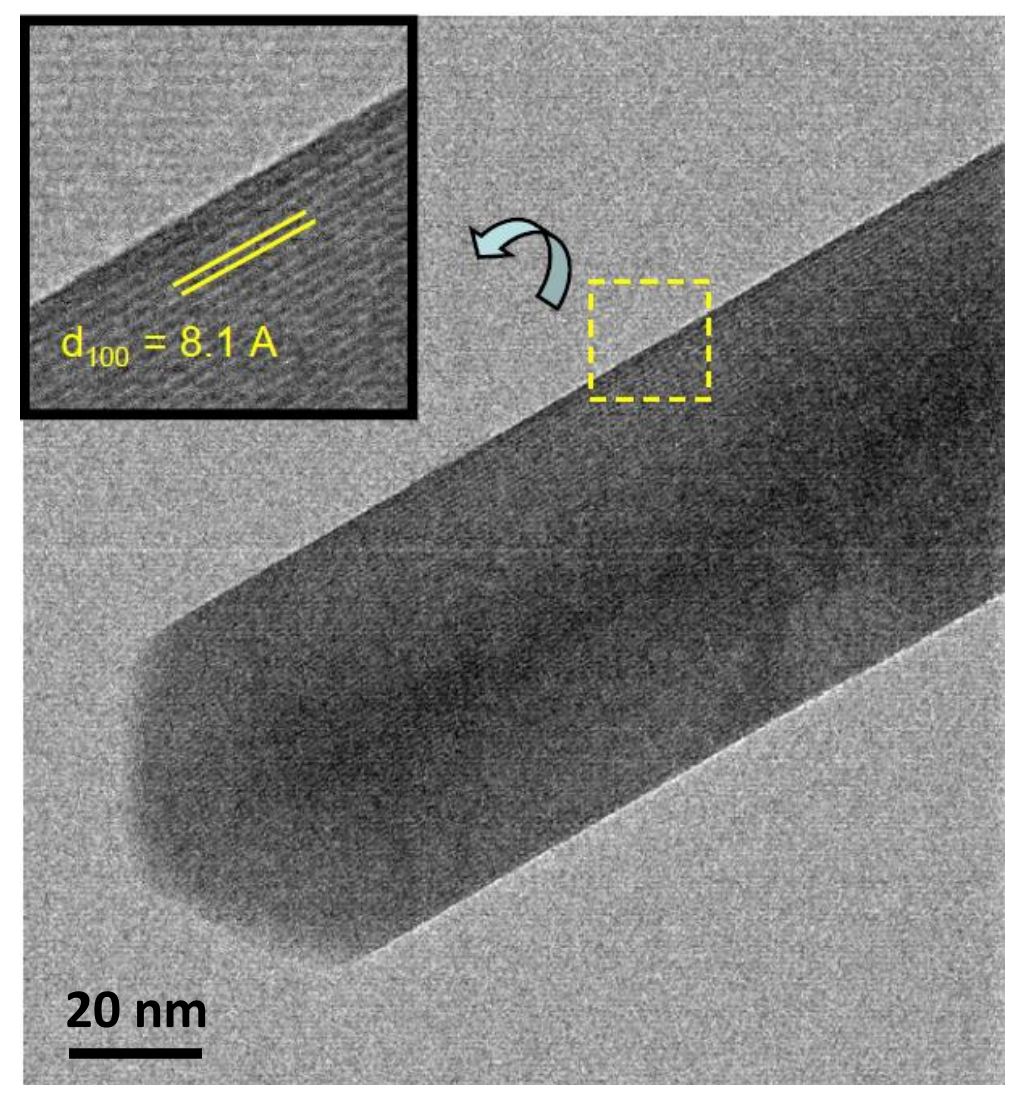

Figure S1a: HRTEM micrograph of $\mathrm{Ca}_{10}\left(\mathrm{PO}_{4}\right)_{6}(\mathrm{OH})_{2}$ illustrating a monocrystalline elongated rod. The inter fringe measured on the image (1.8 A) corresponds to [100] Hap planes. ${ }^{[1]}$

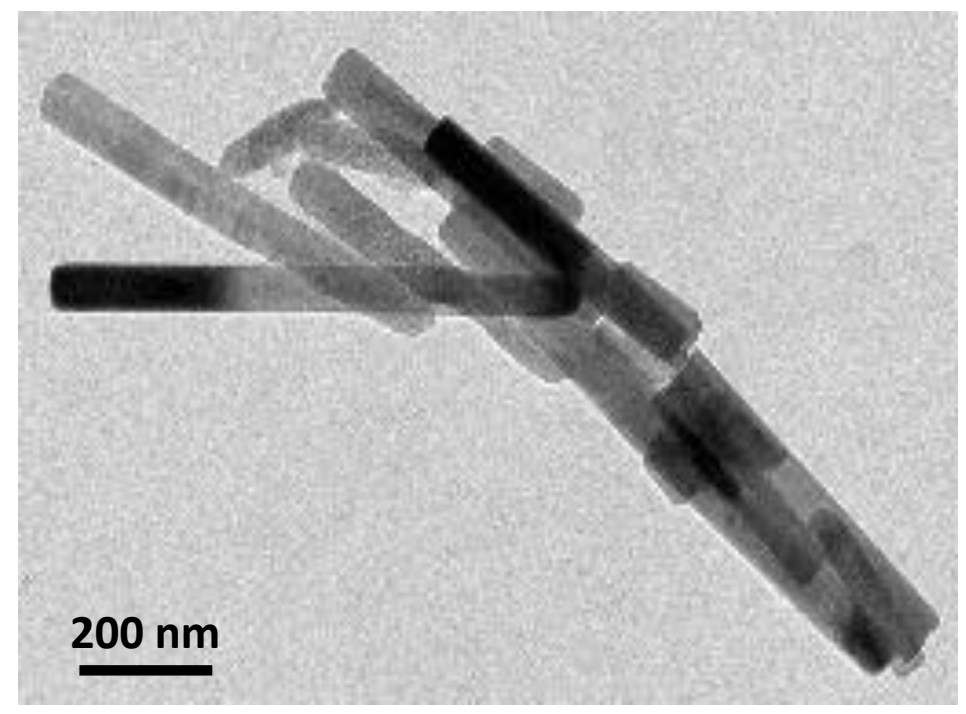

Figure S1b: TEM micrograph of $\mathrm{V}_{6}-\mathrm{HAp}-\mathrm{pH}-9$ exhibiting a single $\mathrm{Ca}_{10}\left(\mathrm{VO}_{4}\right)_{6}(\mathrm{OH})_{2}$ phase. This fully-substituted vanadium hydroxyapatite material was prepared with continuous addition of $\mathrm{NH}_{4} \mathrm{OH}$ to maintain the precipitation medium at $\mathrm{pH} 9$ (measured at $\left.80^{\circ} \mathrm{C}\right) .{ }^{[2]}$ 
Table S1: Comparison of the Ca/V ratio estimated by EDX and XRD for the $V_{x}$-HAp-pH-per samples.

\begin{tabular}{lccc}
\hline$x$ & $\begin{array}{c}y \\
\left(\mathrm{Ca}_{10}\left(\mathrm{PO}_{4}\right)_{6-y}\left(\mathrm{VO}_{4}\right)_{y}(\mathrm{OH})_{2},\right. \\
\text { from Rietveld analysis })\end{array}$ & $X R D^{*}$ & $E D X$ \\
\hline 3 & - & 3.33 & - \\
3.5 & - & 2.86 & 2.5 \\
4 & 3.85 & 2.57 & 2.5 \\
4.5 & - & - & - \\
5.22 & 4.71 & 2.09 & 2.1 \\
6 & - & 1.00 & 1.0 \\
\hline
\end{tabular}

* $\mathrm{Ca} / \mathrm{V}$ molar ratio related to the nominal composition of the solid solutions when no additional diffraction line can be observed, or from Rietveld analysis when available 


\section{S2 TEM characterizations of of ultramicrotome sections of $V_{4-}$ and $V_{5.22}-H A p-p H-p e r$}

\section{samples}

TEM and HRTEM observations of ultramicrotome sections (50-70 $\mathrm{nm}$ thickness) show areas with unembedded terminations for rod particles of $\mathrm{V}_{4^{-}}$and $\mathrm{V}_{5.22}-\mathrm{HAp}-\mathrm{pH}-\mathrm{per}$. Indeed, the fringes in the micrographs due to crystalline planes were found to be uniform until the edges of the particles. Inter-reticular distances were calculated using line profiles on the images and Fourier transform (not shown) of the images (not shown) in which the HAp planes were
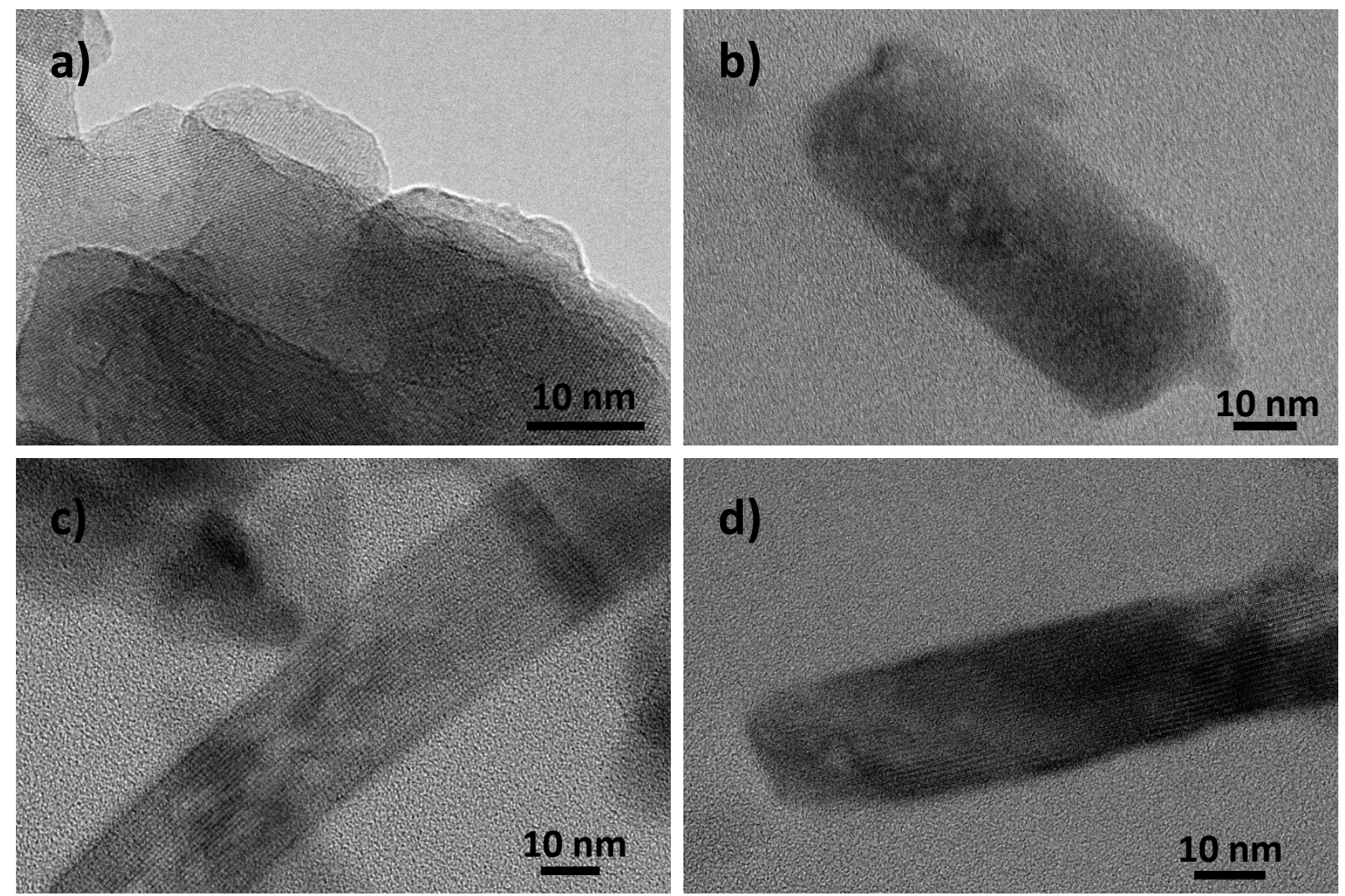
identified (Figure S2).

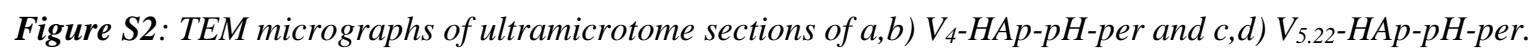




\section{S3 Validation of ${ }^{51} \mathrm{~V} \mathrm{DQ} / \mathrm{SQ}$ sequence for $\alpha-\mathrm{Mg}_{2} \mathrm{~V}_{2} \mathrm{O}_{7}$ sample}

The parameters of the ${ }^{51} \mathrm{~V}$ DQ/SQ double quanta/simple quanta experiments ${ }^{[3]}$ were first optimized on a $\alpha-\mathrm{Mg}_{2} \mathrm{~V}_{2} \mathrm{O}_{7}$ sample. This sample was prepared following the procedure described by Gao et al. by the citrate method with a nominal $\mathrm{Ca} / \mathrm{V}$ molar ratio equal to $1 .{ }^{[4]}$ The purity of the pyrovanadate crystalline structure was ascertained by XRD (Figure S3 a). This compound is built up from $\mathrm{V}_{2} \mathrm{O}_{7}$ entities (two sharing corner tetrahedra) that lead to ${ }^{51} \mathrm{~V}$ fingerprints at -551 and -607 ppm (Figure S3 b). Figure S3 c shows two autocorrelations ((V)(1) and $\mathrm{V}(2)$ ) related to the two identical vanadium species in close proximity. In addition, the cross correlation signals $((\mathrm{V}(1)-\mathrm{V}(1)$ and $\mathrm{V}(2)-\mathrm{V}(1))$ clearly show that each vanadium species is in close proximity with that of the vanadium species of the other type. This confirms that the applied NMR sequence enables the detection of $\mathrm{V}(1)-\mathrm{O}-\mathrm{V}(2)$ bridges characteristic of the pyrovanadate structure.

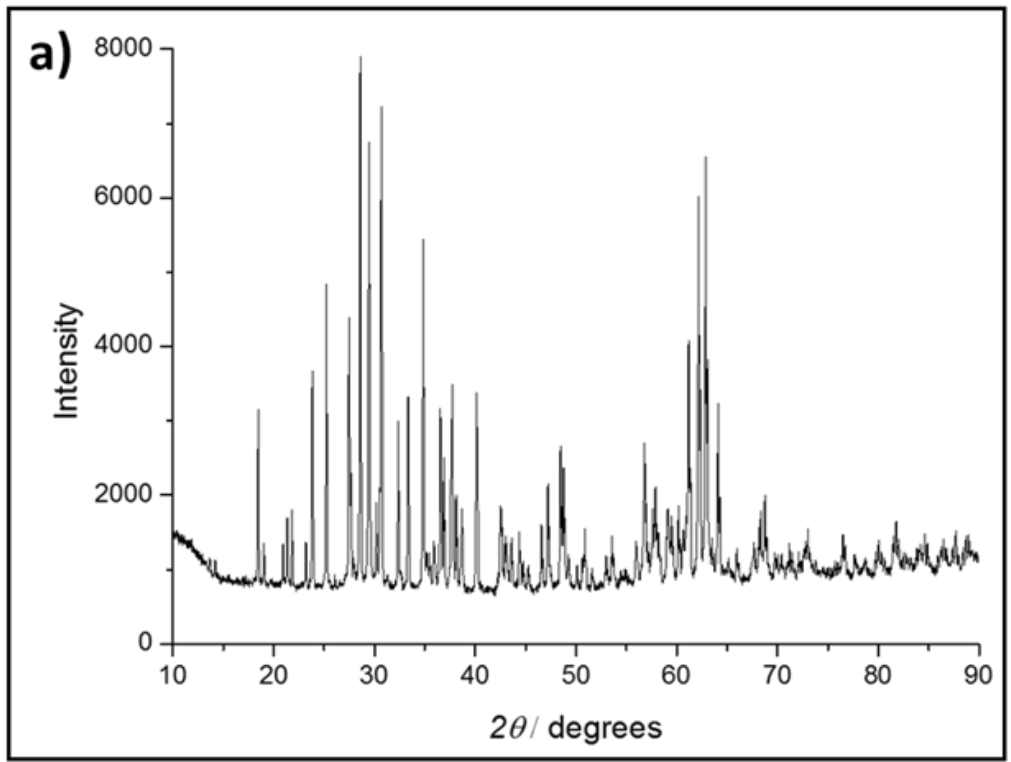




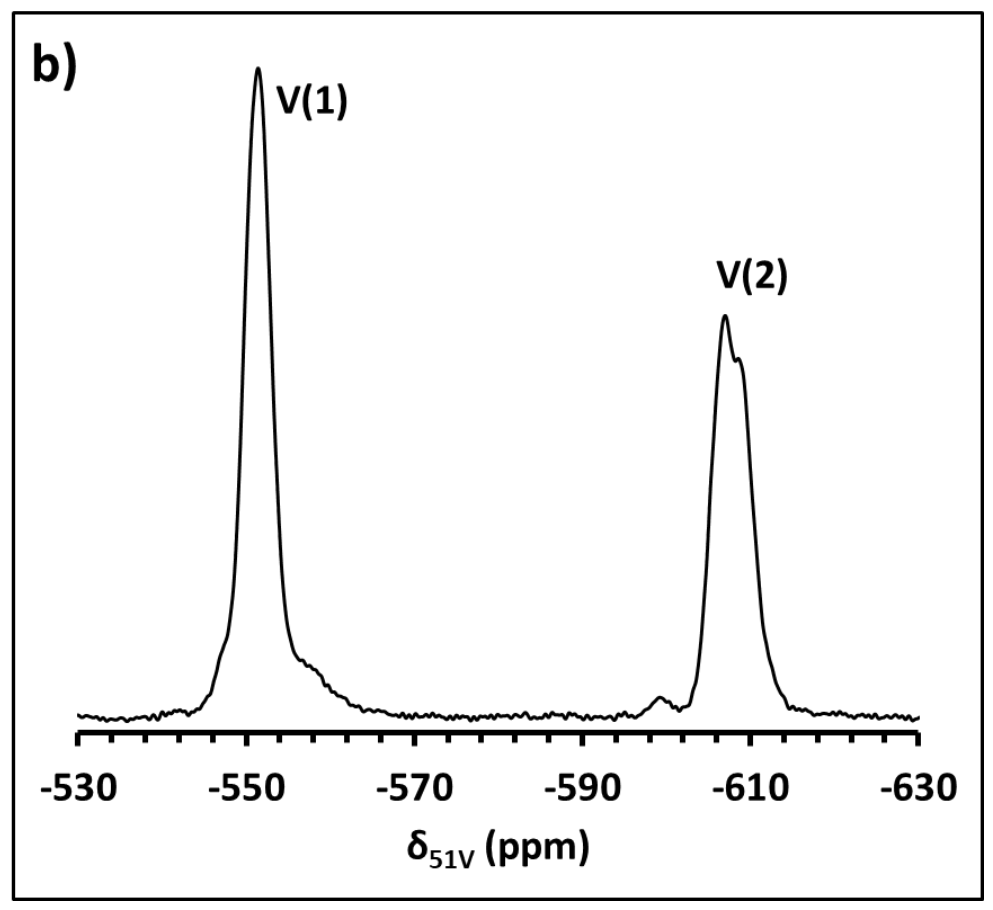

$$
B R 2 \frac{1}{2}: D Q / S Q
$$

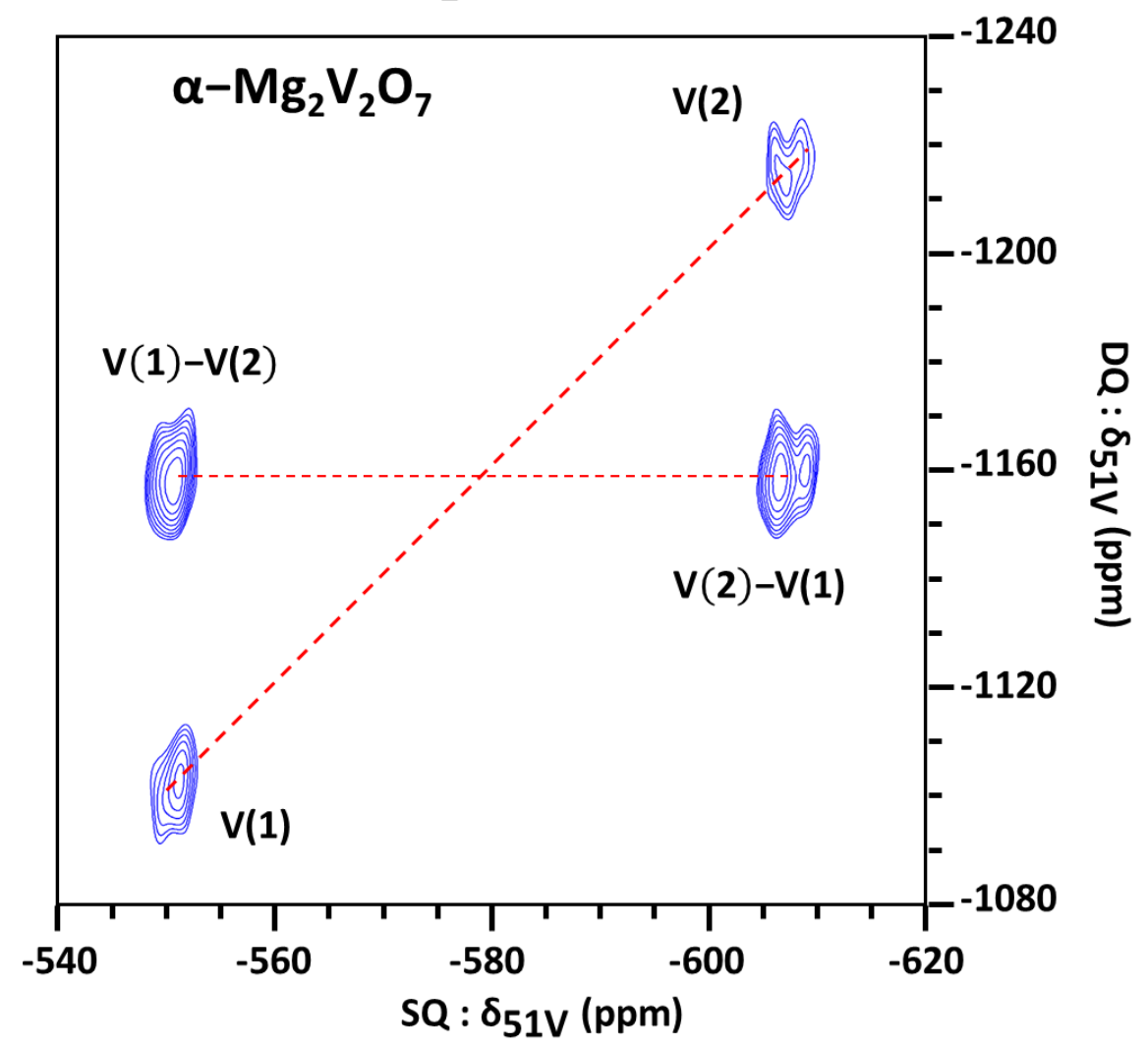

Figure S3: XRD pattern obtained in the 10-90 range for $\alpha-\mathrm{Mg}_{2} \mathrm{~V}_{2} \mathrm{O}_{7}$ magnesium pyrovanadate compound a), related $D P^{51} V N M R$ spectrum $\left.b\right)$ and ${ }^{5 l} V D Q / S Q$ spectrum $\left.c\right)$. 


\section{S4 Influence of temperature on EPR spectra of $\mathrm{Ca}_{4} \mathrm{~V}_{4} \mathrm{O}_{14}$ sample}

Figure S4 shows that the spectra recorded at $77 \mathrm{~K}$ and RT are similar in shape, whereas the intensity of the spectrum recorded at RT is about 4 times lower than that recorded at $77 \mathrm{~K}$. This difference in intensity is in line with the Curie law dependence of the EPR signals (intensity $\propto$ 1/T). This Curie law is, however, not valid for $3 \mathrm{~d}^{1}$ ions such as $\mathrm{V}^{4+}, \mathrm{Cr}^{5+}$ and $\mathrm{Mn}^{6+}$ in tetrahedral coordination (due to their very short relaxation times), which can only be detected at low temperature. ${ }^{[5]}$ Hence, the observed changes in intensity of the signal with the temperature indicates that the $\mathrm{V}^{4+}$ species responsible for these EPR signals should be located in the square pyramids of the $\mathrm{V}_{4} \mathrm{O}_{14}$ units constitutive $\mathrm{Ca}_{4} \mathrm{~V}_{4} \mathrm{O}_{14}$ rather than in their external tetrahedral vanadates.

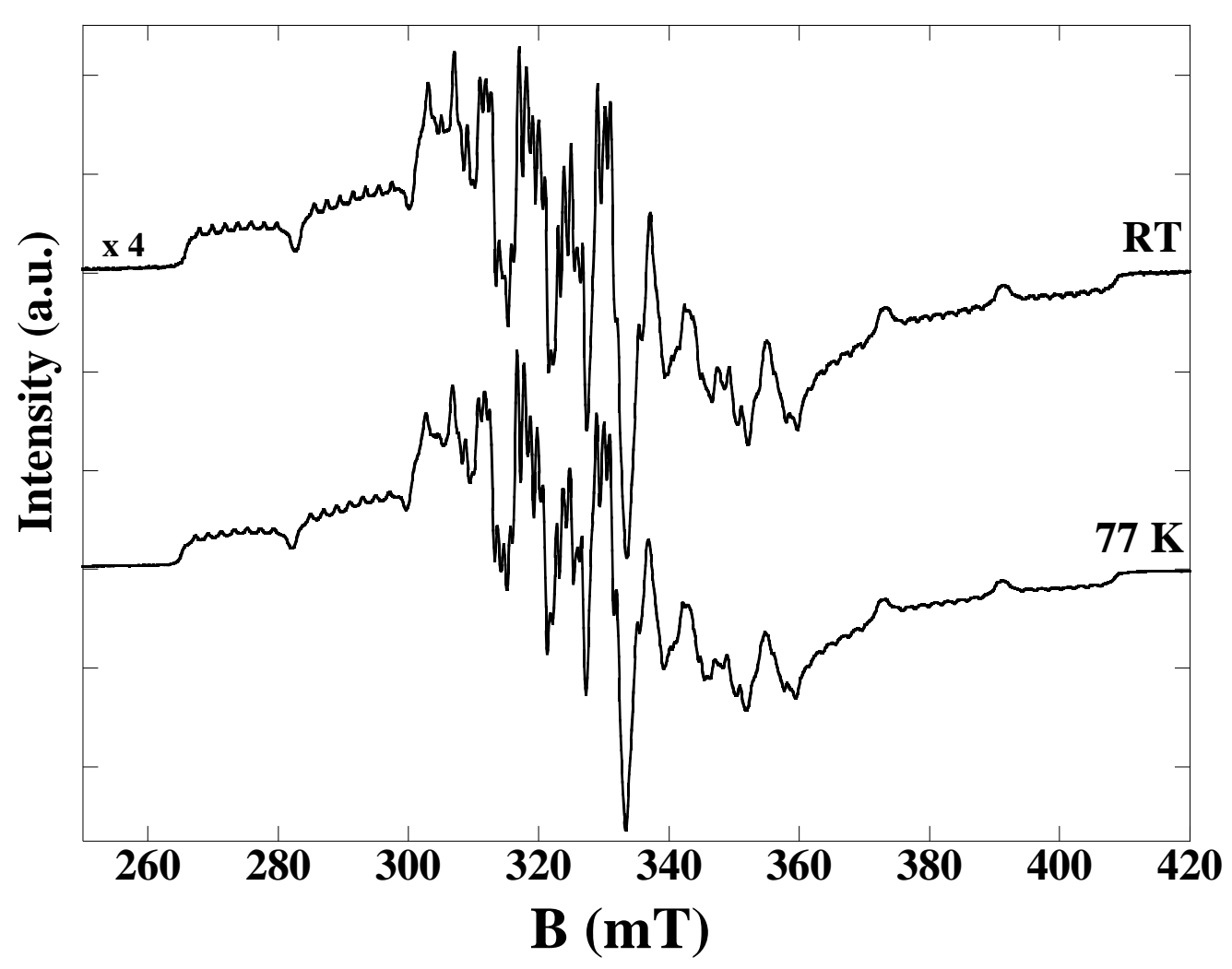

Figure S4: Comparison of the EPR spectra recorded at RT and $77 \mathrm{~K}$ on $V_{6}-H A p-p H-p e r$. 


\section{S5 Typical EPR parameters for $\mathrm{V}^{4+}$ species}

Table S5: EPR features reported for $\mathrm{V}^{4+}$ species exhibiting low $\mathrm{g}_{\|}$value (or related $\mathrm{g}_{\mathrm{x}}$ in case of the orthorhombic symmetry) estimated in various materials and associated geometry for the $\mathrm{V}^{4+}$ ions.

\begin{tabular}{|c|c|c|c|c|c|c|c|}
\hline \multirow[b]{2}{*}{ Matrix } & \multicolumn{3}{|c|}{$\mathrm{A}_{\|}$} & \multirow{2}{*}{$\begin{array}{c}\mathrm{A}_{\perp} \text { or } \mathrm{A}_{\mathrm{x}} \\
(\mathrm{mT})\end{array}$} & \multicolumn{3}{|c|}{$\mathrm{A}_{\mathrm{y}}$} \\
\hline & $\mathrm{g}_{\|}$or $\mathrm{g}_{\mathrm{z}}$ & $(\mathrm{mT})$ & $\mathrm{g}_{\perp}$ or $\mathrm{g}_{\mathrm{x}}$ & & $\mathrm{g}_{\mathrm{y}}$ & $(\mathrm{mT})$ & geometry \\
\hline $\mathrm{ThSiO}_{4}{ }^{[5 \mathrm{c}]}$ & 1.84 & 19.1 & 1.99 & 3.6 & - & - & $\mathrm{Td}^{\$}$ \\
\hline $\mathrm{ThGeO}_{4}{ }^{[5 \mathrm{c}]}$ & 1.83 & 19.4 & 1.98 & 3.5 & - & - & $\mathrm{Td}^{\$}$ \\
\hline Garnet ${ }^{[6]}$ & 1.86 & 17.5 & 1.98 & 3.4 & - & - & $\mathrm{Td}^{\$}$ \\
\hline Vitrous $\mathrm{SiO}_{2}{ }^{[7]}$ & 1.89 & 16.7 & 1.95 & 6.3 & - & - & $\mathrm{Td}^{\$}$ \\
\hline ZSM-12 ${ }^{[8]}$ & 1.88 & 19.5 & 1.99 & 7.2 & - & - & $\mathrm{Td}^{\$}$ \\
\hline $\mathrm{CaYAlO}_{4}{ }^{[9]}$ & 1.84 & 16.5 & 1.94 & 6.5 & 1.90 & 4.3 & $\mathrm{Oh}$ \\
\hline $\mathrm{MoO}_{3}{ }^{[10]}$ & 1.87 & 20.5 & 1.97 & 6.8 & 1.97 & 6.5 & Oh \\
\hline \multicolumn{8}{|l|}{$\mathrm{V}_{5.22}$-HAp-pH-per } \\
\hline $2^{\text {nd }}$ species $\left(^{O}\right.$ & 1.86 & 19.3 & 1.93 & 5.2 & - & - & - \\
\hline label) & & & & & & & \\
\hline
\end{tabular}

\$indicates that no signal was observed at RT

According to the data listed in Table S5, $\mathrm{V}^{4+}$ species can be divided into two environments: on the one hand, $\mathrm{V}^{4+}$ species in a tetrahedral environment $(\mathrm{Td})$, that are detectable only at low temperature and on the other hand, $\mathrm{V}^{4+}$ species in a distorted octahedral environment $(\mathrm{Oh})$ that are detectable as a broadened signal at RT.

If some of the EPR features of the $2^{\text {nd }}$ multiplet detected in $V_{5.22}-\mathrm{HAp}-\mathrm{pH}$-per such as the $A_{\|}$ value are found to be close to those characteristic of the first environment of $\mathrm{V}^{4+}$ species reported in earlier literature reports, the $g_{\perp}$ value is lower than the values reported for the two environments of reference compounds. $A_{\perp}$ is intermediate between the two sets of values obtained for each environment. 
S6 Influence of reaction temperature on the catalytic performance and Activation Energies.

Upon increasing the reaction temperature, the increase in $\mathrm{C}_{3} \mathrm{H}_{8}$ conversion follows quite similar profiles for all of the $\mathrm{V}_{x}$-HAp-pH-per samples (see representative plot for $\mathrm{V}_{5.22}-\mathrm{HAp}$-pH-per in Figure S6), with a marked inflection point from $\sim 715 \mathrm{~K}$, except in the case of the $\mathrm{V}_{4}-\mathrm{HAp}-\mathrm{pH}$ per sample. For the latter sample, a rapid increase of the conversion is observed from $673 \mathrm{~K}$. For the whole $\mathrm{V}_{x}$-HAp-pH-per series, the selectivity in propene was found to remain stable with increasing temperature.

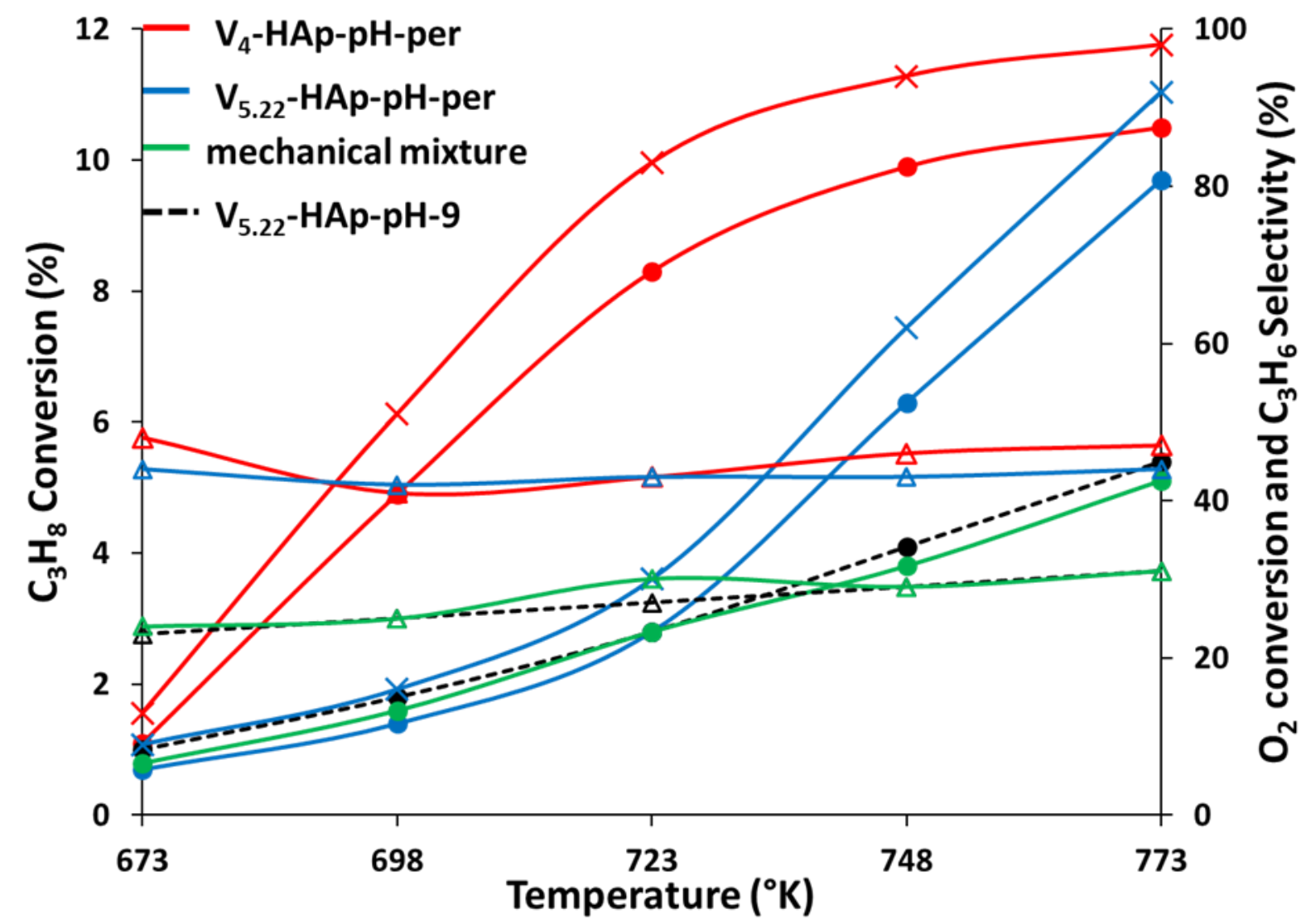

Figure S6: Evolution of $\mathrm{C}_{3} \mathrm{H}_{8}(\boldsymbol{)})$ and $\mathrm{O}_{2}(\mathbf{\times})$ conversions, and $\mathrm{C}_{3} \mathrm{H}_{6}$ selectivity $(\Delta)$ as a function of reaction temperature for the biphasic $\mathrm{V}_{4}-\mathrm{HAp}-\mathrm{pH}$-per and $\mathrm{V}_{5.22}-\mathrm{HAp}$-pH-per catalysts, the single phase $\mathrm{V}_{5.22}-\mathrm{HAp}-\mathrm{pH}-9$, and the mechanical mixture $\left(66 \mathrm{wt} \%\right.$ of $\mathrm{V}_{5.22}-\mathrm{HAp}-\mathrm{pH}-9+34 \mathrm{wt} \%$ of $\left.\mathrm{V}_{6}-\mathrm{HAp}-\mathrm{pH}-\mathrm{per}\right)\left(7.4 \% \mathrm{C}_{3} \mathrm{H}_{8}, 2.2 \% \mathrm{O}_{2}\right.$ in He, $12.5 \mathrm{~mL}_{\mathrm{NTP}} \mathrm{min}^{-1}$ total flow). 
Table S6 Activation energies $\left(E_{a}\right)$ for $\mathrm{C}_{3} \mathrm{H}_{6}$ and $\mathrm{CO}_{x}$ formation in the ODHP reaction $\left(7.4 \% \mathrm{C}_{3} \mathrm{H}_{8}, 2.2 \% \mathrm{O}_{2}\right.$ in $\mathrm{He}_{\text {, }}$ $12.5 \mathrm{~mL}_{\mathrm{NTP}} \mathrm{min}^{-1}$ total flow) determined in the 673-823 $\mathrm{K}$ reaction temperature range and related $r^{2}$ linear correlation factor for the $V_{x}$-HAp-pH-per series.

\begin{tabular}{lcc}
\hline & $\mathrm{E}_{\mathrm{a}}$ to $\mathrm{C}_{3} \mathrm{H}_{6}$ in $\mathrm{kJ} / \mathrm{mol}$ and $\left(\mathrm{r}^{2}\right)$ & $\mathrm{E}_{\mathrm{a}}$ to $\mathrm{CO}_{x}(\mathrm{~kJ} / \mathrm{mol})$ and $\left(\mathrm{r}^{2}\right)$ \\
\cline { 2 - 3 } V.78-HAp-pH-per $_{\text {V3-HAp-pH-per }}$ & $116(0.9981)$ & $114(0.9999)$ \\
V3.5-HAp-pH-per & $118(0.9955)$ & $125(0.9963)$ \\
V4-HAp-pH-per & $115(0.9996)$ & $114(0.9999)$ \\
V4.5-HAp-pH-per & $155(0.9584)^{*}$ & $167(0.9346)^{*}$ \\
V5.22-HAp-pH-per & $126(0.9722)^{*}$ & $153(0.9970)^{*}$ \\
\hline
\end{tabular}

*determined in the 673-723 $\mathrm{K}$ range 
S7 Influence of the operating reactions conditions on the catalytic behavior of $\mathrm{V}_{4}$-HAp and comparison with a VMgO reference catalyst

The catalytic behavior of the $\mathrm{V}_{4}-\mathrm{HAp}-\mathrm{pH}$-per sample has been investigated in the conditions used by Siew Hew Sam et al. ${ }^{[11]}$ for a $69-\mathrm{VMgO}$ catalyst exhibiting a similar V weight loading. A new set of data was obtained with a richer oxygen mixture: $\mathrm{C}_{3} \mathrm{H}_{8} / \mathrm{O}_{2}=0.09,16.7 \mathrm{ml} / \mathrm{min}$ total flow (F) and $\mathrm{W} / \mathrm{F}=6 \mathrm{mg} \mathrm{min} \mathrm{ml}^{-1}$ ). Compared to our previous $\mathrm{O}_{2}$ poor conditions (solid lines), the catalytic ODHP performance of $\mathrm{V}_{4}-\mathrm{HAp}$-pH-per (dashed lines, $\mathrm{O}_{2}$-rich conditions) appears to be no longer limited by the amount of $\mathrm{O}_{2}$ in the reacting feed (Figure S7). $\mathrm{C}_{3} \mathrm{H}_{8}$ conversion at $773 \mathrm{~K}$ was found to be promoted under these $\mathrm{O}_{2}$-rich conditions compared to the $\mathrm{O}_{2}$-poor conditions used in the present work (22.0 vs $10.5 \%$, respectively). In contrast, $\mathrm{C}_{3} \mathrm{H}_{6}$ selectivity was found to be much lower at $773 \mathrm{~K}\left(23 \%\right.$ in $\mathrm{O}_{2}$-rich conditions compared to $43 \%$ in $\mathrm{O}_{2}$-poor conditions) and to decrease moderately as the reaction temperature increased (Figure S7).

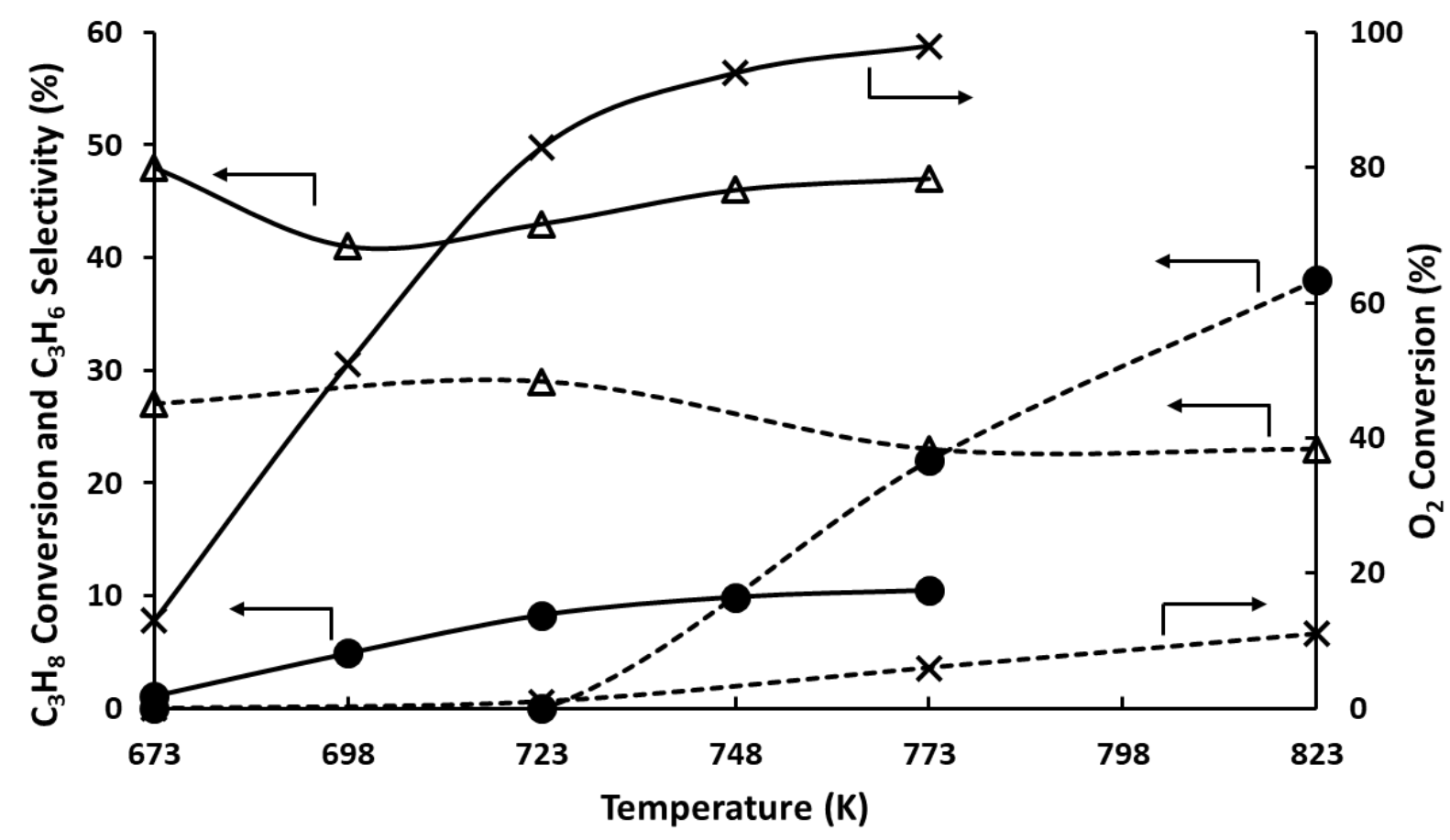

Figure S7: $\mathrm{C}_{3} \mathrm{H}_{8}(\boldsymbol{O})$ and $\mathrm{O}_{2}(\mathbf{\times})$ conversions, and $\mathrm{C}_{3} H_{6}$ selectivity $(\Delta)$ of $V_{4}$-HAp-pH-per as a function of reaction temperature, solid lines for $\mathrm{C}_{3} \mathrm{H}_{8} / \mathrm{O}_{2}=3.4,12.5 \mathrm{~mL}_{N T P} \mathrm{~min}^{-1}$ total flow, W/F $=8 \mathrm{mg} \mathrm{min} \mathrm{mL}_{N T P}{ }^{-1}$ conditions, and dashed lines for $\mathrm{C}_{3} \mathrm{H}_{8} / \mathrm{O}_{2}=0.09,16.7 \mathrm{ml} / \mathrm{min}$ total flow $(F)$ and $W / F=6 \mathrm{mg} \mathrm{min} \mathrm{mL}_{N T P}{ }^{-1}$ conditions (corresponding to the conditions applied by used by Siew Hew Sam et al ${ }^{[11]}$. 
Table S7 shows that the catalytic performance recorded on $\mathrm{V}_{4}-\mathrm{HAp}-\mathrm{pH}$-per compares reasonably well with that reported on $69-\mathrm{VMgO}$ by Siew Hew Sam et al., albeit substantially lower $\mathrm{C}_{3} \mathrm{H}_{6}$ selectivity is achieved on $\mathrm{V}_{4}-\mathrm{HAp}$ - $\mathrm{pH}$-per compared to that reported earlier on a 69-VMgO sample .[11]

Table S7: Comparison of the ODHP catalytic performance at 773 and $823 \mathrm{~K}$ for $\mathrm{V}_{4}-\mathrm{HAp}-\mathrm{pH}$-per and VMgO catalysts ${ }^{[11]}$ under similar conditions $\left(\mathrm{C}_{3} \mathrm{H}_{8} / \mathrm{O}_{2}=0.09,16.7 \mathrm{ml} / \mathrm{min}\right.$ total flow et $\left.\mathrm{W} / \mathrm{F}=6 \mathrm{mg} \mathrm{min} \mathrm{mL} \mathrm{NTP}^{-1}\right)$.

\begin{tabular}{llcc}
\hline & & $69-\mathrm{VMgO}^{[11]}$ & $\mathrm{V}_{4}-\mathrm{HAp}$-pH-per \\
\hline Specific surface area $\left(\mathrm{m}^{2} / \mathrm{g}\right)$ & & 11 & 34 \\
$\mathrm{~V}_{2} \mathrm{O}_{5} \mathrm{wt}(\%)$ & & 66.4 & 67.1 \\
$\mathrm{~V}$ wt $(\%)$ & & 18.6 & 18.8 \\
\hline Reaction at 773K & $\mathrm{C}_{3} \mathrm{H}_{8}$ Conversion (\%) & 18 & 22 \\
& $\mathrm{C}_{3} \mathrm{H}_{6}$ Selectivity (\%) & 44 & 23 \\
\hline Reaction at 823 K & $\mathrm{C}_{3} \mathrm{H}_{8}$ Conversion (\%) & 42 & 38 \\
& $\mathrm{C}_{3} \mathrm{H}_{6}$ Selectivity (\%) & 32 & 23 \\
\hline
\end{tabular}


S8 Mechanical mixture versus biphasic system: illustration of the improved ODHP catalytic performance of the $\mathrm{V}_{\mathrm{x}}-\mathrm{HAp}$-pH-per samples

A mechanical mixture mimicking the composition of the $\mathrm{V}_{5.22}-\mathrm{HAp}-\mathrm{pH}-$ per sample (Table 1) was prepared by grinding the two $\mathrm{V}_{5.22}-\mathrm{HAp}-\mathrm{pH}-9$ and $\mathrm{Ca}_{4} \mathrm{~V}_{4} \mathrm{O}_{14}\left(\mathrm{~V}_{6}-\mathrm{HAp}-\mathrm{pH}\right.$-per) pure phases with a 66/34 weight ratio. It was checked that the crystalline phases constitutive of the mechanical mixture were preserved after annealing at $773 \mathrm{~K}$ under $\mathrm{Ar}$ flow $\left(150 \mathrm{~mL} \mathrm{~min}{ }^{-1}\right)$. $\mathrm{C}_{3} \mathrm{H}_{8}$ conversion measured for the mechanical mixture at $723 \mathrm{~K}$ was found to be comparable to those recorded for the $\mathrm{V}_{5.22}-\mathrm{HAp}-\mathrm{pH}-\mathrm{per}$ and $\mathrm{V}_{5.22}-\mathrm{HAp}-\mathrm{pH}-9$ samples (Figure S8). The selectivity in $\mathrm{C}_{3} \mathrm{H}_{6}$ measured on $\mathrm{V}_{5.22}-\mathrm{HAp}-\mathrm{pH}-9$ was found to be close to that recorded for the mechanical mixture but to be significantly lower than that recorded on the biphasic $\mathrm{V}_{5.22}$-HAppH-per compound (Figure S8). Overall, the mechanical mixture displayed a catalytic behavior similar to that of $\mathrm{V}_{5.22}-\mathrm{HAp}-\mathrm{pH}-9$ and much different from that of $\mathrm{V}_{5.22}-\mathrm{HAp}$-pH-per (Figure S8).

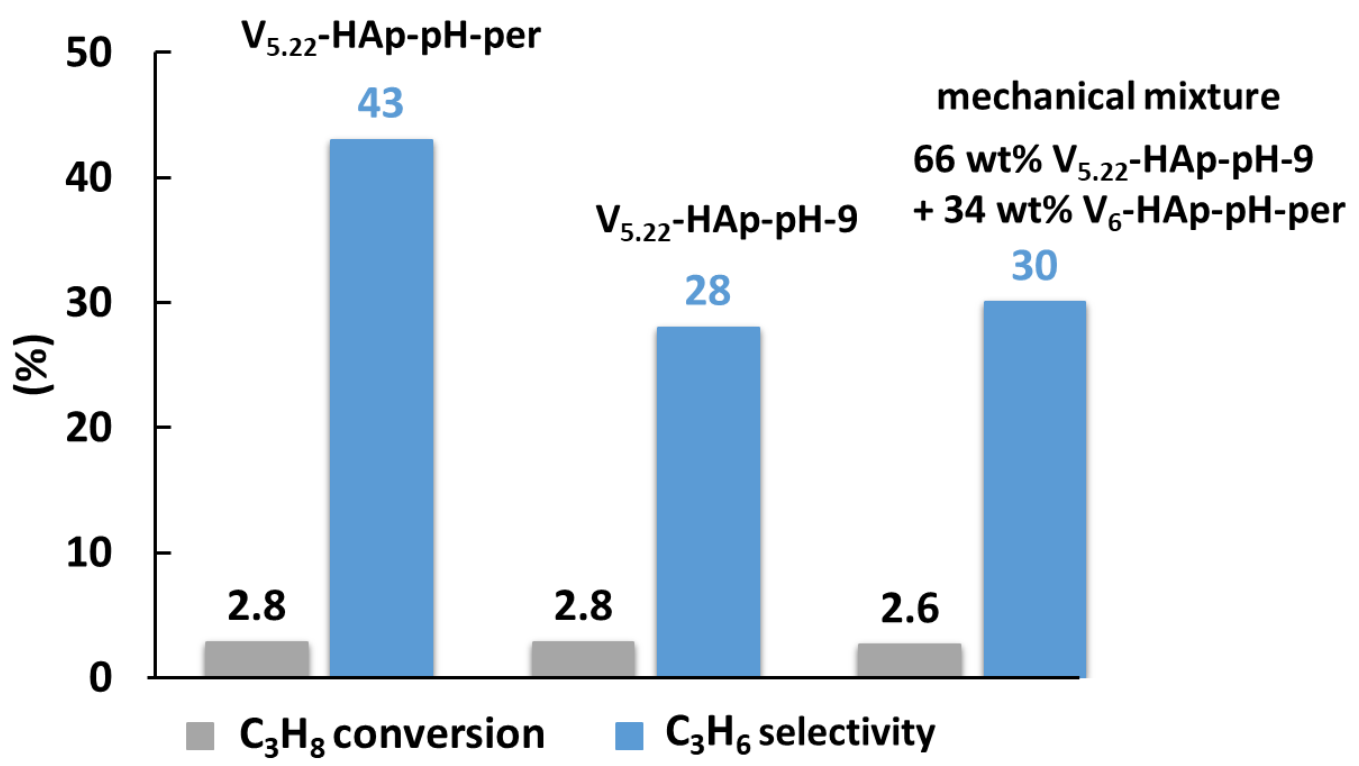

Figure S8: Comparison of the $\mathrm{C}_{3} \mathrm{H}_{8}$ conversion and $\mathrm{C}_{3} \mathrm{H}_{6}$ selectivity for the biphasic $V_{5.22}$-HAp-pH-per sample, the single phase $V_{5.22}-H A p-p H-9$ sample and the mechanical mixture of the two phases taken with the same proportions as those estimated in $V_{5.22}-\mathrm{HAp}-\mathrm{pH}$-per. $\left(7.4 \% \mathrm{C}_{3} \mathrm{H}_{8}, 2.2 \% \mathrm{O}_{2}\right.$ in $\mathrm{He}, 12.5 \mathrm{~mL}_{N T P} \mathrm{~min}^{-1}$ total flow, $\left.W / F=8 \mathrm{mg}_{\min } \mathrm{mL}^{-1}\right)$ at $723 \mathrm{~K}$. 


\section{REFERENCES}

[1] M. Ben Osman, S. Diallo-Garcia, V. Herledan, T. Yoshioka, K. Kubo, Y. Millot, G. Costentin, J. Phys. Chem. C 2015, 119, 23008-23020.

[2] S. Petit, T. Gode, C. Thomas, S. Dzwigaj, Y. Millot, D. Brouri, J. M. Krafft, G. Rousse, C. LabertyRobert, G. Costentin, Phys. Chem. Chem. Phys. 2017, 19, 9630-9640.

[3] a) G. Mali, G. Fink, F. Taulelle, J. Chem. Phys. 2004, 120, 2835-2845; b) Q. Wang, B. Hu, O. Lafon, J. Trebosc, F. Deng, J. P. Amoureux, J. Magn. Reson. 2009, 200, 251-260.

[4] X. Gao, P. Ruiz, Q. Xin, X. Guo, B. Delmon, Catal. Lett. 1994, 23, 321-337.

[5] a) R. Baran, Y. Millot, T. Onfroy, F. Averseng, J. M. Krafft, S. Dzwigaj, Microporous Mesoporous Mater. 2012, 161, 179-186; b) N. Steinfeldt, D. Müller, H. Berndt, Appl. Catal. A 2004, 272, 201-213; c) S. Di Gregorio, M. Greenblatt, J. H. Pifer, M. D. Sturge, J. Chem. Phys. 1982, 76, 2931-2937.

[6] V. Halicek, P. Novak, M. Vichr, Phys. Status Solidi B 1971, 44, K21-K24.

[7] L. D. Bogomolova, A. N. Khabarova, E. V. Klimashina, N. A. Krasil'Nikova, V. A. Jachkin, J. NonCryst. Solids 1988, 103, 319-324.

[8] I. L. Moudrakovski, A. Sayari, C. I. Ratcliffe, J. A. Ripmeester, K. F. Preston, J. Phys. Chem. 1994, 98, 10895-10900.

[9] M. Yamaga, B. Henderson, T. Yosida, N. Kodama, Y. Inoue, Phys. Rev. B 1995, 51, 3438-3448.

[10] G. Sperlich, Phys. Lett. 1969, 29A, 141-142.

[11] D. Siew Hew Sam, V. Soenen, J. C. Volta, J. Catal. 1990, 123, 417-435. 